\title{
HARDWARE REALIZATION OF A RESIDENTIAL STATIC VAR COMPENSATOR
}

\author{
by \\ Muhammad Kamran Latif
}

\author{
A thesis \\ submitted in partial fulfillment \\ of the requirements for the degree of \\ Master of Science in Electrical and Computer Engineering \\ Boise State University
}

May 2017 
(C) 2017

Muhammad Kamran Latif

ALL RIGHTS RESERVED 


\title{
BOISE STATE UNIVERSITY GRADUATE COLLEGE
}

\section{DEFENSE COMMITTEE AND FINAL READING APPROVALS}

\author{
of the thesis submitted by \\ Muhammad Kamran Latif
}

Thesis Title: Hardware Realization of a Residential Static Var Compensator

Date of Final Oral Examination: 24 February 2017

The following individuals read and discussed the thesis submitted by student Muhammad Kamran Latif, and they evaluated his presentation and response to questions during the final oral examination. They found that the student passed the final oral examination.

Dr. Said Ahmed-Zaid, Ph.D. Chair of the Supervisory Committee

Dr. Nader Rafla, Ph.D. Member, Supervisory Committee

Dr. Thad Welch, Ph.D. Member, Supervisory Committee

The final reading approval of the thesis was granted by Dr. Said Ahmed-Zaid, Ph.D., Chair of the Supervisory Committee. The thesis was approved by the Graduate College. 
This thesis is dedicated to my parents. 


\section{ACKNOWLEDGMENTS}

First of all, I would like to express my deepest gratitude to my advisor at Boise State University (BSU), Dr. Said Ahmed-Zaid, for his supervision, guidance, and advice during the entire course of this research work. Dr. Ahmed-Zaid's unflinching encouragement and endless support inspired me during my stay at BSU. I would also like to thank him for his willingness to help me with different experiments. I am truly indebted to him.

Furthermore, I would like to thank Dr. Nader Rafla and Dr. Thad Welch for serving on my thesis committee despite their busy schedules. I would like to thank the Department of Electrical and Computer Engineering at BSU for providing me with an opportunity to use various facilities that helped me in carrying out my research in an efficient manner.

I am also thankful to Dr. John Stubban at BSU for his support during this research. His experience in the electrical power industry was helpful in understanding the operation of an electrical utility and achieving specific goals during the research.

I would like to thank all the members of the Power research lab. Their help and friendship made my stay at graduate school an enjoyable experience. Especially, I would like to acknowledge Andrés Valdepeña and Danyal Mohammadi for their continuous support and fruitful discussions. I am lucky to have had some great

friendships and bonds over the past few years at BSU. Without their support, I would have not accomplished this successful research.

I am extremely thankful to my parents for their boundless love and unwavering 
support. I feel blessed to have my Dad as my mentor for graduate studies. His continuous support during my research was a source of inspiration for me. I would also like to thank my brothers for cheering me through hard times.

Finally, I would like to thank Avista Utilities for their support during this research. Especially, I would like to acknowledge Randy Gnaedinger and Reuben Arts at Avista Utilities for supporting the idea of a Static Var Compensator at the residential level. Their feedback during the research made it possible to come up with a device that is relevant to electric utilities. 


\begin{abstract}
Conservation by Voltage Reduction (CVR) is the implementation of a distribution voltage strategy whereby all distribution voltages are lowered to the minimum allowed by the equipment manufacturer. This strategy is rooted in the fact that many loads consume less power when they are fed with a voltage lower than nominal. Electric utility companies consider CVR as a potential solution for managing power in distribution networks. However, a difficult challenge is to keep end-of-line (EOL) voltages within an acceptable range of the ANSI Standard C84.1. Therefore, to achieve maximum benefit from CVR, electric utilities should be able to regulate residential voltages depending on load requirements. Hence, there is a need for a local solution which can regulate residential voltage levels from the first customer on the distribution feeder until the EOL of the distribution network. Such a solution will not only provide flexibility to electric utilities for better control over residential voltages but it can also maximize the benefits from CVR.

The goal of this research is to develop a Residential Static Var Compensator (RSVC) that will allow electric utility companies to develop strategies for CVR and other applications. The proposed RSVC is in fact a reactive power compensator that can regulate a residential load voltage with a fixed capacitor in shunt with a reactor controlled by two bidirectional switches. The two switches are turned on and off in a complementary manner using a pulse-width modulation (PWM) technique that allows the reactor to function as a continuously-variable inductor. The proposed


RSVC has several advantages compared to a conventional thyristor-based static var compensator (SVC), such as a quasi-sinusoidal inductor current, sub-cycle reactive power controllability, lower footprint for reactive components, and its realization as a single-phase device. 


\section{TABLE OF CONTENTS}

ACKNOWLEDGMENTS ....................

ABSTRACT $\ldots \ldots \ldots \ldots \ldots \ldots \ldots \ldots \ldots \ldots \ldots \ldots \ldots \ldots$ vii

LIST OF TABLES $\ldots \ldots \ldots \ldots \ldots \ldots \ldots \ldots \ldots \ldots \ldots \ldots \ldots \ldots \ldots$

LIST OF FIGURES ..................... xiv

LIST OF ABBREVIATIONS ................. xviii

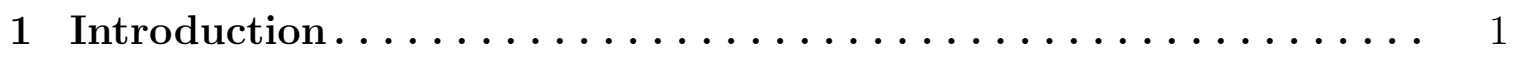

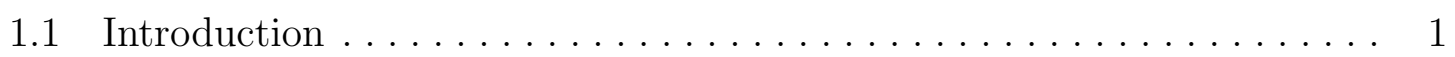

1.2 CVR Implementation on Different Distribution Feeders . . . . . . . . . . 3

1.3 Problem Statement. . . . . . . . . . . . . . . . . . . 4

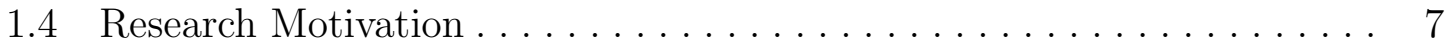

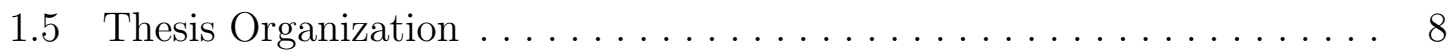

2 Literature Review on Reactive Power Compensation Techniques • 10

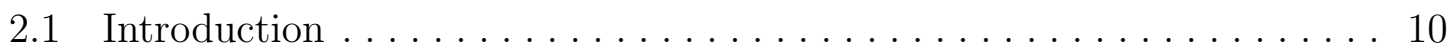

2.2 Principles of Reactive Power Compensation . . . . . . . . . . . . . 11

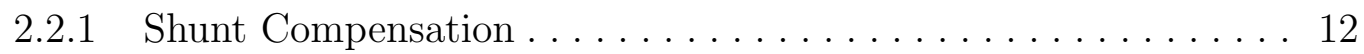

2.2 .2 Series Compensation . . . . . . . . . . . . . . . . . 13

2.3 Traditional Reactive Power Generators . . . . . . . . . . . . . . 13 
2.3.1 Thyristor-Switched Capacitor $\ldots \ldots \ldots \ldots \ldots \ldots \ldots \ldots$

2.3.2 Thyristor-Controller Reactor . . . . . . . . . . . . . . . . . 15

2.3.3 Thyristor-Controlled Reactor with a Fixed Capacitor ....... 18

2.3.4 Harmonic Analysis of the Reactor Current for the TCR-FC . . . 19

2.4 Pulse Width Modulated based Switched Reactor . . . . . . . . . . 22

2.4.1 Operating Principle ...................... 22

3 The Bidirectional Switch Commutation ............... 25

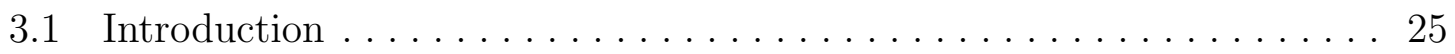

3.2 Bidirectional Switch Topology $\ldots \ldots \ldots \ldots \ldots \ldots \ldots \ldots \ldots$

3.3 Bidirectional Switch Commutation . . . . . . . . . . . . . . . . . 29

3.4 Four-Step Commutation using Output Load Current . . . . . . . . . . . 29

3.5 Four-Step Commutation using Input Voltage Sign . . . . . . . . . . . 33

3.6 Commutation Methodology for the Single-Phase RSVC . . . . . . . . . 35

4 Generation of Commutation Signals for Bidirectional Switches . . 37

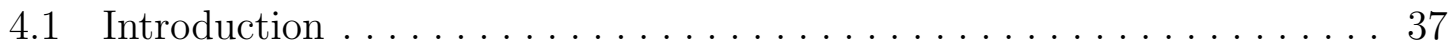

4.2 Commutation Prohibition Strategy $\ldots \ldots \ldots \ldots \ldots \ldots \ldots \ldots \ldots$

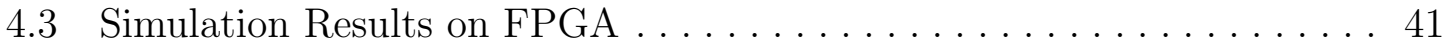

5 RSVC Design with Simulation Results ................ 44

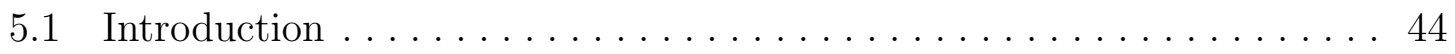

5.2 Distribution Network Modeling $\ldots \ldots \ldots \ldots \ldots \ldots \ldots \ldots \ldots$

5.3 Residential Loads Modeling . . . . . . . . . . . . . . . . . . 47

5.4 Modeling the Service Transformer Leakage Reactance ............ . 49

5.5 RSVC Reactive Component Sizing _.................... 49 
5.6 Summary for the RSVC Reactive Requirements . . . . . . . . . . . . 52

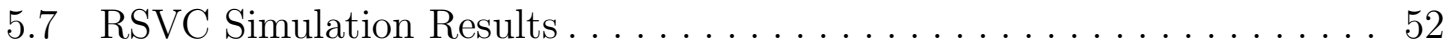

5.8 Gate Driving Signals . . . . . . . . . . . . . . . . . 54

5.9 Input and Output Voltage Waveforms . . . . . . . . . . . . . 55

5.10 Inductor Voltage and Current Waveforms . . . . . . . . . . . . 56

5.11 Current through Bidirectional Switches . . . . . . . . . . . . 57

5.12 RSVC Output Voltage for Different Duty Cycles . . . . . . . . . . . . 58

6 RSVC Experimental Results and Performance Analysis . . . . . . . 60

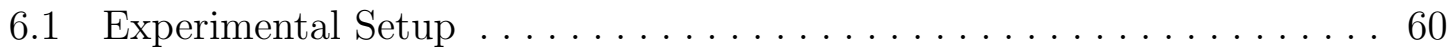

6.2 IGBT Gate Driving Signals . . . . . . . . . . . . . . . 61

6.3 RSVC Experimental Results . . . . . . . . . . . . . . . . . . 62

6.3 .1 Input and Output Voltage Waveforms . . . . . . . . . . . . . 62

6.3.2 Reactor Voltage and Current Waveforms . . . . . . . . . . . . 62

6.3.3 Current through Bidirectional Switches . . . . . . . . . . . . . 64

6.3.4 Input Current Waveform . . . . . . . . . . . . . . . . . . . . 65

6.4 Performance of the Laboratory RSVC with a Resistive Load . . . . . . . 66

6.4.1 Reactive Power Generated by the RSVC . . . . . . . . . . . 66

6.4.2 RSVC Output Voltage and Voltage Regulation . . . . . . . . . 67

6.4.3 RSVC Power Loss at Different Switching Frequencies . . . . . . . . 69

6.4.4 Input and Output Power Regulation . . . . . . . . . . . . 70

6.5 Hamonic Analysis . . . . . . . . . . . . . . . . . . . . . . . . 70

6.5.1 Harmonic Analysis of the RSVC Output Voltage . . . . . . . . 70

6.5.2 Harmonic Analysis of the Reactor Current . . . . . . . . . . . 71

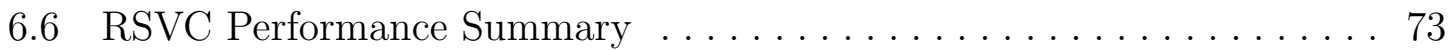


6.7 RSVC Novel Features . . . . . . . . . . . . . . . . . . . . 74

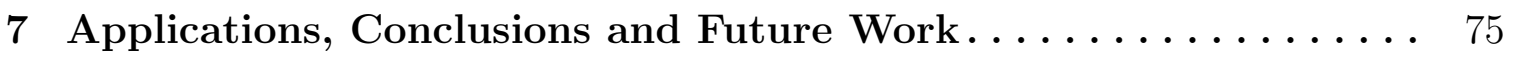

$7.1 \quad$ RSVC Applications. . . . . . . . . . . . . . . . . . . . 75

7.1.1 Conservation by Voltage Reduction using the RSVC . . . . . . 75

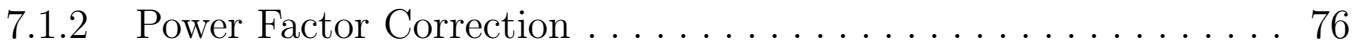

7.2 Conclusions............................... 76

7.3 Recommendation for Future Work . . . . . . . . . . . . . . 77

7.3.1 Voltage Reference Tracking $\ldots \ldots \ldots \ldots \ldots \ldots \ldots \ldots$

7.3.2 Optimal Power Flow Algorithm for RSVC . . . . . . . . . 77

7.3.3 Interaction of RSVC with Distribution Network .......... 78

REFERENCES.......................... 79

APPENDIX A Bill Of Materials for RSVC Prototype ......... 83 


\section{LIST OF TABLES}

3.1 Non-hazardous devices combination for current commutation based on the direction of the output current. . . . . . . . . . . . . 31

3.2 Non-hazardous devices combination for current commutation based on the $\operatorname{sign}$ of the input voltage. . . . . . . . . . . . . . . . 35

5.1 Reactive power requirement for each generator in the Distribution Network. . . . . . . . . . . . . . . . . . . . . . . . 47

5.2 Reactive power requirement for each generator in the Distribution Network. . . . . . . . . . . . . . . . . . . . . . . . 53

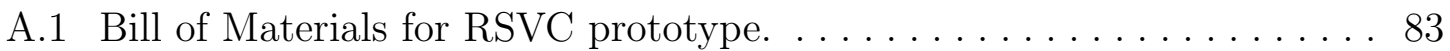




\section{LIST OF FIGURES}

1.1 ANSI C84.1 voltage levels for CVR operation. . . . . . . . . . . . 3

1.2 Typical voltage drop from the substation to the end-of-line point in a

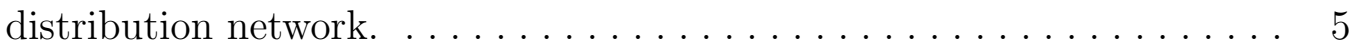

1.3 Voltage profile from the substation to the end-of-line point in a distribution network with capacitor banks and inline voltage regulators. . . . 6

2.1 (a) Radial AC system without reactive compensation (b) Radial AC system with shunt reactive compensation. . . . . . . . . . . . . . . 12

2.2 (a) Radial AC system without reactive compensation (b) Radial AC system with series reactive compensation. . . . . . . . . . . . 13

2.3 Switchable capacitor banks. . . . . . . . . . . . . . . . 14

2.4 (a) Thyristor control reactor (b) Voltage and current wave forms in a TCR for different thyristor gating angles. . . . . . . . . . . . . 16

2.5 (a) Thyristor control reactor with fixed capacitor (TCR-FC) (b) V-I characteristics for Thyristor control reactor with fixed capacitor. . . . . 18

2.6 Static Var Compensator with Thyristor Controlled Reactor in Simulink. 19

2.7 Reactor current and harmonic analysis for TCR-FC at a thyristor firing

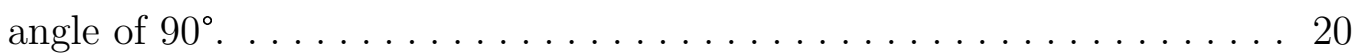

2.8 Reactor current and harmonic analysis for TCR-FC at a thyristor firing

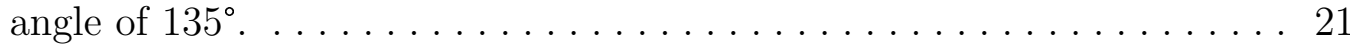

2.9 Proposed PWM-based Reacted Switching. . . . . . . . . . . . . . . 23 


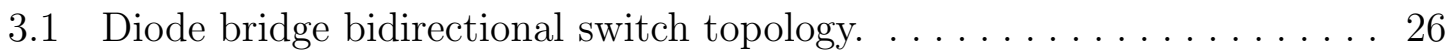

3.2 (a) Input phase with two bidirectional switches (b) Short circuiting the input phase using "make-before-break" strategy. . . . . . . . . . 27

3.3 (a) Input phase with two bidirectional switches (b) Inductive current interruption using "break-before-make" strategy. . . . . . . . . . 27

3.4 (a) Common-emitter configuration for a bidirectional switch (b) Commoncollector configuration for a bidirectional switch. . . . . . . . . 28

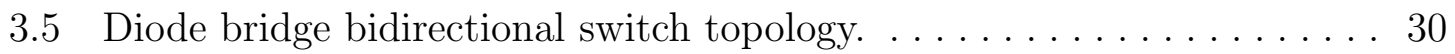

3.6 Four-step switching diagram for two bidirectional switches based on output load current direction. . . . . . . . . . . . . . . . 32

3.7 Freewheel diode current path when $\mathrm{V} 1>\mathrm{V} 2 \ldots \ldots \ldots \ldots \ldots \ldots$

3.8 Four-step switching state machine diagram for two bidirectional switches based on the input voltage sign. . . . . . . . . . . . . . . 36

4.1 Block diagram for the generation of commutation signals for two bidirectional switches used in the RSVC device. . . . . . . . . . 38

4.2 Diode bridge bidirectional switch topology. . . . . . . . . . . . 40

4.3 Bidirectional switches with inductive load. . . . . . . . . . . . 41

4.4 Test bench waveform for switching from top bidirectional switch to bottom bidirectional switch when the input voltage is positive. . . . . . 42

4.5 Test bench waveform for switching from bottom bidirectional switch to top bidirectional switch when the input voltage is positive. . . . . . 43

5.1 PowerWorld Model for a Distribution Network. . . . . . . . . . . . 45

5.2 Equivalent impedance circuit for the distribution network to calculate

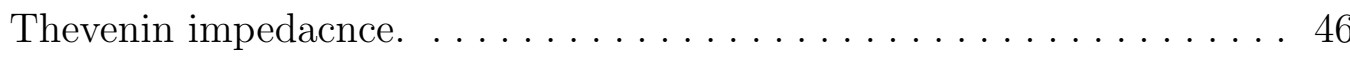


5.3 Power Factor variation during January 2013 and June 2013 for a distribution feeder in Spokane, Washington. . . . . . . . . . . . . . . . . . 48

5.4 RSVC circuit for calculating the fixed capacitor and inductor. . . . . . . 50

5.5 Simulation results for the RSVC capacitor modeling when the AC

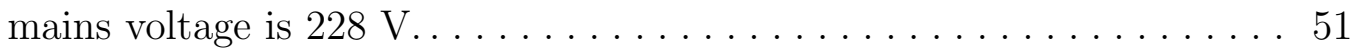

5.6 Simulation results for the RSVC inductor modeling with fixed capacitor and an AC mains voltage of $240 \mathrm{~V} \ldots \ldots \ldots \ldots \ldots \ldots$

5.7 The RSVC Simulink model with a fixed capacitor and a switched inductor having bidirectional switches. . . . . . . . . . . . . 53

5.8 The commutation sequences for the bidirectional switches. . . . . . . . 54

5.9 Simulation results for AC mains and the RSVC output voltage. . . . . 55

5.10 Simulation results for the RSVC inductor voltage and the RSVC in-

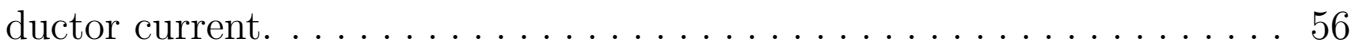

5.11 Simulation results for the RSVC current through the top and bottom bidirectional switches. . . . . . . . . . . . . . . . . . 57

5.12 Simulation results for the RSVC output voltages at different duty

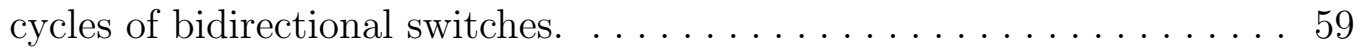

6.1 Circuit Diagram for the laboratory setup for the RSVC testing. . . . . . 61

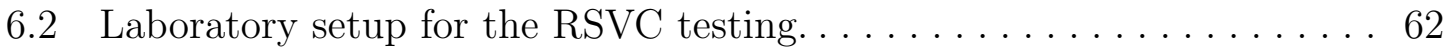

6.3 (a) IGBT gate driving signals at $\mathrm{D}=0.25$ (b) IGBT gate driving

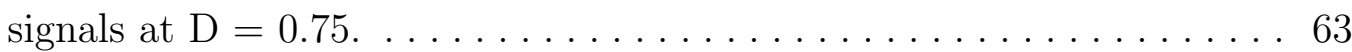


6.4 (a) IGBT gate driving signals transition from top switch to bottom switch when input voltage is greater than $0\left(\mathrm{~V}_{\mathrm{SVC}}>0\right)(\mathrm{b})$ IGBT gate driving signals transition from top switch to bottom switch when input

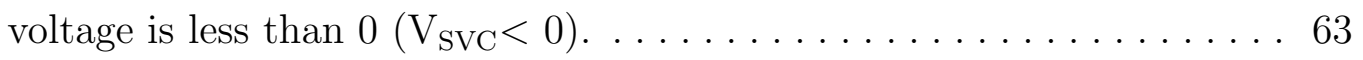

6.5 (a) AC Mains Voltage (b) RSVC Output Voltage. . . . . . . . . . . . . 64

6.6 Sinusoidal Reactor Current. . . . . . . . . . . . . . . . . . . . 64

6.7 Chopped Inductor Voltage when duty cycle $\mathrm{D}=0.5 \ldots \ldots \ldots \ldots$

6.8 Current through the top switch when duty cycle $D=0.5 \ldots \ldots \ldots \ldots$

6.9 Input Current Waveform from the distribution feeder to the RSVC

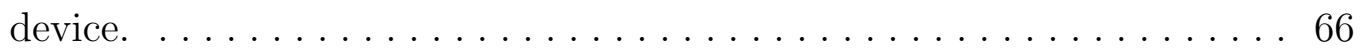

6.10 Variation of the reactive power generated by the RSVC with variation

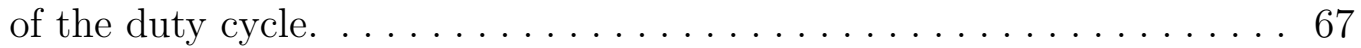

6.11 Plot of the RSVC voltage at various duty cycles for different switching

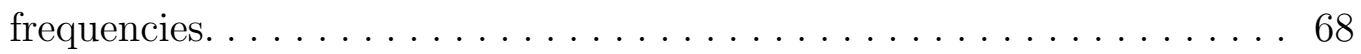

6.12 Plot of the RSVC power losses at different switching frequencies. . . . . 69

6.13 Plot of the RSVC input and output power regulation at different switching frequencies. . . . . . . . . . . . . . . . . 70

6.14 Plot of the RSVC output voltage at different duty cycles with their corresponding harmonic analysis. . . . . . . . . . . . . . 71

6.15 Plot of the RSVC reactor current at switching frequency of $2.4 \mathrm{kHz}$ and at different duty cycles with their corresponding harmonic analysis. 72

6.16 Plot of the RSVC reactor current at switching frequency of $6 \mathrm{kHz}$ and at different duty cycles with their corresponding harmonic analysis. . . 73

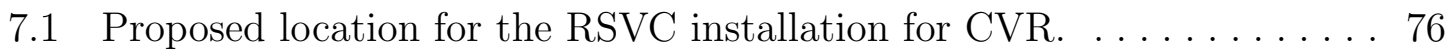




\section{LIST OF ABBREVIATIONS}

- AC Alternating Current

- ANSI American National Standards Institute

- CVR Conservation by Voltage Reduction

- EOL End-of-Line

- EPRI Electric Power Research Institute

- FACTS Flexible Alternating Current Transmission System

- FPGA Field Programmable Gate Array

- HDL Hardware Descriptive Language

- IGBT Insulated Gate Bipolar Transistor

- MOSFET Metal Oxide Semiconductor Field Effect Transistor

- PFC Power Factor Correction

- PWM Pulse Width Modulation

- RSVC Residential Static Var Compensator

- SVC Static Var Compensator

- TCR Thyristor Controlled Reactor

- TSC Thyristor Switched Capacitor

- TCR-FC Thyristor Controlled Reactor-Fixed Capcitor 
- VAR Volt-Ampere Reactive

- VHDL VHSIC Hardware Description Language

- VHSIC Very High Speed Integrated Circuits

- VVO Volt-Var Optimization 


\section{CHAPTER 1}

\section{INTRODUCTION}

\section{$1.1 \quad$ Introduction}

Conservation by Voltage Reduction (CVR) is the implementation of a distribution voltage strategy whereby all voltages are lowered to the minimum allowed by the equipment manufacturer. This is a consequence of the observation that many loads consume less power when they are fed with a voltage lower than nominal. In order to guarantee good quality service, loads should not be supplied with a voltage higher or lower than $5 \%$ of nominal. The range of standard service voltages used in the United States is specified by the American National Standards Institute (ANSI) Standard C84.1 - 2016 "Electrical Power Systems and Equipment - Voltage Ratings (60 Hertz)" as 120 volts nominal, 114 volts minimum (120 V minus 5\%) and 126 volts maximum (120 V plus 5\%).

Electrical companies are forced to become more efficient and competitive by working to reduce costs. One such major cost is when a company buys energy from another utility in the market, i.e., when it cannot satisfy its own demand with its installed capacity. Furthermore, distribution companies, as well as residential customers, must pay a higher price per kWh during peak demand hours. The goal of the proposed residential CVR implementation is to reduce power consumption during peak hours in order to save energy and costs [1-3]. 
Before applying CVR, power system operators and electric utilities must understand the behavior of their loads under reduced voltages. Even if all loads consumed less power with less voltage, which is generally not true, the overall energy savings may not be significant. Some devices can give good service by working at a lower voltage. For example, decreasing the voltage of a resistive load such as a lightbulb will definitely yield energy savings. However, there are other devices such as air conditioners and ovens which will have to work longer to give the same service. In the end, the energy saving might not be substantial and, instead of saving energy, it is possible to consume even more. Whereas lowering the voltage may increase line current losses, the decrease in power consumption is expected to be larger, so that the overall balance will be positive $[4,5]$.

The voltage ranges in ANSI Standard C84.1 for a nominal service voltage of 120 $\mathrm{V}$ are shown in Figure 1.1. In this figure, Service Range "A" shows the voltage range of $\pm 5 \%$ of the nominal voltage of $120 \mathrm{~V}$. For CVR implementation, the service voltage can be reduced by $5 \%$ of the nominal voltage level. Most utilities plan their distribution systems based on the voltage limits within Range A of the standard. In addition, ANSI Standard C84.1 also specifies a second out-of-normal service voltage range (Range "B"). The voltage levels mentioned in Range "B" are only acceptable for a brief period of time and should be infrequent.

The CVR effectiveness is measured by the CVR factor. The CVR factor is defined as the ratio of the percentage of the energy saved to the percentage of the voltage reduction used to achieve the energy saving. The CVR factor can also be represented in mathematical form as given in Equation (1.1).

$$
C V R \text { Factor }=\frac{\% \text { energy saved }}{\% \text { change in voltage }}
$$




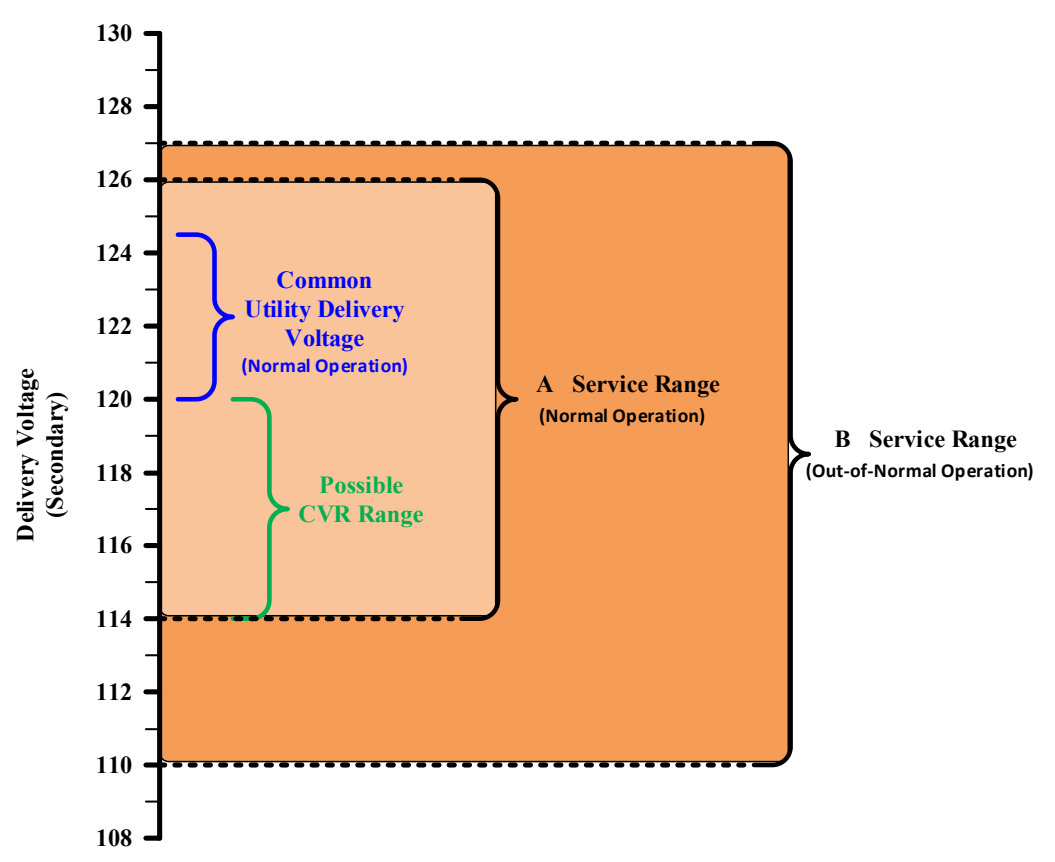

Figure 1.1: ANSI C84.1 voltage levels for CVR operation.

\subsection{CVR Implementation on Different Distribution Feeders}

In the 1970s, electric utilities began investigating the effects of reducing the voltage at the customer level as a method for energy conservation. In 1973, American Electric Power (AEP) conducted a study to examine the impact of voltage reduction on loads. Their test results showed significant savings by reducing the level of residential voltages. In the study, the voltage levels were reduced for a duration of four hours. For a five percent voltage drop, an immediate saving of four percent in the load power demand was achieved [6].

In 1985, the Northwest Power Planning Council (NWPPC) concluded that, if CVR were applied to the distribution system across the Pacific Northwest, it could result in an energy conservation of up to $2.37 \times 10^{6} \mathrm{MWh} /$ year [7]. In 1988-90, Snohomish 
County Public Utility District launched a CVR pilot program on 12 distribution circuits and concluded that, for a one percent change in voltage, $0.621 \%$ CVR energy savings would be achieved [1]. In 1990, a study was conducted to understand the voltage dependency for a B.C. Hydro substation in Vancouver Island. The study concluded that a significant reduction in real power and reactive power was possible by lowering the voltage [8]. In 2003, the Northwest Energy Efficiency Alliance (NEEA) conducted a study on the Distribution Efficiency Initiative (DEI). The DEI project was focused on studying the effect of CVR on 500 residential homes in the Pacific Northwest region. In this study, it was concluded that CVR could reduce energy consumption by an average of $0.8 \%$ for every $1 \%$ reduction in the voltage [9].

More recently, in 2010 a study conducted by the Pacific Northwest National Laboratory (PNNL), showed that CVR would result in an annual energy reduction of approximately $0.5 \%-4 \%$ depending on the specific feeder [10]. The PNNL report also contained plots of the real and reactive power consumption for different end-user loads (such as Liquid Crystal Display, incandescent lightbulbs, etc.) when operated between $100 \mathrm{~V}$ and 126 V. In 2011, the Electric Power Research Institute (EPRI) published a report on CVR with findings from different electric power companies including the Salt River Project (SRP), Hydro Quebec, AEP and Ameren [11].

\subsection{Problem Statement}

Electric utility companies consider CVR as a potential solution for managing

power in their distribution systems. As every distribution circuit has its own load demand characteristics, it becomes difficult for electric utilities to impose a particular strategy for energy savings from one distribution feeder to another. When electric 
utilities apply CVR on a distribution feeder, the load tap-changing transformer (LTC) at the distribution substation decreases the feeder voltages. However, it becomes a challenge to keep the end-of-line (EOL) voltage within an acceptable range of ANSI Standard C84.1.

Figure 1.2 shows the typical voltage drop from a substation to an EOL of the distribution network [11]. Due to voltage drops, utilities avoid reducing the voltage at the substation to the minimum permissible value for CVR and, therefore, cannot get the maximum benefits from CVR at all points along the distribution network.

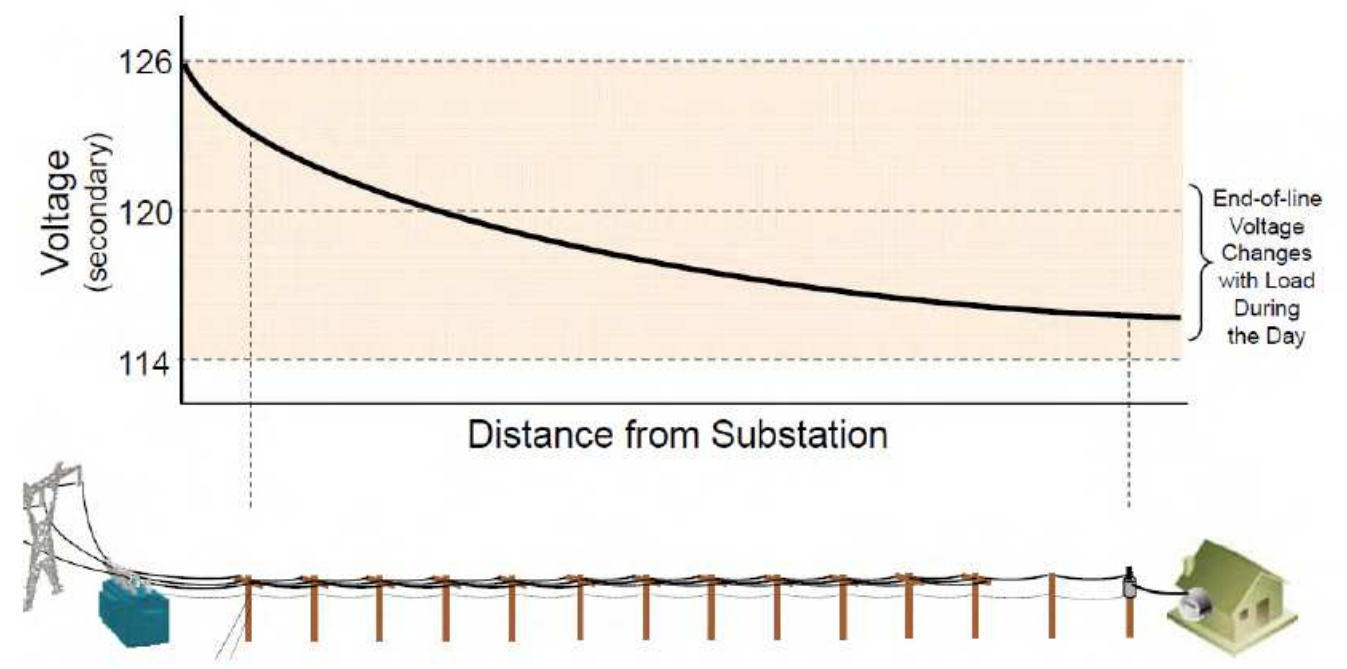

Figure 1.2: Typical voltage drop from the substation to the end-of-line point in a distribution network.

In order to yield the maximum benefits from CVR, electric utilities install fixed capacitors or switched capacitor banks at different points along the distribution network to boost the voltage along the circuit. This permits electric utilities to lower the voltage at the substation and safely operate within the Range "A" specified 
in Figure 1.1. Electric utilities also use inline voltage regulators to flatten the voltage level along the distribution network.

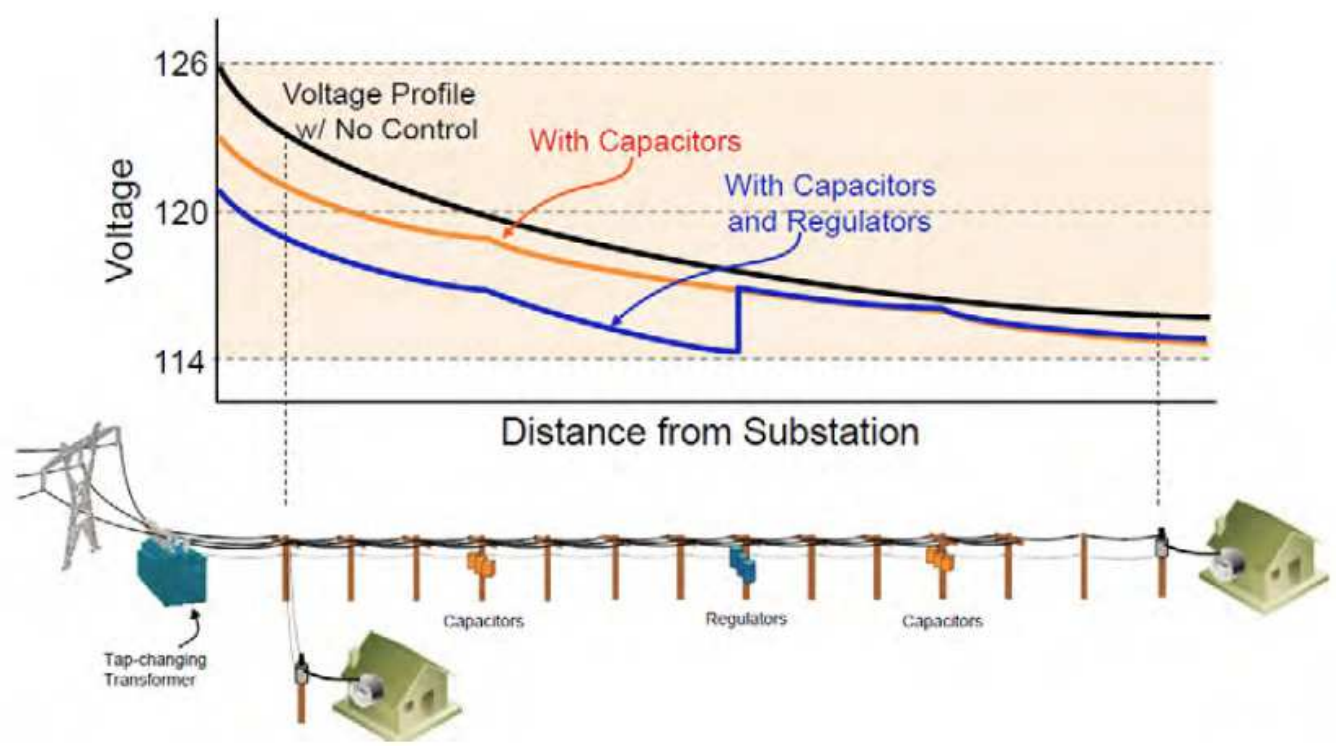

Figure 1.3: Voltage profile from the substation to the end-of-line point in a distribution network with capacitor banks and inline voltage regulators.

Figure 1.3 shows the improved voltage profile for the same distribution feeder with capacitor banks and inline voltage regulators [11]. However, to achieve maximum benefit from CVR, a method is needed that can regulate the residential voltages depending on the load requirements. Thus, there is a need for a local solution which can control the residential voltage level from the first customer on the distribution feeder until the EOL of the distribution network. Such a solution will not only provide flexibility to electric utilities for better control over residential voltages but can also maximize the benefits from CVR. 


\subsection{Research Motivation}

This research focuses on developing a solution based on the concept of a residential static var compensator (RSVC) for regulating residential voltages, especially during peak demand hours, when the benefits coincide best with the interests of the customers and those of the electric companies. These RSVCs can be an additional tool for smart demand-side management. By remotely controlling the RSVC, a utility can apply CVR at specified individual locations during specified periods.

The goal of this research is to develop an RSVC prototype that will allow electric utility companies to develop strategies for CVR. One of the proposed strategies involves installing an individual apparatus which will decrease the service voltage of each customer. This may not be inexpensive, but many independent studies have showed that great savings can be achieved by working with CVR and the additional development and deployment costs can be justified over the long term [10]. In other words, the cost of implementing CVR per kWh saved would be smaller than buying that amount of $\mathrm{kWh}$ in the market.

In terms of reactive power sources, capacitors provide reactive power and reactors absorb reactive power. The proposed solution in this thesis is based on a device that consists of a fixed capacitor in shunt with a controlled reactor. The thesis discusses two methods of controlling the reactive power from the shunt reactor. The first method uses a conventional angle firing to control the closing of a bidirectional solid-state switch (generally made up of thyristors) in series with the shunt reactor. This method has the drawback of generating current harmonics which require harmonic filters to mitigate their effects. The second and proposed method uses a Pulse-Width Modulation (PWM) switching technique of the reactor with the help of 
two bidirectional switches, one in series and the other in parallel with the reactor. These bidirectional switches are operated in a complementary fashion, meaning that when one is closed, the other is open and vice-versa. The PWM-based reactor switching yields a quasi-sinusoidal RSVC voltage and an almost sinusoidal reactor current.

\subsection{Thesis Organization}

This thesis is organized in seven chapters. In addition, appendices and a list of references are provided at the end of the thesis.

Chapter 2 provides an overview of the principles of reactive power compensation. Traditional var compensators are reviewed, with emphasis on a Thyristor-Controlled Reactor (TCR). A novel approach for reactor switching based on a PWM technique is also described in this chapter. The drawbacks for TCR and advantages for a PWM-based reactor switching over a traditional thyristor angle firing switching are also discussed in the chapter.

Chapter 3 describes the basic issues of the bidirectional switch commutation. Different topologies for bidirectional switches are reviewed. The possibilities for commutating the bidirectional switches are based on the sign of the input voltage or the direction of the output current. For the RSVC prototype, the preference of the bidirectional switches commutation based on the input voltage sign was chosen over the direction of the output current.

Chapter 4 gives an overview for generating the gate driving signals for the bidirectional switches on an FPGA. These signals are verified using VHDL test benches.

Chapter 5 focuses on the design guideline for the RSVC system. A method to 
size the reactive components for the RSVC system is explained. Simulation results are presented and different criteria for measuring the success of the RSVC system are discussed and analyzed.

Chapter 6 presents the experimental setup for testing the laboratory prototype of the RSVC system. The performance of the RSVC laboratory prototype is analyzed and discussed on the basis of the experimental results. The power losses for the RSVC system and discussion regarding the optimal performance parameters are also part of this chapter.

Chapter 7 gives applications for RSVC devices. It also provides some recommendations for improving the RSVC device. 


\section{CHAPTER 2}

\section{LITERATURE REVIEW ON REACTIVE POWER COMPENSATION TECHNIQUES}

\subsection{Introduction}

Reactive power planning plays an important role in enhancing the operation of power systems. In theory, the reactive power is defined as the $\mathrm{AC}$ component of the instantaneous power with double the system frequency and zero average value. This means that the reactive power generated by an $\mathrm{AC}$ source can oscillate between the source and reactive components (capacitors and reactors) at twice the rated frequency $(60 \mathrm{~Hz})$. Additionally, sources of reactive power provide the means for the power factor correction (PFC) of industrial plants that present a poor or low power factor. Many methods for achieving PFC by using reactive power compensation have been proposed in the literature [12-14].

Shunt capacitors are commonly used to provide the reactive power compensation in a distribution system. But with widely varying loads, fixed shunt capacitors can often lead to either under-compensation or over-compensation.

Dynamic reactive power compensation can be achieved using switchable capacitor banks. Depending on the reactive power requirements, these capacitor banks are switched in or out of operation. However, they require a reactor to avoid resonance 
between the capacitor and source impedance [13].

Modern reactive power compensation techniques use Flexible AC Transmission Systems (FACTS) devices that provide dynamic reactive power to the power system. FACTS devices are high-speed power electronics devices that combine advanced control system techniques with the fast processing power of microprocessors to respond to the reactive power needs of the power system $[15,16]$. Commonly-used FACTS devices are static var compensators (SVCs) and inverter-based static Synchronous Compensators (STATCOMs).

For utilities, FACTS technology has become an essential tool to alleviate certain problems associated with the scheduling of reactive power and to get the most service from their transmission and distribution networks by enhancing grid reliability [17]. This chapter describes the principles for series and shunt reactive power compensation. An overview for the commonly-used FACTS devices is also presented. At the end of this chapter, an improved method of reactor switching is proposed which helps to mitigate the problems caused by the conventional angle-firing of thyristors for reactor switching.

\subsection{Principles of Reactive Power Compensation}

Reactive power compensation can be categorized as shunt var compensation and series var compensation. Shunt var compensation changes the effective equivalent impedance of the load whereas the series var compensation modifies the series transmission or distribution parameters [12]. In both compensation techniques, reactive power is generated with the goal of improving the performance of the overall $\mathrm{AC}$ power system. 


\subsubsection{Shunt Compensation}

In shunt compensation, the lagging current drawn due to an inductive load is compensated by the leading current generated by the compensator device [12]. The leading current can be achieved in three different ways: using a current source, a voltage source, or a single capacitor or capacitor banks. The reactive source provides part of the total reactive power requirement by injecting positive vars into the power system, thus improving the voltage regulation at the receiving terminals. In Figure 2.1(a), a typical power system is shown, which draws a lagging current due to an inductive load. This lagging current results in a reduced voltage level at the receiving end.

The power system is compensated by providing the leading current to reduce the lagging current supplied by the AC source [12]. This leading current is supplied by the generator (reactive power source) as shown in Figure 2.1(b). It helps to improve the power factor as well as the overall voltage profile of the power system.

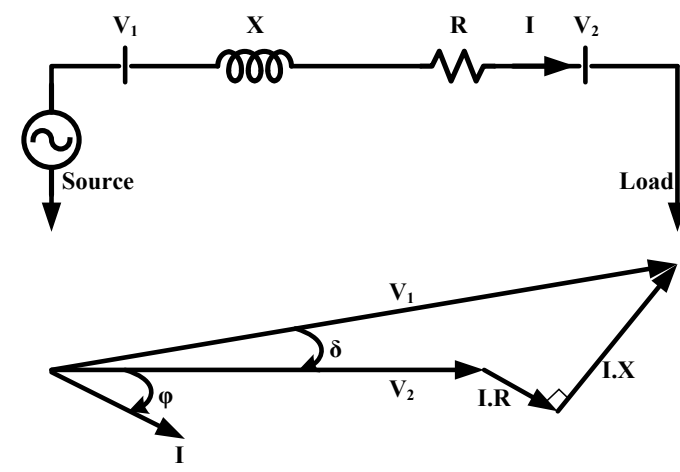

(a)
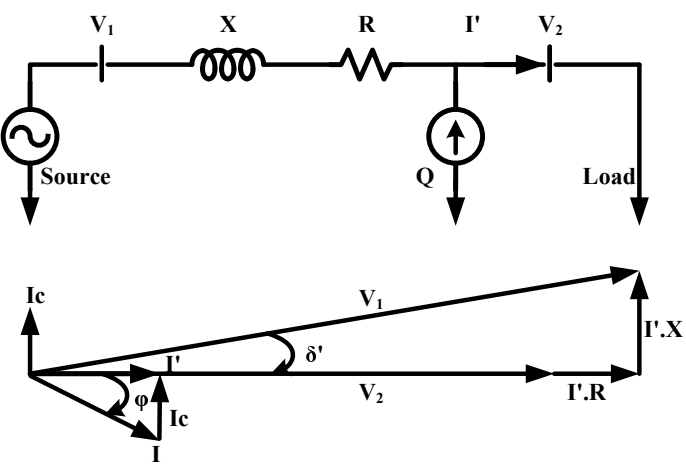

(b)

Figure 2.1: (a) Radial AC system without reactive compensation (b) Radial AC system with shunt reactive compensation. 


\subsubsection{Series Compensation}

Series compensation involves decreasing the inductive reactance of the power lines by installing series capacitors. As a result of series var compensation, the total reactance of the lines is reduced, which helps minimize the voltage drops.

Figure 2.2(a) represents the phasor diagram of an $\mathrm{AC}$ system without series reactive compensation and Figure 2.2(b) shows the effect of series compensation in the overall AC system. A decrease in the line reactance not only reduces the voltage drop in the lines, but also improves the voltage at the receiving end.

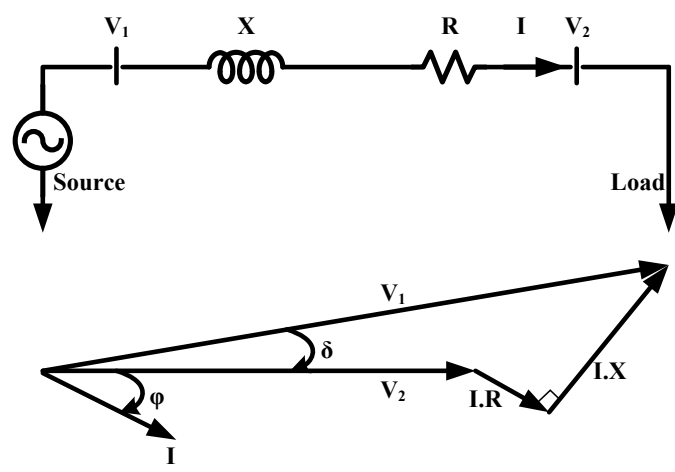

(a)
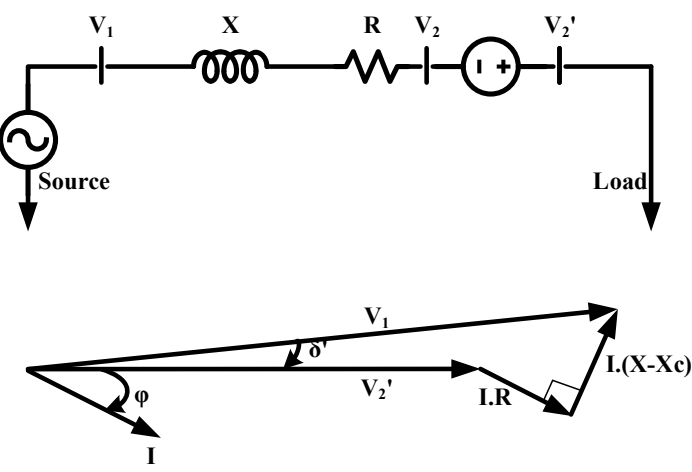

(b)

Figure 2.2: (a) Radial AC system without reactive compensation (b) Radial AC system with series reactive compensation.

\subsection{Traditional Reactive Power Generators}

This section provides an overview of the shunt var compensators which are discussed in the literature and are commonly used in electric utilities to minimize the effects of poor power factor and low receiving-end voltages. 
Common shunt var compensators employed by electric utilities include capacitor banks and static var compensators (SVCs). An SVC has various topologies depending on the nature of the reactive components used and on the nature of the reactive compensation required. Common SVC topologies include: Thyristor Controlled Reactor (TCR), Thyristor Switched Capacitor (TSC) and Thyristor Controlled Reactor with a Fixed Capacitor (TCR-FC).

\subsubsection{Thyristor-Switched Capacitor}

Capacitor banks provide static reactive power to the power system. In capacitor banks, individual capacitors can be switched, either on or off, in discrete steps depending on the reactive power need. Figure 2.3 shows a capacitor bank where the reactive components are sized to address the needs of varying reactive power.

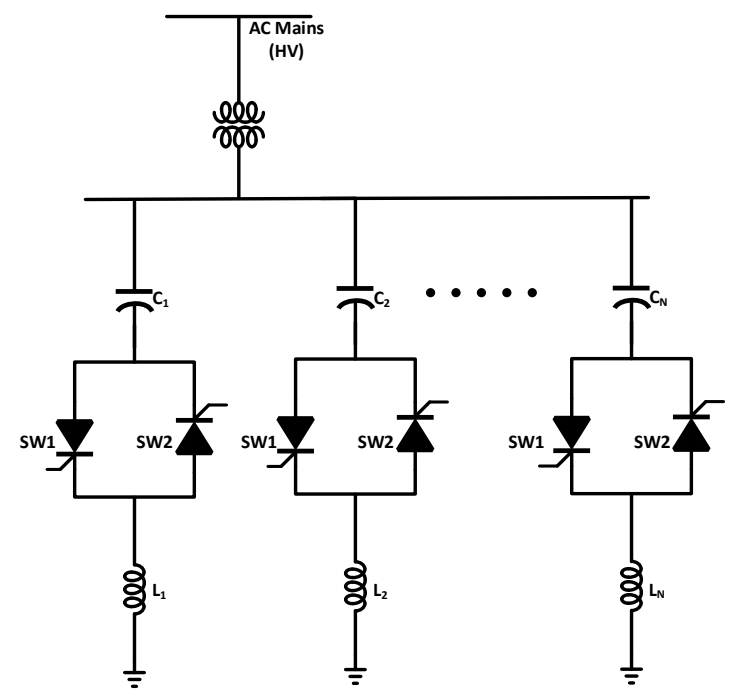

Figure 2.3: Switchable capacitor banks. 
Each branch consists of a capacitor C in series with two thyristor valves, SW1 and SW2. This assembly is connected in series with a small reactor L to avoid a sudden increase in the rate of current increase through the thyristor switches and to prevent resonance with the power network. Each branch in Figure 2.3 is also referred to as a Thyristor-Switched Capacitor (TSC).

It is important to provide the gating signals to the thyristor at an instant when the system voltage is equal to the capacitor voltage to allow transient free switching. This is done by using a synchronization block implemented by a phase-locked loop (PLL).

Moreover, when the capacitors are turned on, their stored charge adds to the network voltage. The thyristors are then exposed to the capacitor charge as well as the network voltage. Therefore, the thyristor maximum rating should be at least twice as much as the peak of the system voltage.

TSCs are not commonly used for reactive power compensation since their usage is limited practically by a number of disadvantages: the reactive power is provided in discrete steps; thyristor valves are required for each TSC branch, resulting in a bulky structure; and the thyristor switches are required to be rated at least at twice the maximum voltage of the power system.

\subsubsection{Thyristor-Controller Reactor}

Figure 2.4(a) shows a Thyristor Controlled Reactor (TCR) used in an SVC. In a TCR, the reactor is connected in series with two thyristor valves mounted back to back. The reactive power generated by the TCR can be continuously varied by controlling the current flowing through the reactor. 
The current conduction through the reactor depends on the firing angle (a gating angle) of the thyristors. The maximum current contribution is obtained when the forward thyristor is fired at an angle of $90^{\circ}$. Partial current contribution is obtained when the firing angle is varied between $90^{\circ}$ and $180^{\circ}$. By increasing the thyristor firing angle, the lagging current injected into the power system is reduced which, in turn, increases the inductance of the TCR and reduces the reactive power of the reactor.

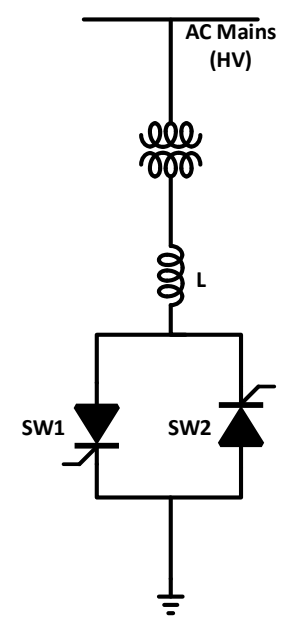

(a)

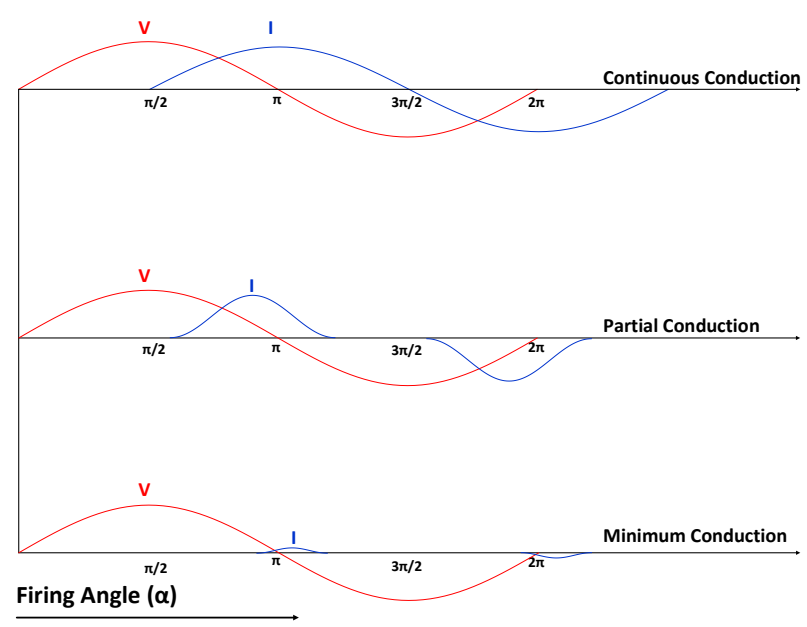

(b)

Figure 2.4: (a) Thyristor control reactor (b) Voltage and current wave forms in a TCR for different thyristor gating angles.

The fundamental component of the instantaneous current supplied by the TCR is given by the following equation [12]:

$$
I_{1}=\frac{V_{r m s}}{X_{L}}(2 \pi-2 \alpha+\sin (2 \alpha))
$$


In Equation (2.1), $\alpha$ is the firing angle of the thyristor and $X_{L}=\omega L$ is the reactance of the reactor. At $\alpha=90^{\circ}$, the contribution of the reactor current is maximum and it reduces to zero when $\alpha$ reaches $180^{\circ}$.

Figure 2.4(b) shows three cases of different thyristor firing angles. The continuous current conduction is obtained when thyristors are fired at $90^{\circ}$ during each half cycle. Figure 2.4(b) also shows the firing of the thyristor at angles greater than $90^{\circ}$. These conditions are labeled as partial conduction and minimum conduction. At firing angles greater than $90^{\circ}$, the lagging current injected by the reactor becomes nonsinusoidal. This produces low-order harmonics, which require harmonic filtering at an additional cost.

For thyristors fired with gate signals generated at specific firing angles, the change in reactor current can only happen once during each half cycle. This lack of controllability of the reactive power during a complete cycle is another drawback for the thyristor-controlled reactor.

The thyristor gating signals must stay in synchronization with the AC mains voltage under all circumstances. This synchronization is achieved by using a phaselocked loop (PLL) that operates synchronously with the AC system voltage and produces a thyristor gate-firing sequence with respect to the peak of that voltage. The control system responsible for the PLL must be fast enough to respond during system faults and voltage fluctuations. The use of a synchronization block for producing gate signals not only poses technical difficulties, but also increases the total components required for building a single-phase SVC.

Due to the above mentioned difficulties, the use of conventional thyristor anglefiring based reactor switching is inefficient and generates harmonics. An advanced method for reactor switching is presented in the final section of this chapter. 


\subsubsection{Thyristor-Controlled Reactor with a Fixed Capacitor}

Figure 2.5(a) shows a Thyristor-Controlled Reactor (TCR) with a Fixed Capacitor (FC). This assembly combines the capacitor and the reactor to provide a variable amount of reactive power for supporting the system voltage. The amount of the reactive power generated or absorbed is a function of the input voltage and it can be varied depending upon the input bus voltage.

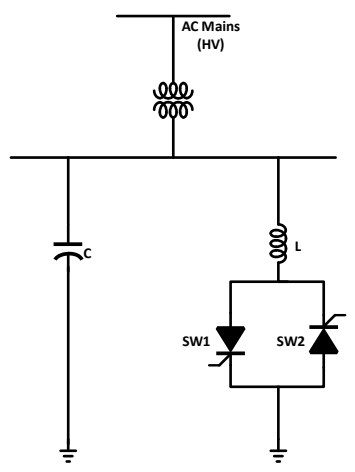

(a)

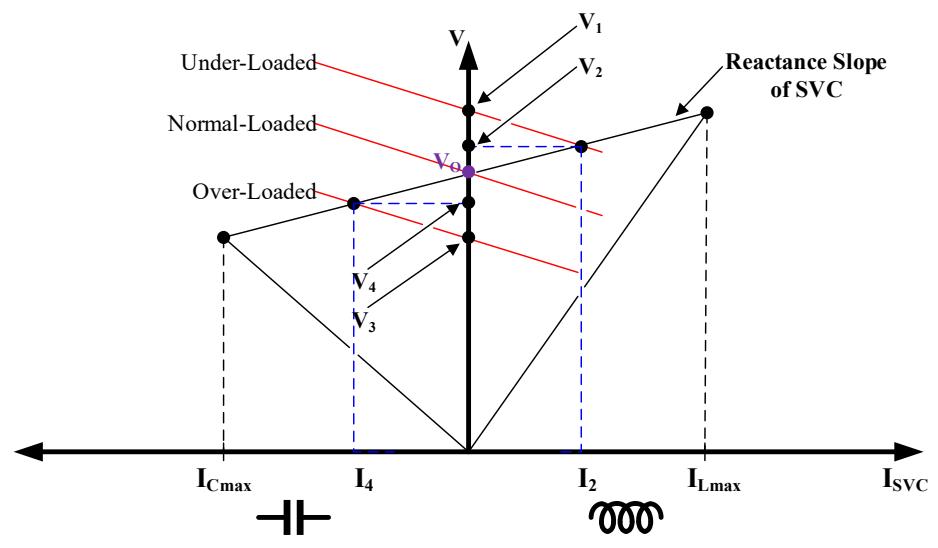

(b)

Figure 2.5: (a) Thyristor control reactor with fixed capacitor (TCR-FC) (b) V-I characteristics for Thyristor control reactor with fixed capacitor.

Figure 2.5(b) shows the V-I characteristics of an SVC with a fixed capacitor and a thyristor-controlled reactor. In this figure, $V_{0}$ represents the nominal voltage of the transmission bus where the SVC is connected. The three load-lines represent the transmission network at normal load, under-load and over-load conditions. The reactance slope of the SVC is also represented in the figure. At an under-loaded condition, when the bus voltage increases from $V_{0}$ to $V_{1}$, the SVC operates in the inductive region. The SVC generates a lagging inductive current of magnitude $I_{2}$ to 
reduce the voltage level from $V_{1}$ to $V_{2}$. Similarly, during the over-loaded condition of the transmission network, the bus voltage drops to $V_{3}$. The SVC operates in the capacitive region to inject leading current of magnitude $I_{4}$ to boost the SVC bus voltage from $V_{3}$ to $V_{4}$. Hence, it is possible to vary the bus voltage by changing the reactance of the SVC.

The linear region of SVC operation is limited by the rated reactive power of the reactive components. When the $\mathrm{SVC}$ is operating at $I_{C \max }$, the reactive power provided to boost the bus voltage is at maximum. As the contribution of inductive current increases, the reactive power of the SVC reduces and drops to a minimum value when the SVC is operating at $I_{L \max }$.

\subsubsection{Harmonic Analysis of the Reactor Current for the TCR-FC}

Figure 2.6 shows an SVC using a thyristor-controlled reactor with a fixed capacitor. It consists of a thyristor valve connected to a reactor and a fixed shunt capacitor.

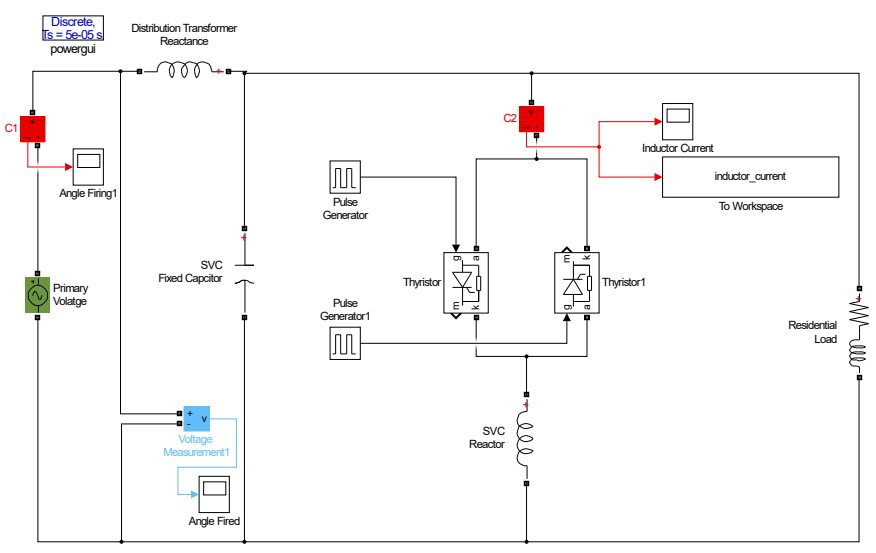

Figure 2.6: Static Var Compensator with Thyristor Controlled Reactor in Simulink. 
To study the harmonic content of the reactor current, the SVC was simulated in MATLAB/Simulink and the forward thyristor was fired at $90^{\circ}$ and $135^{\circ}$. Figures 2.7 and 2.8 show the reactor current and harmonic analysis of the reactor current at firing angles of $90^{\circ}$ and $135^{\circ}$ respectively. It can be seen that, as the thyristor firing angle increases, the reactor current becomes increasingly non-sinusoidal.

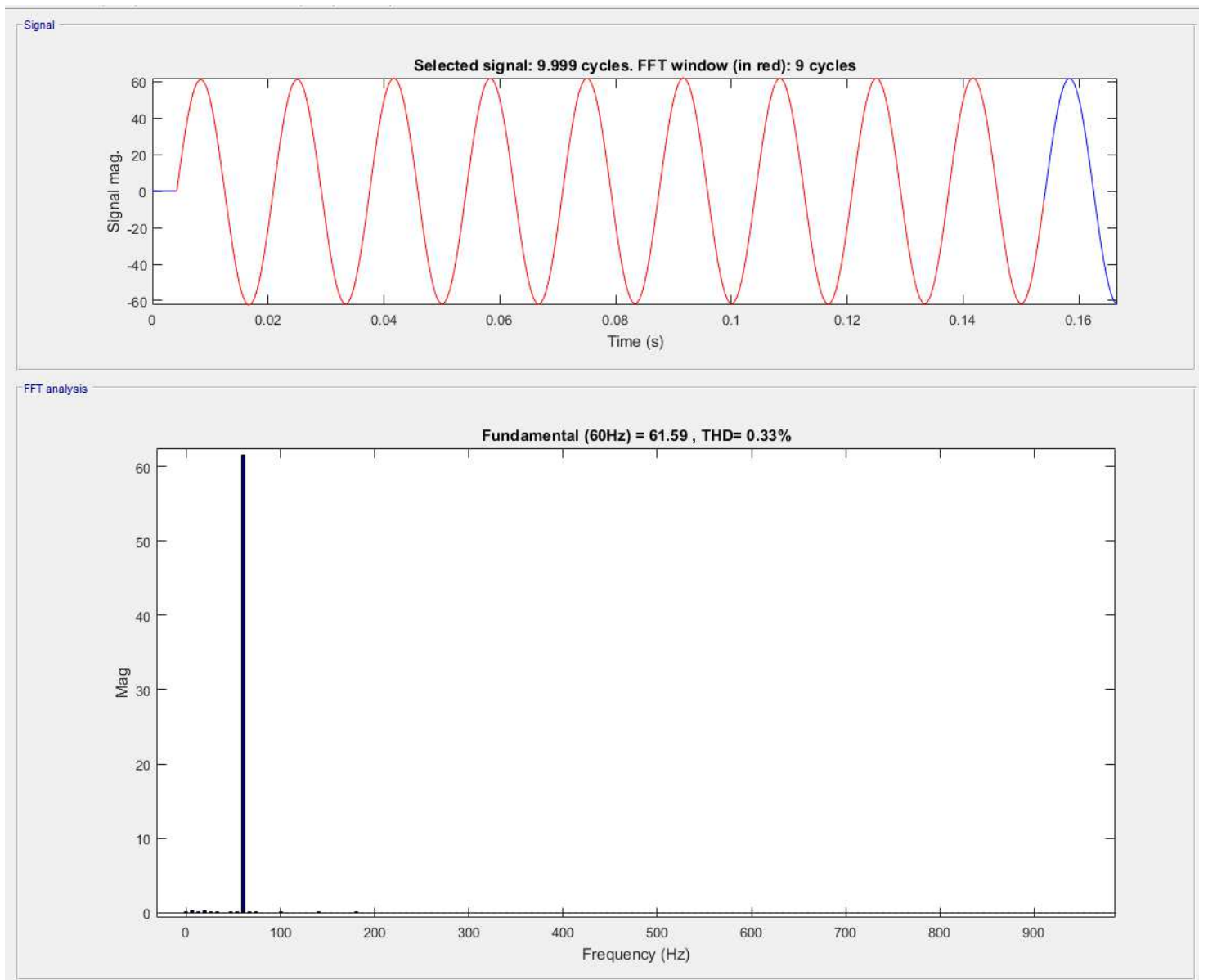

Figure 2.7: Reactor current and harmonic analysis for TCR-FC at a thyristor firing angle of $90^{\circ}$. 
Firing thyristors at an angle greater than $90^{\circ}$ generates low-order odd harmonics. These harmonics are injected into the power system and affect the performance of the power system. Thyristor-controlled reactors are generally connected in a three-phase delta configuration in order to trap the triplen harmonics. However, the development of a TCR as a single-phase device is difficult, due to a non-sinusoidal reactor current and low-order harmonics.

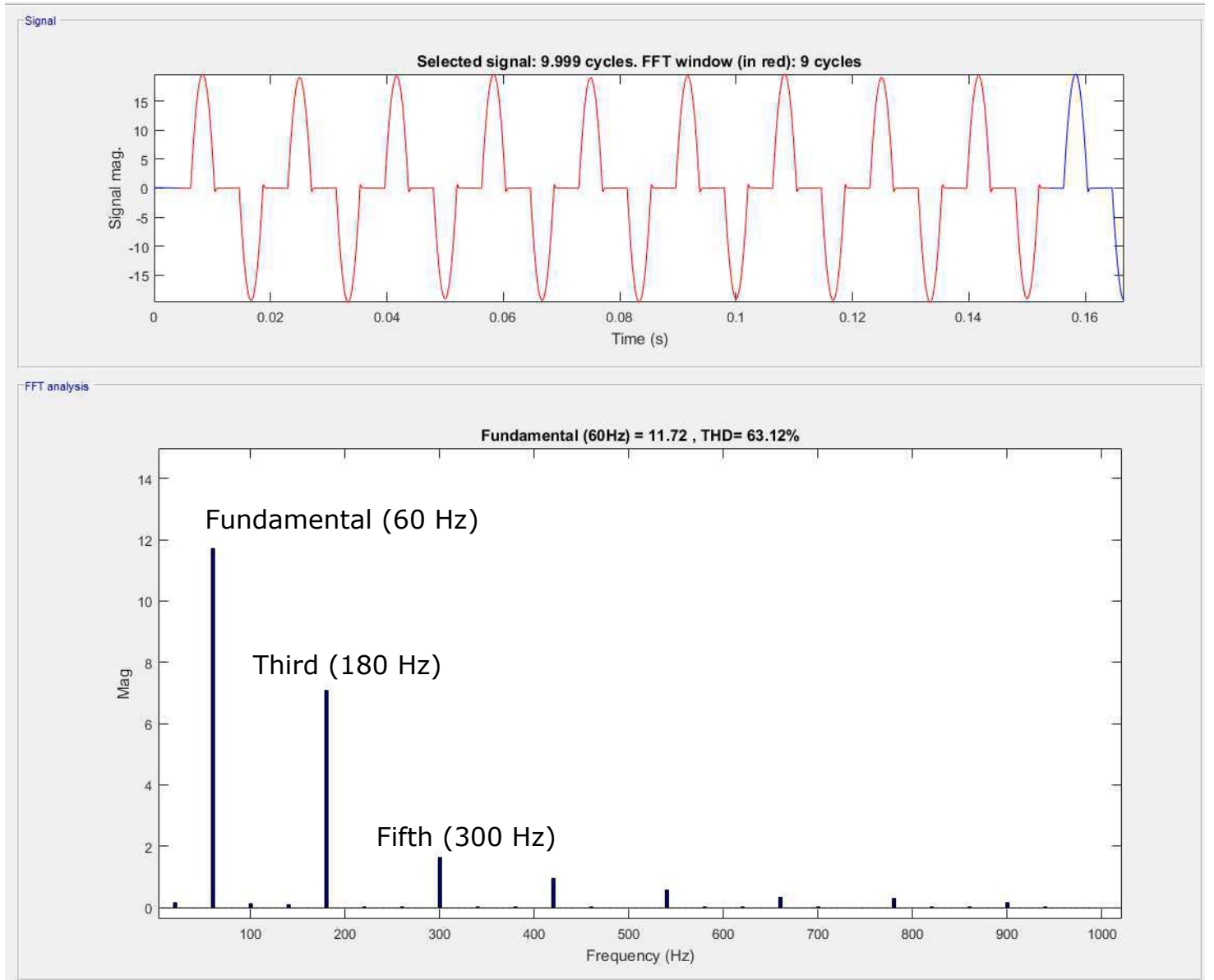

Figure 2.8: Reactor current and harmonic analysis for TCR-FC at a thyristor firing angle of $135^{\circ}$. 


\subsection{Pulse Width Modulated based Switched Reactor}

As discussed in previous sections, the thyristor-controlled reactor has multiple problems associated with it. The problems associated with the TCR can be summarized as follow:

- The control system for the TCR (as well as for the TSC) requires synchronization with the $\mathrm{AC}$ mains for generating the gate signals.

- The TCR var compensator produces low-order harmonics due to the discontinuous current.

- Var compensation is not continuous. It can only occur once in each half cycle.

Using an alternative approach, it is possible to switch a reactor while maintaining a continuous inductor current. This approach is based on a pulse-width modulated (PWM) switching of the reactor using two bidirectional switches which are operated in

a complementary manner. The advantages of PWM-based var compensators include a simpler control system that does not require synchronization with the SVC voltage, an ability to provide an uninterrupted reactor current for continuous reactive power, and a substantial reduction in the component size and cost.

\subsubsection{Operating Principle}

Figure 2.9 shows a single-phase PWM-based switched reactor topology. A detailed analysis for this topology can also be found in the literature $[18,19]$. The single-phase circuit requires two bidirectional switches or four unidirectional switches. 


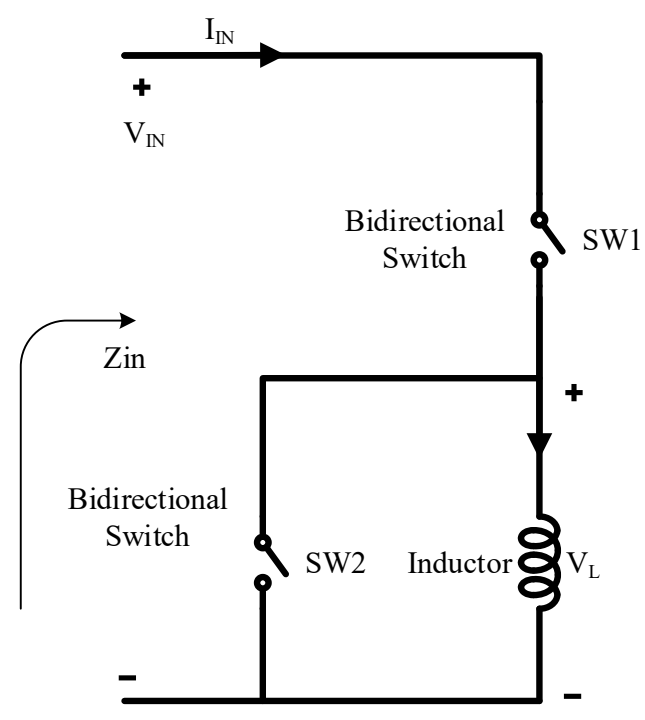

Figure 2.9: Proposed PWM-based Reacted Switching.

In Figure 2.9, switches SW1 and SW2 represent two bidirectional switches with complementary gating signals. The switch SW2 is used to conduct the reactor current when switch SW1 is open and vice versa. By using high frequency switching, the fundamental component of the reactor current can be controlled [18].

Assuming the switches to be ideal, meaning that their switching and conduction losses are negligible, when SW1 is closed (SW2 is open), the input voltage $V_{I N}$ appears across the reactor. This reactor voltage $V_{L}$ can be expressed by the following equation:

$$
V_{L, R M S}=V_{I N, R M S} D
$$

where $D$ is the duty cycle ratio, defined as the time interval when SW1 is conducting. Similarly, the fundamental component of reactor current $I_{L 1}$ can be expressed as follows:

$$
I_{L 1, R M S}=\frac{I_{I N, R M S}}{D}
$$


where $D$ is the duty cycle for switch SW1. From the above equations, the equivalent input inductive reactance, $X_{I N}$, can be found by using following expression:

$$
\left|X_{I N}\right|=\frac{\left|V_{I N}\right|}{\left|I_{I N}\right|}=\frac{\left|V_{L} / D\right|}{\left|I_{L 1} D\right|}=\frac{\left|X_{L}\right|}{D^{2}}
$$

where $X_{L}$ is the reactance of the reactor. From Equation 2.4, it can be seen that the input reactance $X_{I N}$ can be controlled by varying the duty cycle $D$. This makes the reactance of a fixed reactor $X_{L}$ appear as a continuously variable reactance, i.e., as a function of duty cycle. The dynamic reactive power generated by the PWM-based switched reactor can be expressed as follows:

$$
Q_{L}(D)=\frac{V_{I N}^{2}}{X_{I N}(D)}
$$

It can be seen that by increasing the duty cycle, the input inductive reactance $X_{I N}$ decreases, while the supplied reactive power increases.

There is a noticeable improvement in the performance of the PWM-based switched reactor compared to the conventional TCR. This configuration provides an alternative path for the reactor current through switch SW2. This free-wheeling current path is helpful in keeping the reactor current sinusoidal. This improvement also eliminates the requirement for additional filtering circuits that are required for limiting the harmonics in the reactor current and, thus, it makes it possible to build a single-phase SVC device.

Moreover, the reactive power injected by the PWM-based switched reactor is continuous. It can be varied during a sub-cycle by varying the duty cycle $D$ of switch SW1. This fact eliminates the need of any synchronization block, which was an essential component for producing the gating signals for the series thyristors. 


\section{CHAPTER 3}

\section{THE BIDIRECTIONAL SWITCH COMMUTATION}

\subsection{Introduction}

A bidirectional switch (also known as a four-quadrant switch or 4Q switch or AC switch) is an essential part of the proposed residential static var compensator. A bidirectional switch has the capability of conducting current in both directions, as well as blocking voltages of both polarities. The realization of a bidirectional switch is a technical challenge in the implementation of forced commutation techniques in direct AC switching. Research has been underway to fabricate a bidirectional switch on a single silicon die $[20,21]$. So far, very few bidirectional switches are available in the power-electronics market. Therefore, discrete unidirectional switches have been used to implement bidirectional switches [22].

This chapter provides a brief introduction to bidirectional switch topologies described in the literature. Different current commutation strategies are also reviewed based on the output current direction and input voltage polarity across the bidirectional switches. Preferring one strategy over another depends on a particular application. For the RSVC, a voltage-based current commutation is chosen because of the ease of detecting the voltage polarity across the bidirectional switches. For the sake of simplicity, "bidirectional switches" and "switches" will be used interchangeably in the following discussion. 


\subsection{Bidirectional Switch Topology}

Bidirectional switches are realized using discrete semiconductor devices. The diode bridge bidirectional switch arrangement shown in Figure 3.1 consists of an insulated gate bipolar transistor (IGBT) at the center of a diode bridge arrangement [23]. The main advantage associated with a diode bridge topology is that only one active driving circuitry is required to control the flow of current. However, the direction of current cannot be controlled through the bidirectional switch. When the current direction changes, it is commuted through the opposite conducting diodes. Moreover, there are three (3) devices involved in the conduction of the current which contributes to greater conduction losses compared to other bidirectional topologies. These disadvantages restrict the use of a diode bridge bidirectional switch to a limited number of applications.

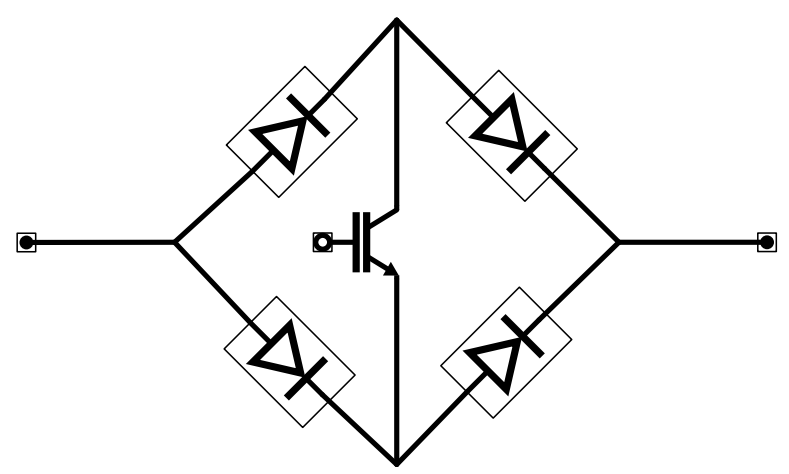

Figure 3.1: Diode bridge bidirectional switch topology.

Consider the circuit shown in Figure 3.2(a). In this figure, the switches represent diode bridge bidirectional switches. In case of a "make-before-break" strategy, the on-coming switch SW2 turns on before the off-going switch SW1 turns off. This causes a short circuit for the input sources which leads to huge current spikes, as illustrated in Figure 3.2(b). These current spikes are destructive for the semiconductor devices 
and may lead to permanent damage of the switching devices. In the circuit where a "make-before-break" strategy is applied, reactors are added to facilitate current transition during commutation and snubber circuits are required to limit the voltage transients [24].

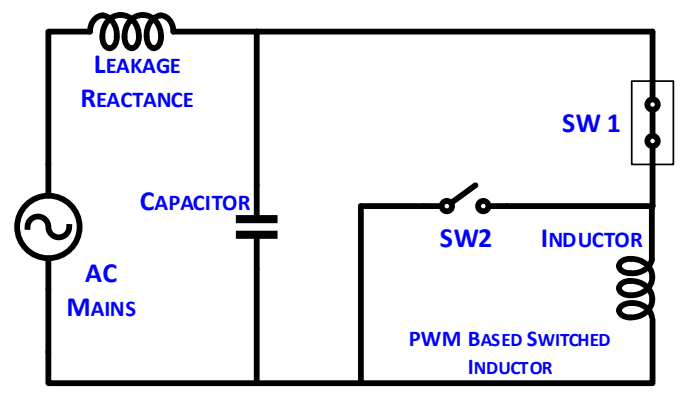

(a)

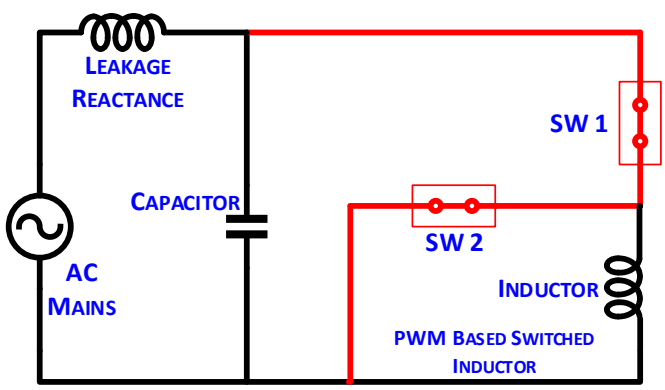

(b)

Figure 3.2: (a) Input phase with two bidirectional switches (b) Short circuiting the input phase using "make-before-break" strategy.

Consider now the circuit shown in Figure 3.3(a). For a "break-before-make" topology, the off-going switch, SW1, is turned off before the on-coming switch SW2 is turned on. This causes a breakage in the conduction of the inductive load current which, in turn, produces huge voltage spikes across the opened switches, as shown in Figure 3.3(b).

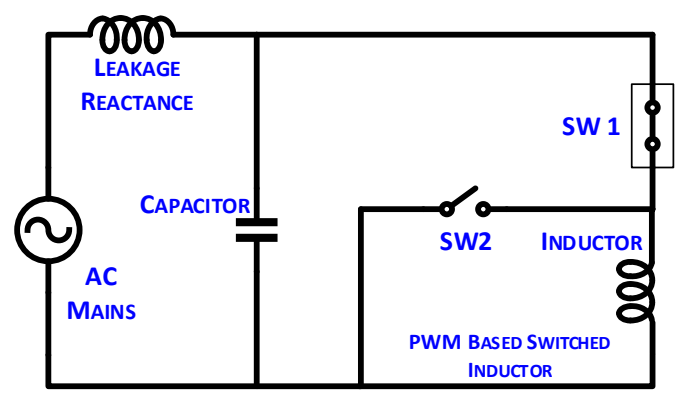

(a)

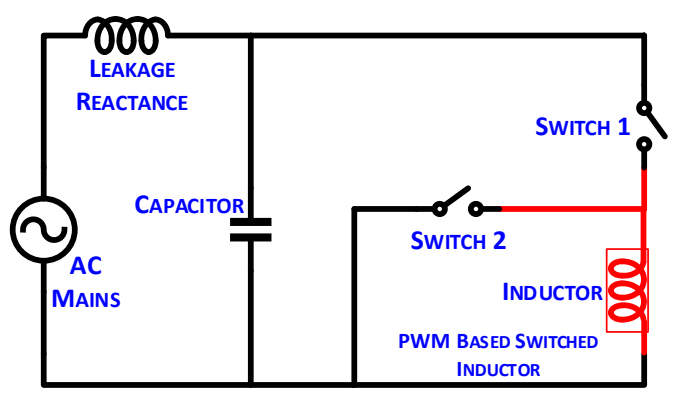

(b)

Figure 3.3: (a) Input phase with two bidirectional switches (b) Inductive current interruption using "break-before-make" strategy. 
These voltage spikes are destructive for the switches and can harm their safe functioning. Circuits using a "break-before-make" strategy normally use a voltage clamp circuit along with local snubber circuits to prevent against damaging voltage spikes [25].

Another proposed bidirectional switch topology includes two IGBTs with series diodes connected in an anti-parallel configuration $[26,27]$. In this topology shown in Figure 3.4(a)-(b), a conduction path for the current exists in both directions. The two IGBTs can be used to independently control the current paths. Also, the diodes provide the reverse voltage blocking capability. By using a proper commutation strategy, a safe commutation of the RSVC and inductor currents is possible, thus eliminating the risk of the short circuit and overvoltage spikes. This topology has reduced conduction losses, as only two active devices are used to conduct current in either direction. These features allow the two IGBTs with series diodes topology to be superior to the diode-bridge topology. Depending on the application, commonemitter or common-collector configurations, shown in Figure 3.4(a) and Figure 3.4(b) respectively, can be used for constructing a bidirectional switch. A common-emitter configuration requires only one isolated power supply for the gate driver circuitry for each bidirectional switch.

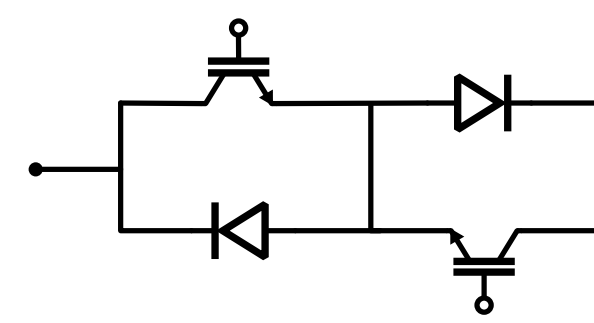

(a)

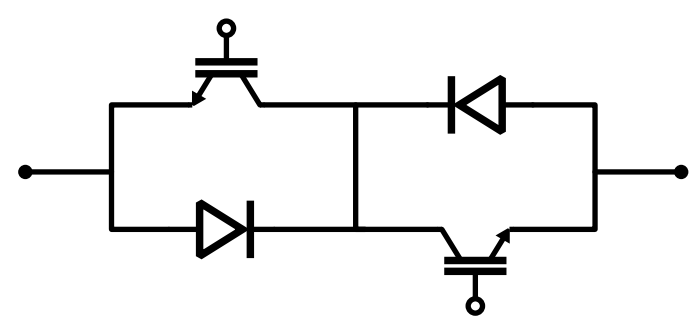

(b)

Figure 3.4: (a) Common-emitter configuration for a bidirectional switch (b) Common-collector configuration for a bidirectional switch. 


\subsection{Bidirectional Switch Commutation}

The commutation of a bidirectional switch consisting of two IGBTs with series diodes connected in the anti-parallel manner can be based on either the output load current direction or on the sign of the input voltage across the commutating bidirectional switches. In the following the discussion refer to Figure 3.5. When the output phase needs to be commutated from one input phase to other, it must satisfy following two rules:

1. The commutation from one input phase to the other should not short circuit the two input phases. Indeed, a short circuit of the input phases leads to destructive current spikes which are fatal for the switching devices.

2. The commutation should not interrupt the output load current. Interrupting the flow of inductive current leads to overvoltage spikes which are likely to destroy the IGBT devices.

In order to ensure that the above conditions are met, it is required to know either the sign of the input voltage across the switches or the direction of the output load current before a safe commutation sequence is applied [28-34].

\subsection{Four-Step Commutation using Output Load Current}

A reliable method for current commutation involves a four-step commutation strategy, which can be used to control the direction of current through the commutation switches [35]. The goal of this strategy is to strictly follow the two aforementioned rules for safe commutation. In order to explain this strategy, consider the two-phase circuit shown in Figure 3.5. In this circuit, the output load current $I_{o}$ is assumed to 


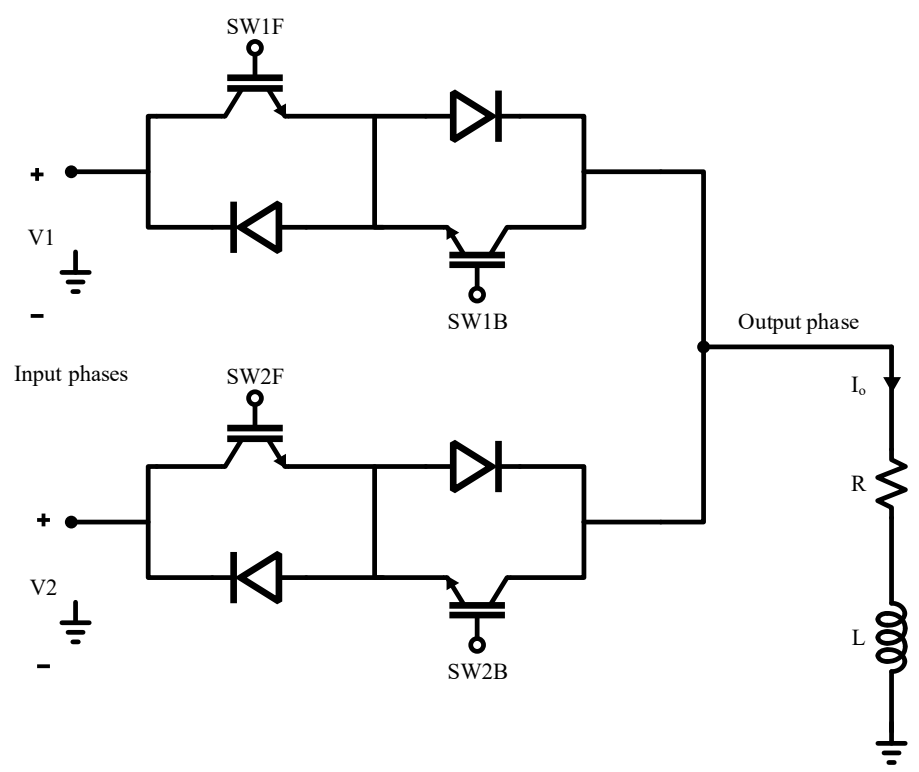

Figure 3.5: Diode bridge bidirectional switch topology.

be positive if it flows from one of the input phases to the output phase. A letter " $F$ ", on the switching devices represents the forward or positive direction of current flow whereas a letter "B" means the backward or negative direction of the current flow. It can be seen that the forward current, from the input phase to the output phase, flows through switches SW1F or SW2F, and the backward current, from the output phase to the input phase, flows through switches named SW1B or SW2B.

Looking at the circuit in Figure 3.5, a list of non-hazardous combinations of switching sequences can be achieved. These switching combinations are listed in Table 3.1.

In Table 3.1, a logic-high or logic-one (1) means the IGBT is ON or conducting whereas a logic-low or logic-zero (0) means that the IGBT is OFF or open. Any other combination of switching signals will violate either one of the two rules for safe-commutation. States 1 and 2 are called steady states and States 3 through 8 are called transitional states. The commutation of switches should start from a steady 
Table 3.1: Non-hazardous devices combination for current commutation based on the direction of the output current.

\begin{tabular}{|c|c|c|c|c|c|}
\hline State & SW1F & SW1B & SW2F & SW2B & Output current $\left(I_{o}\right)$ \\
\hline \hline 1 & 1 & 1 & 0 & 0 & + or - \\
\hline 2 & 0 & 0 & 1 & 1 & + or - \\
\hline 3 & 1 & 0 & 0 & 0 & + \\
\hline 4 & 0 & 0 & 1 & 0 & + \\
\hline 5 & 1 & 0 & 1 & 0 & + \\
\hline 6 & 0 & 1 & 0 & 0 & - \\
\hline 7 & 0 & 0 & 0 & 1 & - \\
\hline 8 & 0 & 1 & 0 & 1 & - \\
\hline
\end{tabular}

state and end in another steady state while going through three transitional states.

In the circuit shown in Figure 3.5, suppose that switch SW1 is turning off and SW2 is turning on. Assuming that the output load current $I_{o}$ is flowing in the positive directions, the current commutation from the outgoing switch SW1 to the incoming switch, SW2, based on output current direction, involves the following four steps:

1. the IGBT from the outgoing switch that is not conducting the output current is turned off. In this case, SW1B is turned off;

2. the IGBT from the incoming switch that will conduct the output current is turned on. In this case, SW2F is turned on;

3. the IGBT from the outgoing switch that is conducting the output current is turned off. In this case, SW1F is turned off;

4. the IGBT from the incoming switch that will not conduct the output current is turned on. In this case, SW2B is turned on. 
In case the output current is flowing in the opposite direction, i.e., from the output phase to the input phase, the commutation from outgoing switch SW1 to the incoming switch SW2 is performed in the following steps:

1. IGBT SW1F is turned off;

2. IGBT SW2B is turned on;

3. IGBT SW1B is turned off;

4. IGBT SW2F is turned on.

The commutation sequence can be summarized in the state machine diagram shown in Figure 3.6. It should be noted that there is a built-in time delay, $t_{d}$, between each transition. This time delay should be greater than the maximum propagation delays required by the IGBT gating signals.

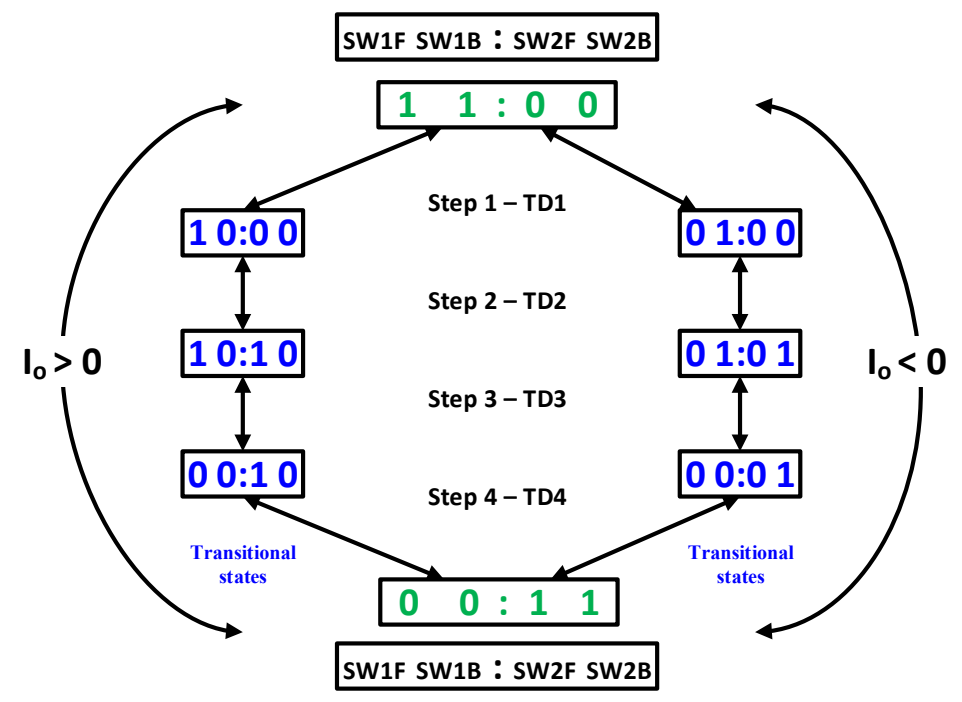

Steady states

Figure 3.6: Four-step switching diagram for two bidirectional switches based on output load current direction. 


\subsection{Four-Step Commutation using Input Voltage Sign}

In the previous method, the output load current was used to properly commutate between two input phases. This section will describe another method for current commutation between the two input phases. This commutation technique is based on the sign of the input voltage across the bidirectional switches, which are involved in the commutation [35].

As with the commutation using load current, this strategy assumes, that when an output phase is connected to the input phase, both the IGBT devices for the corresponding bidirectional switch are on. A general strategy is to identify the freewheeling diodes between the two bidirectional switches. Freewheeling diode paths are those that allow the current to follow from the lower input phase to the higher input phase voltage. Consider the circuit shown in Figure 3.7. For the first case assume that the voltage at SW1, i.e., V1 is at a higher potential than the voltage across SW2, i.e., V2. The IGBTs that aid the freewheeling diode path for the current to flow from V2 to V1 are SW2F and SW1B. The current commutation from SW1 to SW2 involves the following steps:

1. the IGBT of the incoming switch aiding the freewheeling diode, i.e., SW2F, is turned on;

2. the IGBT of the outgoing switch present in the non-freewheeling current path, i.e., SW1F, is turned off;

3. the IGBT of the incoming switch present in the non-freewheeling current path, i.e., SW2B, is turned on; 
4. the IGBT of the outgoing switch aiding the freewheeling diode, i.e., SW1B, is turned off;

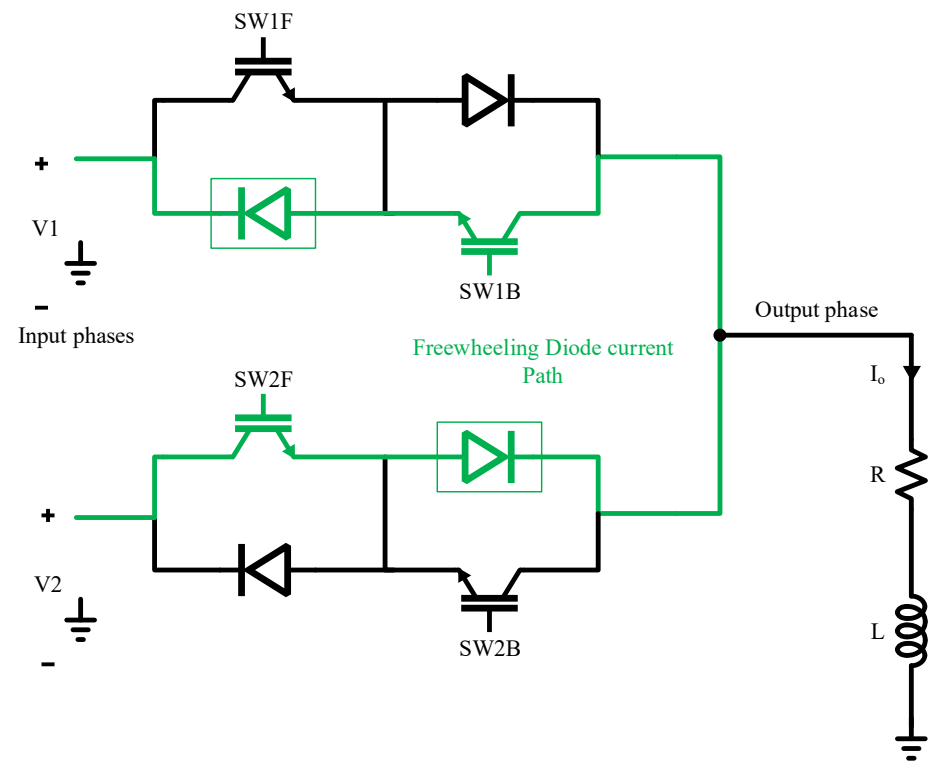

Figure 3.7: Freewheel diode current path when V1 $>$ V2.

In the case when V1 $<$ V2, the current commutation from SW1 to SW2 involves the following steps:

1. the IGBT of the incoming switch aiding the freewheeling diode, i.e., SW2B, is turned on;

2. the IGBT of the outgoing switch present in non-freewheeling current path, i.e., SW1B, is turned off;

3. the IGBT of the incoming switch present in the non-freewheeling current path, i.e., SW2F, is turned on;

4. the IGBT of the outgoing switch aiding the freewheeling diode, i.e., SW1F, is turned off; 
By looking at the circuit, the following combination of non-hazardous combinations of switching sequences can be achieved.

Table 3.2: Non-hazardous devices combination for current commutation based on the sign of the input voltage.

\begin{tabular}{|c|c|c|c|c|c|}
\hline State & SW1F & SW1B & SW2F & SW2B & Input Voltage Sign $\left(V_{12}\right)$ \\
\hline \hline I & 1 & 1 & 0 & 0 & + or - \\
\hline II & 0 & 0 & 1 & 1 & + or - \\
\hline III & 1 & 1 & 1 & 0 & + \\
\hline IV & 1 & 1 & 0 & 1 & + \\
\hline V & 0 & 1 & 1 & 1 & + \\
\hline VI & 1 & 0 & 1 & 1 & - \\
\hline VII & 0 & 1 & 1 & 0 & - \\
\hline VIII & 1 & 0 & 0 & 1 & - \\
\hline
\end{tabular}

This switching commutation is presented in a state machine diagram in Figure 3.8. As in the case of load current based current commutation, states where only both IGBTs for the bidirectional switches are on are called steady states and the remaining states are called transitional states. A small delay time between each transition is required to account for the propagation delays in the gating signals for the IGBTs.

\subsection{Commutation Methodology for the Single-Phase RSVC}

For the commutation of the bidirectional switches in an RSVC, voltage-based current commutation is preferred over the output load current commutation. For a single-phase voltage, the bidirectional switch commutation becomes relatively simpler, as it only involves detecting the sign of the main line with respect to the neutral point. For a balanced three-phase system, the neutral is often grounded (i.e., it is at zero potential), and thus V2 in the circuit shown in Figure 3.7 reduces to zero volts. 


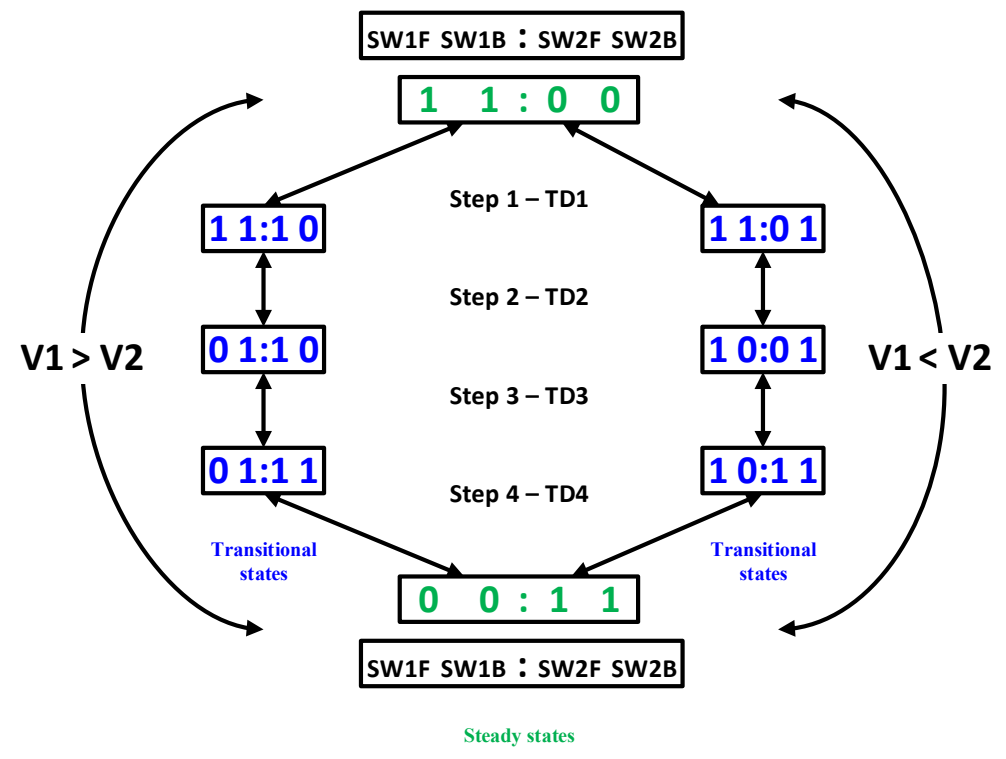

Figure 3.8: Four-step switching state machine diagram for two bidirectional switches based on the input voltage sign.

Detection of the voltage sign is done using a high-accuracy analog-to-digital (ADC) converter. An incorrect measurement of the voltage sign during the commutation process may result in a short-circuit path.

For an RSVC, the detection of the voltage sign is achieved using a ADC from Maxim Integrated Santa FE (MAXREFDES5\#) [22]. This ADC is capable of 16-bit high-accuracy analog to digital conversion that accepts $-10 \mathrm{~V}$ to $+10 \mathrm{~V}$ biplolar analog signals. The digital output from the ADC is then passed on to a programmable device like a micro-controller or an FPGA for the execution of the proper state machine sequence. 


\section{CHAPTER 4}

\section{GENERATION OF COMMUTATION SIGNALS FOR BIDIRECTIONAL SWITCHES}

\subsection{Introduction}

The single-phase RSVC device requires two bidirectional switches for its operation. These bidirectional switches operate in a complementary manner to control the reactive power of the reactor. The commutation from one switch to the another is carried out using a four-step commutation method based on the input voltage polarity, as explained in the previous chapter. These commutation signals are generated using a Spartan3E FPGA board. This chapter discusses the design methodology used to develop the commutation signals for the bidirectional switches. Simulation results for the commutation scheme are also provided at the end of this chapter.

Figure 4.1 shows the block diagram for the generation of the commutation signals for the two bidirectional switches. The RSVC device consists of a PWM switched inductor that is controlled by changing the duty cycle of the bidirectional switches. The gating signals for the bidirectional switches are generated using an FPGA with a Hardware Descriptive Language (HDL). The following discussion will focus on the implementation of the gate driving signals on the FPGA. 

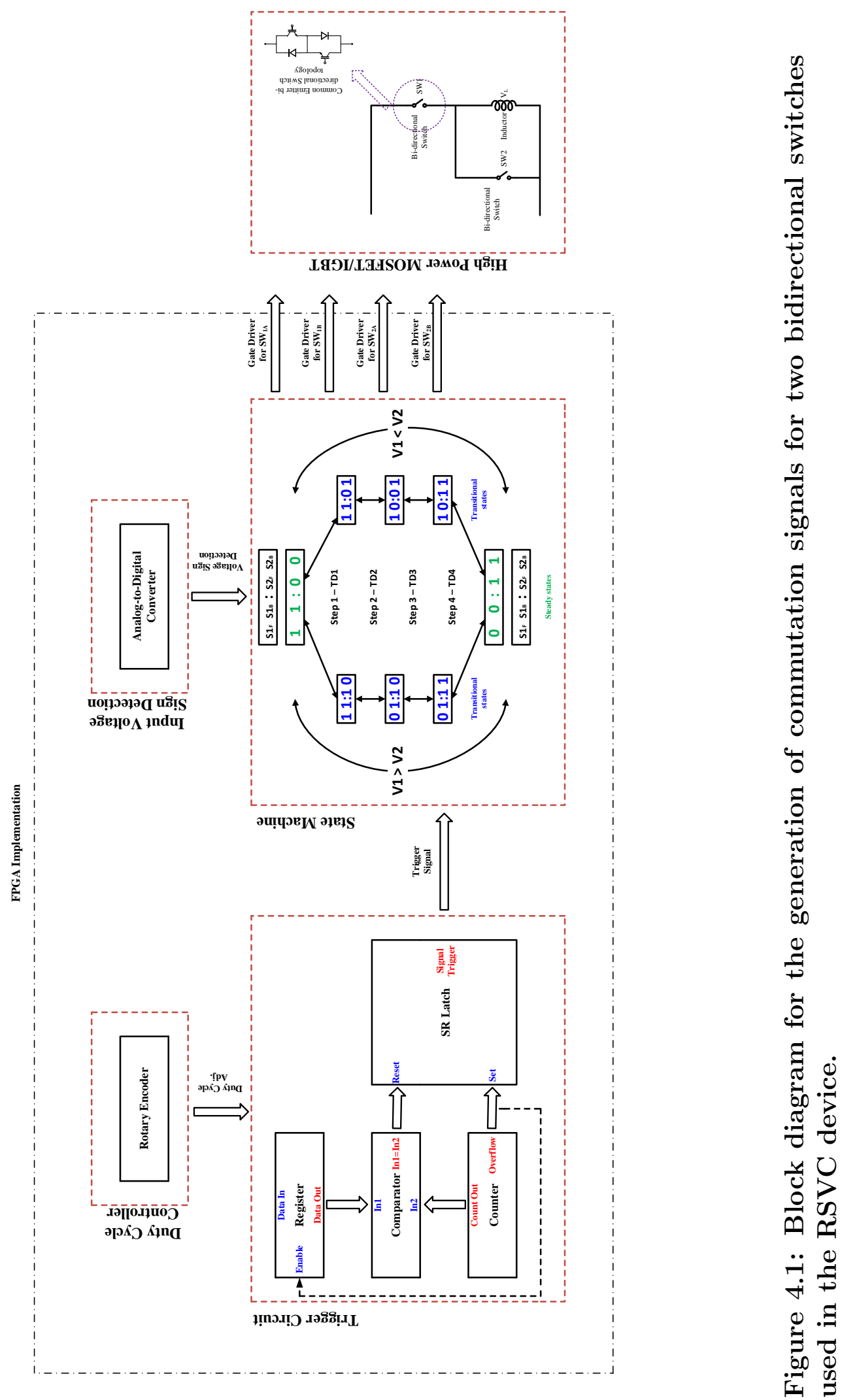
It is supposed that the state machine is in a steady state of (SW1F, SW1B, SW2F, $\mathrm{SW} 2 \mathrm{~B})=(1,1,0,0)$, meaning the top switch is on and the freewheeling switch is off. The 24-bit input data from a rotary encoder is loaded into the hardware register whenever the load signal is high. This hardware register holds the information for the duty cycle of the top bidirectional switch. At every positive edge of the clock, the value in the register is compared with the upcounter. The reset signal for the S-R latch sets high whenever the duty cycle becomes equal to the counter value. The output of S-R latch controls the triggering signal for the state machine. This causes the state machine to move from one steady state $(1,1,0,0)$ to the other steady state $(0,0,1,1)$. The state machine returns back to the original steady state $(1,1,0,0)$ when the counter overflows.

The commutation from one switch to another involves a change in the state of four switching devices. The switching devices have finite turn-on and turn-off times. Therefore, it is essential to provide sufficient dead time between the transition states to avoid short circuiting the AC input.

The initial prototype of the RSVC used four IRGP4066DPbF IGBTs from International Rectifier as the switching devices. A typical turn-on delay for this type of IGBT switch is $50 \mathrm{~ns}$ and a typical rise time is $70 \mathrm{~ns}$. The typical turn-off delay time is $200 \mathrm{~ns}$ and typical fall time is $60 \mathrm{~ns}$. All of these timings are based on a 200 $\mu \mathrm{H}$ load. According to these values, the total turn-on delay for each IGBT device is $120 \mathrm{~ns}$ and total turn-off delay is $260 \mathrm{~ns}$. Hence, the four-step commutation process involves at least $760 \mathrm{~ns}(2 \times 120 \mathrm{~ns}+2 \times 260 \mathrm{~ns})$. In order to avoid any parasitic delays, both turn-on and turn-off delays should be scaled up to avoid overlapping of the gate driving signals. For the RSVC prototype testing, the time delay between each transitional state is set at $1 \mu \mathrm{s}$. Therefore, the four-step commutation process 
completes in $4 \mu \mathrm{s}$.

\subsection{Commutation Prohibition Strategy}

The input voltage-based current commutation is a reliable method for commutating current from one switch to another. However, the detection of the voltage sign becomes critically important near the zero-crossing of the phase-to-neutral voltage. In order to safely commutate from one switch to another, it becomes necessary to stop the bidirectional switching state machine near the zero crossing.

Figure 4.2 shows the input AC mains waveform. In the region of the waveform marked as "Non-Critical Region", the current commutation using the bidirectional switching state machine can be carried out normally. The "Critical Region" occurs near the zero-crossing, when the phase-to-neutral voltage becomes nearly equal to zero.

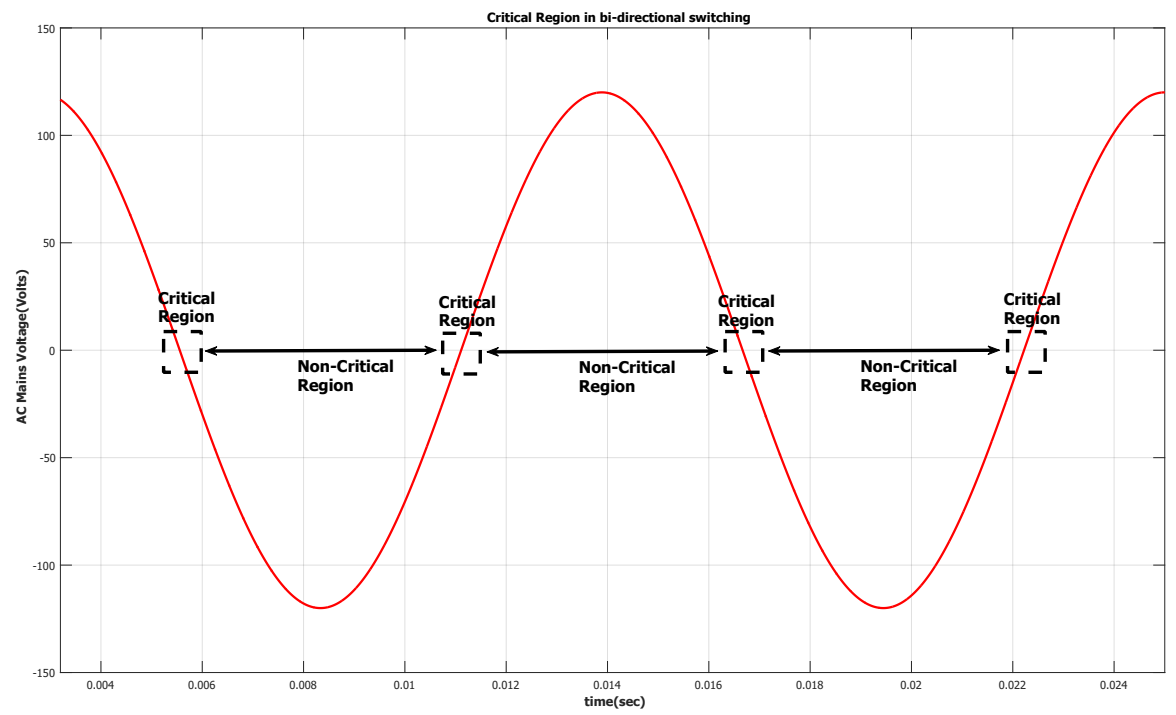

Figure 4.2: Diode bridge bidirectional switch topology. 
To avoid commutating in the critical region, the commutation sequence is not executed until the input voltage has significantly increased (or decreased) away from zero. The commutation sequence is halted at a steady state of $(0,0,1,1)$ during the critical region. The effect of a commutation halt on the output voltage and the output current is not significant, as long as the critical region is kept small. However, due to a halt in the commutation, the inductor current waveform will differ slightly from a sinusoidal shape.

As shown in the block diagram in Figure 4.1, the RSVC prototype uses an ADC to identify the critical region and to detect the sign of the input voltage which is needed for the execution of the state machine.

\subsection{Simulation Results on FPGA}

This section describes the commutation from one switch to another with the help of test bench waveforms. Consider the circuit shown in Figure 4.3 which consists of top and bottom bidirectional switches connected to an input phase and a neutral point, respectively.

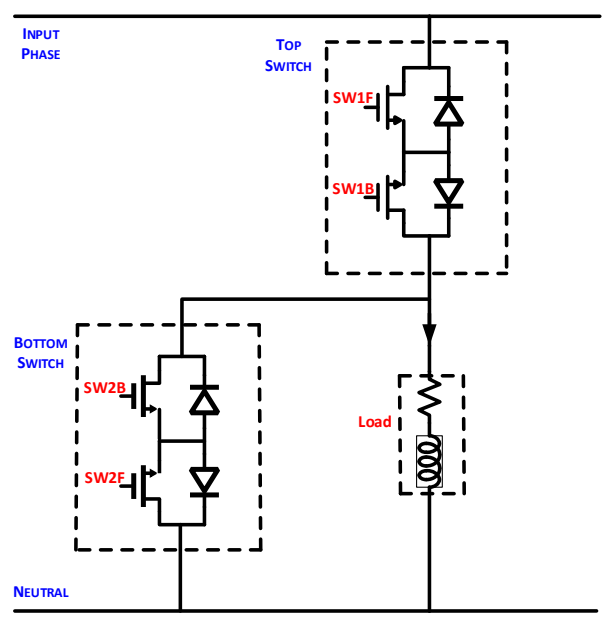

Figure 4.3: Bidirectional switches with inductive load. 
An inductive load is attached to the outputs of the bidirectional switches. In this section, the test benches are only provided when the input voltage is positive. Similar waveforms can be obtained when the input phase is negative with respect to the phase neutral.

Figure 4.4 shows the test bench waveform for commutating from the top bidirectional switch to the bottom bidirectional switch when the input voltage is positive. At each step of the four-step commutation, it is ensured that a short-circuiting of the input phase is avoided and that the inductor current remain fairly sinusoidal. The commutation follows the following steps:

1. SW2F is turned on;

2. SW1F is turned off;

3. SW2B is turned on;

4. SW1B is turned off;

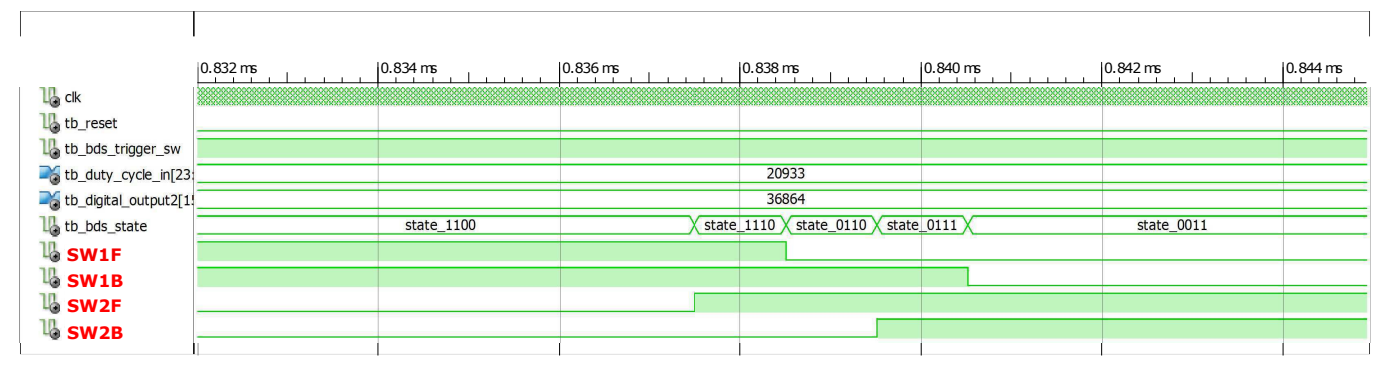

Figure 4.4: Test bench waveform for switching from top bidirectional switch to bottom bidirectional switch when the input voltage is positive.

Figure 4.5 shows the reverse path of commutation, i.e., from the bottom bidirectional switch to the top bidirectional switch when the input voltage is positive. The steps followed by the commutation are as follows: 
1. SW1B is turned on;

2. SW2B is trend off;

3. SW1F is turned on;

4. SW2F is turned off.

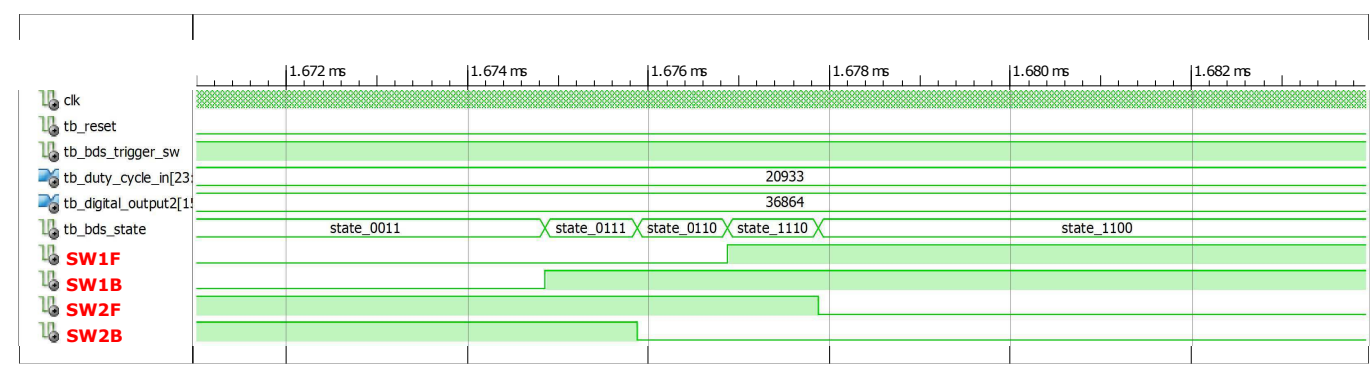

Figure 4.5: Test bench waveform for switching from bottom bidirectional switch to top bidirectional switch when the input voltage is positive.

Similar test benches can be obtained when the input voltage is negative. These test benches verify that correct switching signals are generated based on the input voltage polarity across the RSVC device. 


\section{CHAPTER 5}

\section{RSVC DESIGN WITH SIMULATION RESULTS}

\subsection{Introduction}

The RSVC is conceived as a device that can provide voltage regulation and implement Conservation by Voltage Reduction (CVR) at the distribution level of the power system. SVCs have been in operation on the transmission side of the power systems for several decades. But their rare deployment at the distribution level forces utilities to opt for solutions that lead to switching transients and overvoltage problems $[36,37]$.

The prototype RSVC is simulated as a shunt device at the secondary of a $25-\mathrm{kVA}$ pole-mounted distribution transformer typically serving three residential homes. A service transformer or distribution transformer is a transformer that transforms the voltage in the distribution feeders to the level used by the customer. The concept

of an RSVC is an extension of the already developed SVC that is in service on the transmission side of the power system.

The discussion in this chapter focuses on designing a single-phase RSVC that will serve a $25-\mathrm{kVA}$ residential load from a pole-mounted distribution transformer. The reactive components are sized to regulate the residential voltage in the lower half of the ANSI C84.1 Standard. The simulation results are presented at the end of this chapter. 


\subsection{Distribution Network Modeling}

The RSVC is simulated as a single-phase device which is connected in shunt with a $25 \mathrm{kVA}$ pole-mounted service transformer. For sizing the RSVC reactive components, it is necessary to analyze the primary side of a pole-mounted transformer so that the strength of the substation network as seen from the RSVC device is included in the simulations. In general, an ideal distribution network will appear as an infinite bus (with negligible reactance) to the RSVC device.

To study the effects of the distribution network on the RSVC, a 5-mile-long distribution feeder, serving five uniformly distributed 1 MW loads, was modeled using 397.5 MCM ACSR (Aluminum Conductor Steel Reinforced) conductors. The secondary sides of the distribution transformers were held at 0.95 per unit, i.e., at the minimum allowable service voltage outlined in ANSI C84.1 Standard, by using reactive generators.

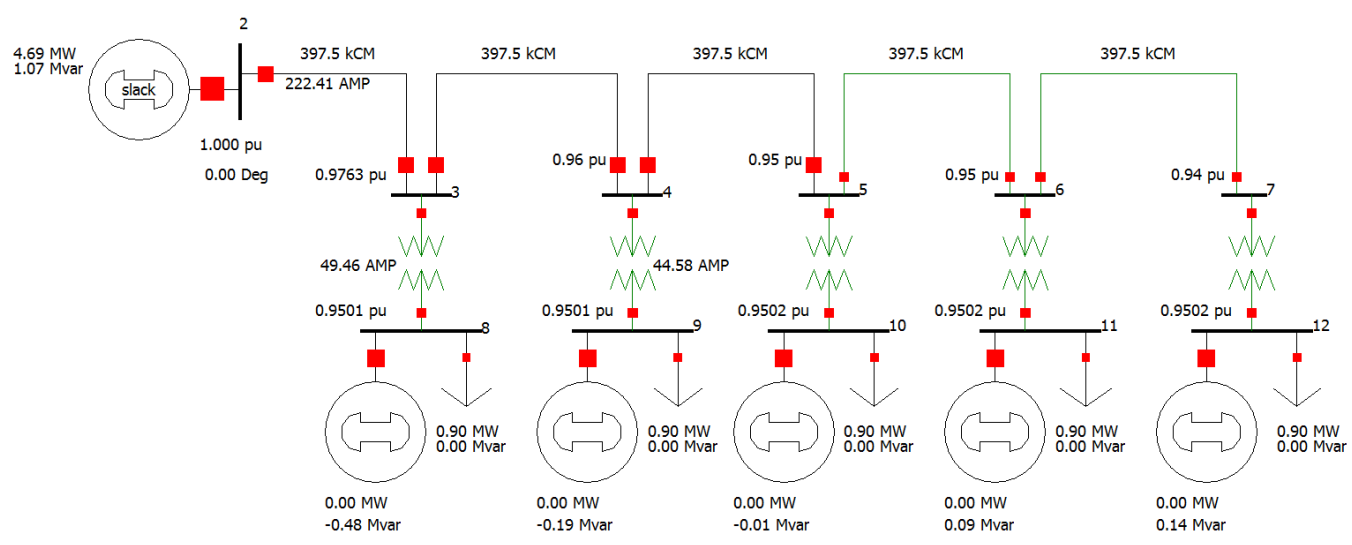

Figure 5.1: PowerWorld Model for a Distribution Network.

Figure 5.1 shows a PowerWorld model of a distribution feeder which is fed from a distribution substation. The substation is modeled as an ideal source that can generate the real and reactive power required by the distribution network. The dis- 
tribution network consists of five distributed loads of $1 \mathrm{MW}$ at unity power factor. The parameters used to calculate the Thevenin equivalent impedance of the distribution feeder are as follows: the power base is $100 \mathrm{MVA}$; the voltage base is $240 \mathrm{~V}$ or 1.0 per unit; the leakage reactance for the service transformer is $10 \%$ on a 2 MVA base. The reactive generator maintains the voltage at the secondary of the service transformer at 0.95 per unit by providing the reactive power that is specified in Table 5.1. In Table 5.1 , the reactive generator that is nearest to the substation is labeled as Q1 whereas the reactive generator at the end of the feeder is labeled as Q5. The total active and reactive power supplied by the substation is $4.69 \mathrm{MW}$ and 1.07 MVar respectively.

In order to calculate the strength of the distribution network, the Thevenin equivalent of the distribution network is found at a suitable point from the substation. In this case, the Thevenin equivalent of the distribution network is calculated at the third generation point Q3. Figure 5.2 shows the impedance diagram for the distribution network represented in Figure 5.1. The components value shown in the impedance diagram are in per unit and are referred to the lower side of the service transformer.

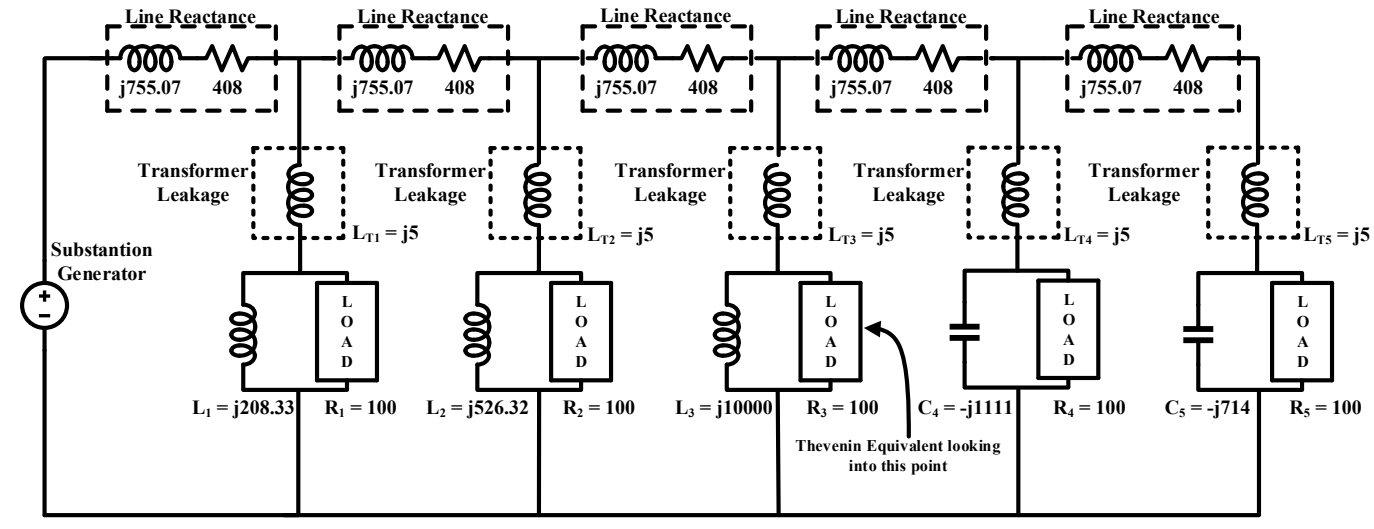

Figure 5.2: Equivalent impedance circuit for the distribution network to calculate Thevenin impedacnce. 
Table 5.1: Reactive power requirement for each generator in the Distribution Network.

\begin{tabular}{|c|c|c|}
\hline Reactive Generator & Reactive Power (MVar) & Reactance (per unit) \\
\hline \hline Q1 & -0.48 & -208.33 \\
\hline Q2 & -0.19 & -526.32 \\
\hline Q3 & -0.01 & -10000 \\
\hline Q4 & 0.09 & 1111.11 \\
\hline Q5 & 0.14 & 714.29 \\
\hline
\end{tabular}

Using a MATLAB script to solve for the Thevenin equivalent circuit, this impedance value $\left(\mathrm{Z}_{\mathrm{TH}}\right)$ comes out to be $0.0501+j 0.0086$ per unit. The results show that a distribution network appears as an infinite bus to the RSVC device.

\subsection{Residential Loads Modeling}

Residential loads vary substantially and involve sophisticated load modeling algorithms to predict the residential load profiles [38-40]. However, for designing the RSVC, a general perception of the load profile is sufficient to model the residential loads.

For the RSVC, residential loads are modeled using load profiles provided by Avista Utilities for a Spokane downtown network for the year 2013. The load profile data is available on a per-hour basis. In order to understand the behavior of residential loads at the distribution transformer, the power factor of the load was calculated using the load profiles. Based on the calculated power factor, average power factors were determined for the winter peak month (January) and the summer peak month (June).

Figure 5.3 shows the power factor variations during January 2013 and June 2013. The dashed line in Figure 5.3 represents the average power factor calculated for each 
season peak. The average power factor for the winter peak is 0.9446 (lagging) while the average power factor for summer peak is 0.8724 (lagging).
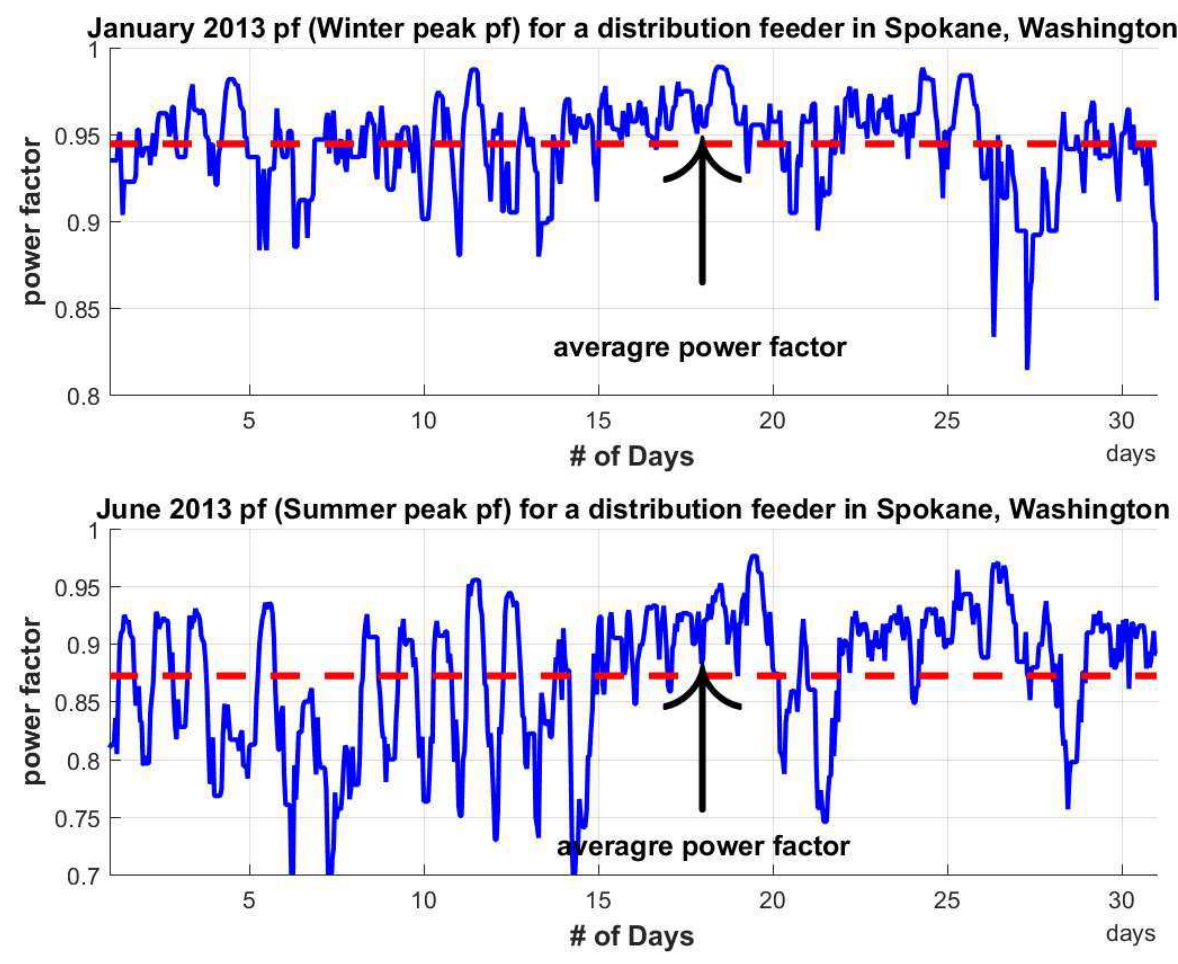

Figure 5.3: Power Factor variation during January 2013 and June 2013 for a distribution feeder in Spokane, Washington.

The voltage regulation capability of the RSVC is mainly dependent on the size of the reactive components involved. Therefore, a general idea regarding the residential loads is sufficient to properly simulate the RSVC device with residential customer loads fed from a 25-kVA pole-mounted service transformer. For the purpose of the RSVC, the power factor of the residential loads is considered to be 0.95 lagging. The resistive and inductive components of the load model was calculated to be $2.43 \Omega$ and $19.57 \mathrm{mH}$, respectively. 


\subsection{Modeling the Service Transformer Leakage Reactance}

The leakage reactance of a service transformer plays an important role when considering the operation of the RSVC. The proposed location for the RSVC installation is in close proximity to the service transformer. Thus, it is important to study the effects of the service transformer leakage reactance.

In an ideal transformer, all the flux will link with both the primary and secondary windings of the transformer. However, in practice, it is impossible for this flux to link with both the primary and secondary windings of a transformer. There will be a small amount of flux which will leak out of either winding. This leakage flux passes through the winding insulation, thus contributing to the leakage reactance of the transformer.

While sizing the RSVC components, the transformer leakage reactance is assumed to vary between $10 \%$ to $20 \%$ of the rated transformer reactance $\mathrm{X}_{\mathrm{L} \text {,rated }}$. The parameters used to calculate the transformer leakage reactance are similar to the parameters used for modeling the Thevenin equivalent of the distribution network, i.e., the power base is $25 \mathrm{kVA}$ and the voltage base is $240 \mathrm{~V}$. Assuming the core resistance to be negligible, for $10 \%$ or 0.1 per unit of the rated distribution transformer reactance, the leakage reactance is $0.23 \Omega$, whereas for $20 \%$ or 0.2 per unit, the leakage reactance is $0.46 \Omega$.

\subsection{RSVC Reactive Component Sizing}

The discussion in this section focuses on the RSVC circuit shown in Figure 5.4. In this circuit, the leakage reactance for transformer is assumed to be $10 \%$ of the rated transformer reactance and residential loads at the distribution transformer are modeled at 0.95 lagging power factor. It is assumed that an additional $5 \%$ reactance 
of cable wiring is also present which is added to the transformer reactance to increase it to $15 \%$.

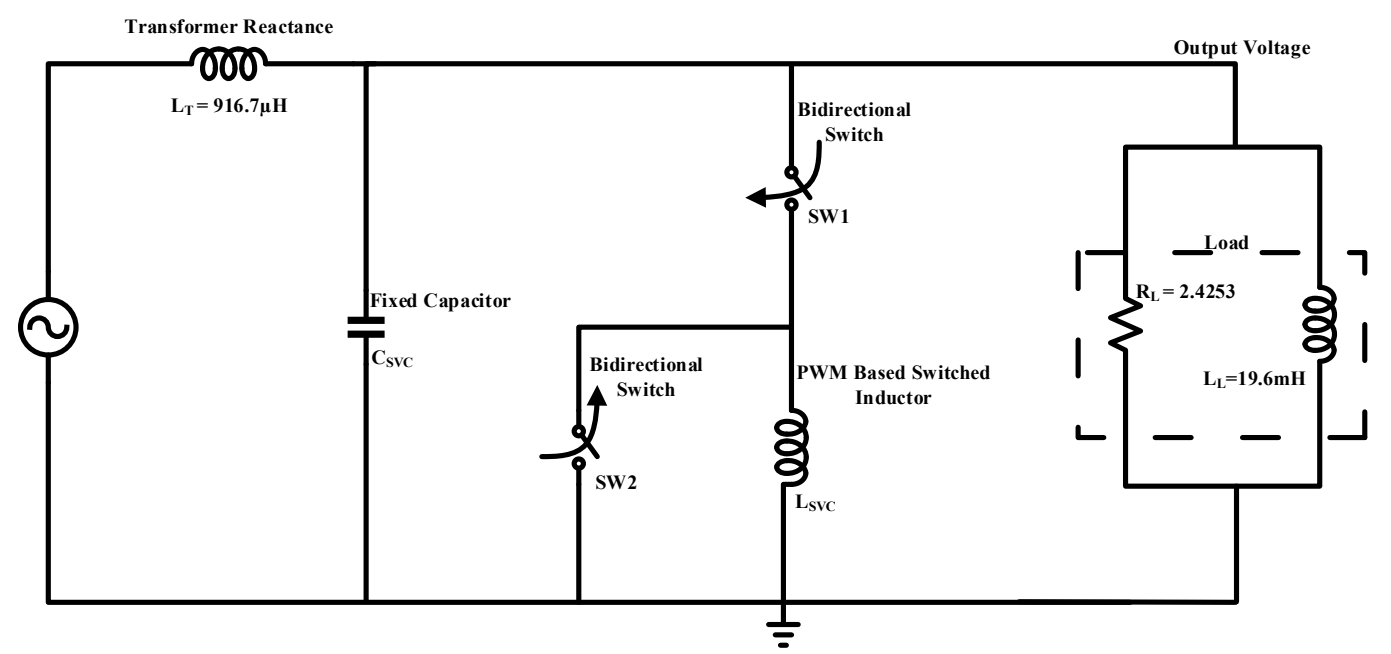

Figure 5.4: RSVC circuit for calculating the fixed capacitor and inductor.

The most important design parameters for the RSVC are its reactive components. The success of the RSVC lies in its ability to regulate the voltage on the secondary side of the distribution transformer. Reactive power needs are highly dependent on the load profiles for the specific distribution transformer but in order to generalize the RSVC design, worst-case scenarios for voltage regulations are considered for sizing the reactive components.

The fixed shunt capacitor $\left(\mathrm{C}_{\mathrm{SVC}}\right)$ provides reactive power support by providing vars to the power system. Adding vars helps in boosting the receiving-end voltage. For residential customers, the minimum permissible voltage is minus $5 \%$ of the nominal voltage (on a $120 \mathrm{~V}$ voltage base) as outlined in ANSI C84.1 Standard. Therefore, the RSVC capacitive power needs should be calculated in order to maintain the minimum voltage at the distribution transformers. As the reactor $\left(\mathrm{L}_{\mathrm{SVC}}\right)$ contributes in absorbing vars, it can be isolated from the proposed RSVC design by opening switch 
SW1. The reactor $\mathrm{L}_{\mathrm{SVC}}$ is essentially cut off from the remaining circuit when switch SW1 is opened and the reactor current flows through switch SW2. The simulations performed resulted in a capacitive reactive power of $10.2 \mathrm{kVar}$. Simulation results for the capacitor modeling are shown in Figure 5.5.

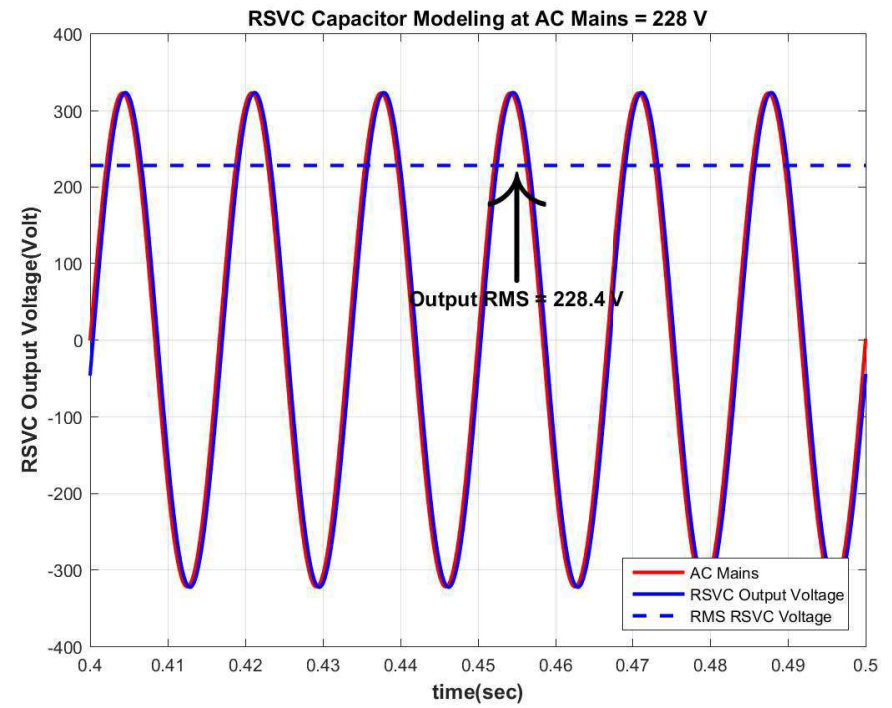

Figure 5.5: Simulation results for the RSVC capacitor modeling when the AC mains voltage is $228 \mathrm{~V}$.

The proposed RSVC design is based on a Fixed Capacitor with a PWM-based controlled inductor. Once the reactive requirements for $\mathrm{C}_{\mathrm{SVC}}$ are determined, the reactor can be sized accordingly to meet the RSVC reactive power needs. As with the case of sizing the capacitor, the reactor is modeled at the worst-case voltage condition for CVR purposes. This condition will occur when the secondary of the service transformer is operating at the nominal voltage, i.e., at 240 VAC. In addition to the voltage at the distribution transformer, the effect of the fixed $\mathrm{C}_{\mathrm{SvC}}$ must be included for determining the reactive power requirement for the reactor. In other words, the reactor is sized to compensate the voltage at the secondary of the distribution 
transformer along with the vars added by the fixed capacitor. The simulations performed resulted in a reactor reactive power of $11.8 \mathrm{kVar}$. The simulation results for inductor modeling are shown in Figure 5.6.

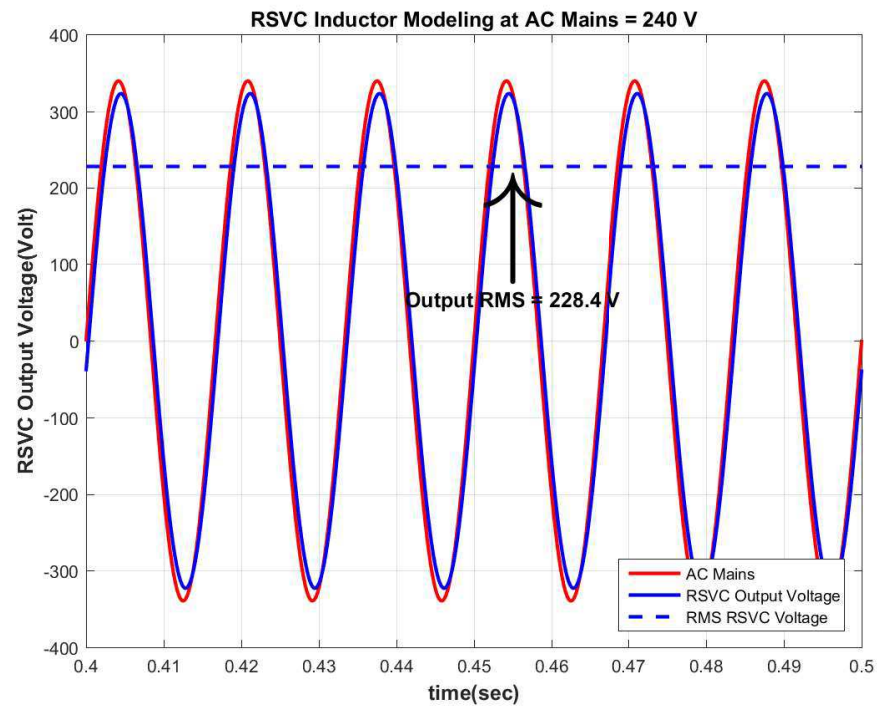

Figure 5.6: Simulation results for the RSVC inductor modeling with fixed capacitor and an AC mains voltage of $240 \mathrm{~V}$.

\subsection{Summary for the RSVC Reactive Requirements}

Various sets of simulations were performed with different distribution transformer leakage reactances. Table 5.2 shows the reactive requirements for the RSVC components with different transformer leakage reactances at $10 \%, 15 \%$ and $20 \%$.

\subsection{RSVC Simulation Results}

The simulation for the RSVC is performed using a fixed 10-kVAr capacitor and a 11.8-kVAr inductor. The leakage inductance of the distribution transformer is 
Table 5.2: Reactive power requirement for each generator in the Distribution Network.

\begin{tabular}{|c|c|c|c|c|}
\hline \multirow{2}{*}{$\begin{array}{c}\text { Transformer Reactance } \\
\text { (including the wire reactance) }\end{array}$} & \multicolumn{2}{|c|}{ Load } & \multicolumn{2}{c|}{ Reactive Requirement } \\
\cline { 2 - 5 } & $\mathrm{R}_{\mathrm{L}}(\mathrm{ohms})$ & $\mathrm{X}_{\mathrm{L}}(\mathrm{ohms})$ & $\mathrm{Q}_{\mathrm{C}}(\mathrm{kVAr})$ & $\mathrm{Q}_{\mathrm{L}}(\mathrm{kVAr})$ \\
\hline $10 \%$ & 2.43 & 7.39 & 10.2 & 11.8 \\
\hline $15 \%$ & 2.43 & 7.39 & 11.4 & 6.79 \\
\hline $20 \%$ & 2.43 & 7.39 & 12.5 & 3.82 \\
\hline
\end{tabular}

modeled as $10 \%$ of the base impedance at $25-\mathrm{kVAr}$ and $240-\mathrm{V}$. The reactor is switched with two bidirectional switches at a high switching frequency in a complementary manner. Figure 5.7 shows the simulation model for the RSVC. The simulation results were obtained a switching frequency of $1 \mathrm{kHz}$ and a fixed duty cycle of 0.5 . The simulation results presented in this section are plotted in MATLAB for readability.

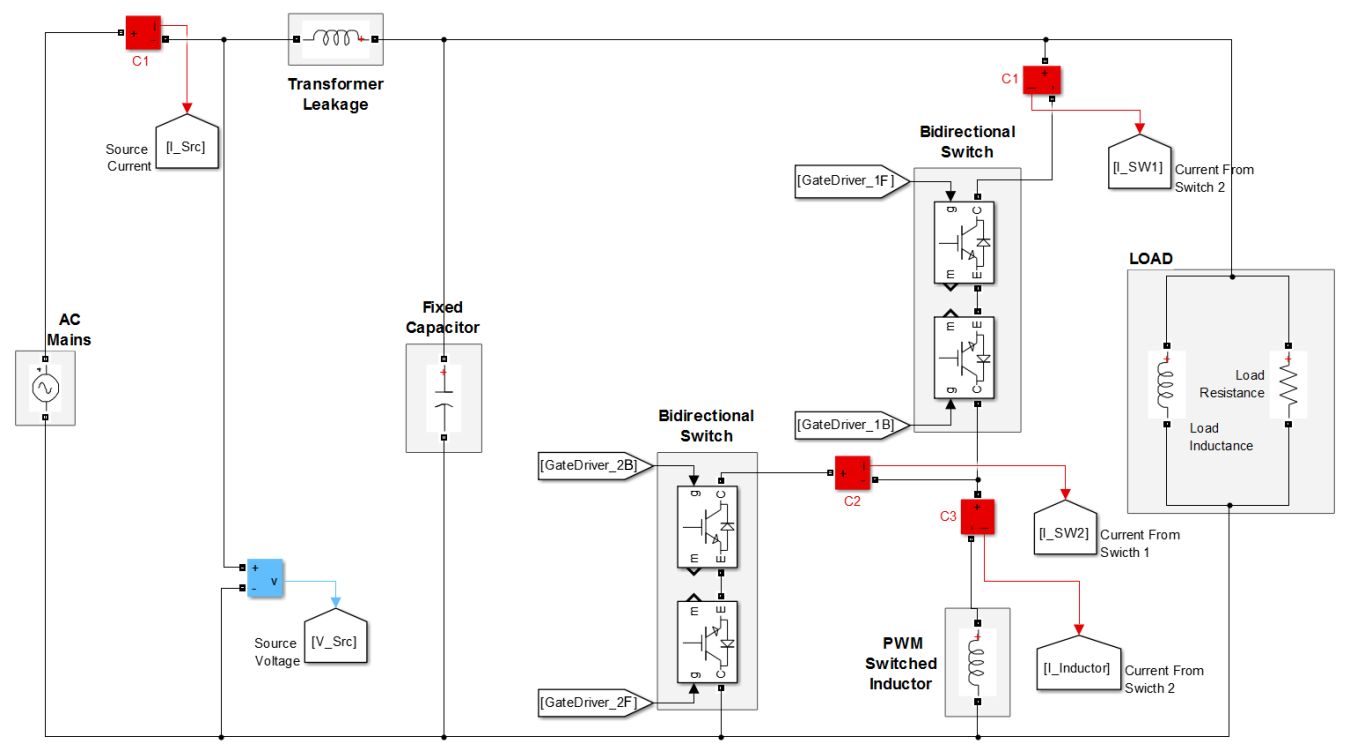

Figure 5.7: The RSVC Simulink model with a fixed capacitor and a switched inductor having bidirectional switches. 


\subsection{Gate Driving Signals}

In the Simulink model, the gate driving signals are generated using the Xilinx System Generator, which incorporates hardware descriptive language procedures to produce the logical conditions for a bidirectional switch commutation. These logic conditions are generated based on the state machine in Figure 3.8 which shows the transitioning from the top bidirectional switch to the bottom bidirectional switch and vice versa for both voltage polarities. It is important that the commutation from one switch to another be performed according to the state machine described in the previous chapter. An incorrect transition state may result in large current and voltage spikes which will destroy the switching devices.
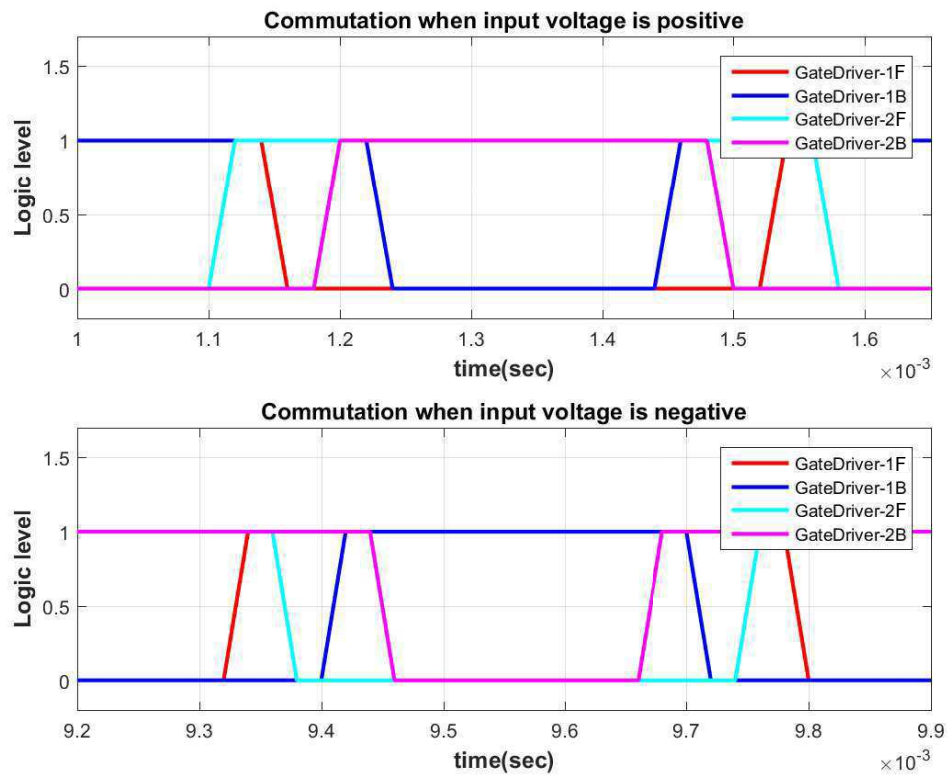

Figure 5.8: The commutation sequences for the bidirectional switches. 


\subsection{Input and Output Voltage Waveforms}

As mentioned in the previous chapters, the PWM switched inductor with bidirectional switches poses two serious hazards for the safe operation of the RSVC. These threats include the short circuiting of the AC mains and an opening of an inductive current path. The commutation strategy proposed ensures that the input mains is not shorted at any instant during the operation of the RSVC. Figure 5.9 shows the simulation results for both the AC mains input voltage and the RSVC output voltage, indicating that both voltages are not being short-circuited at any time.
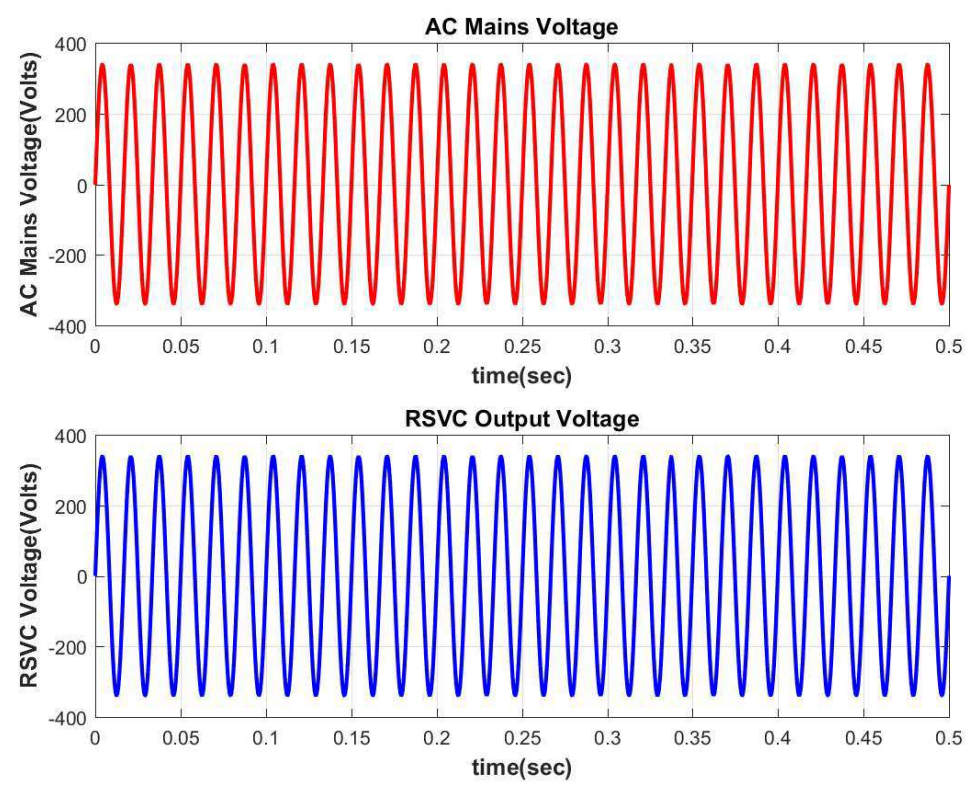

Figure 5.9: Simulation results for AC mains and the RSVC output voltage. 


\subsection{Inductor Voltage and Current Waveforms}

An important criterion of success during the RSVC operation is that the inductor current remains fairly sinusoidal with negligible harmonics. Figure 5.10 shows the RSVC inductor voltage and the RSVC inductor current. It can be seen that the inductor voltage is a chopped replica of the RSVC output voltage waveform for the time specified by the duty cycle of the top bidirectional switch. The inductor current, which lags the inductor voltage by about $90^{\circ}$, remains sinusoidal at all duty cycles for which the inductor is switched.
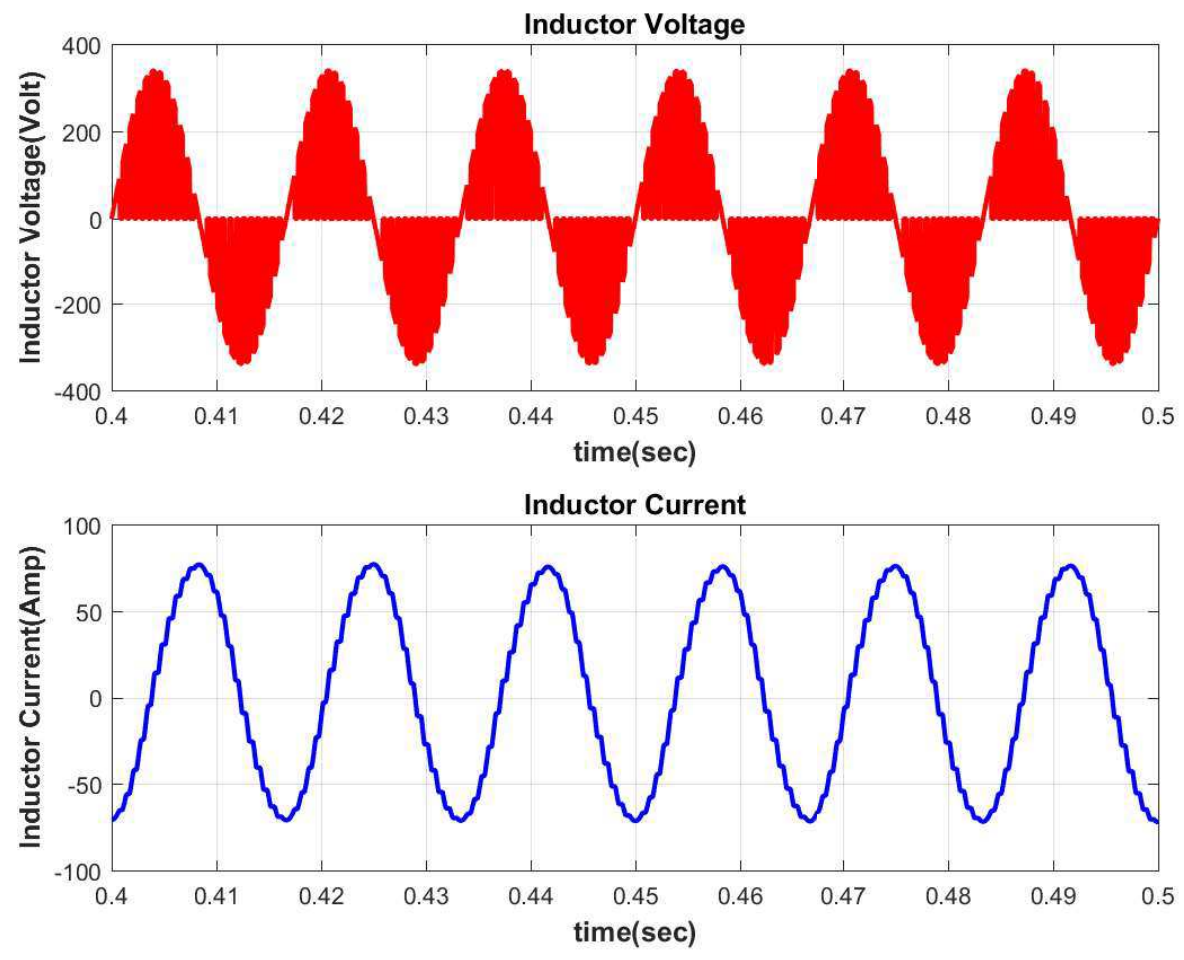

Figure 5.10: Simulation results for the RSVC inductor voltage and the RSVC inductor current. 


\subsection{Current through Bidirectional Switches}

The bidirectional switches have the capability to conduct current in both directions. The current through the top and bottom switches combine to form the envelope of the total inductor current. Figure 5.11 shows the current through the top and the bottom switches of the RSVC. There is a short prohibition period when stops the commutation of the gate driver signals is stopped near a zero crossing of the RSVC voltage. In this way, the commutation for the gate signals is properly carried out and the possibility of detecting the wrong sign of the input voltage near zero crossings is eliminated.
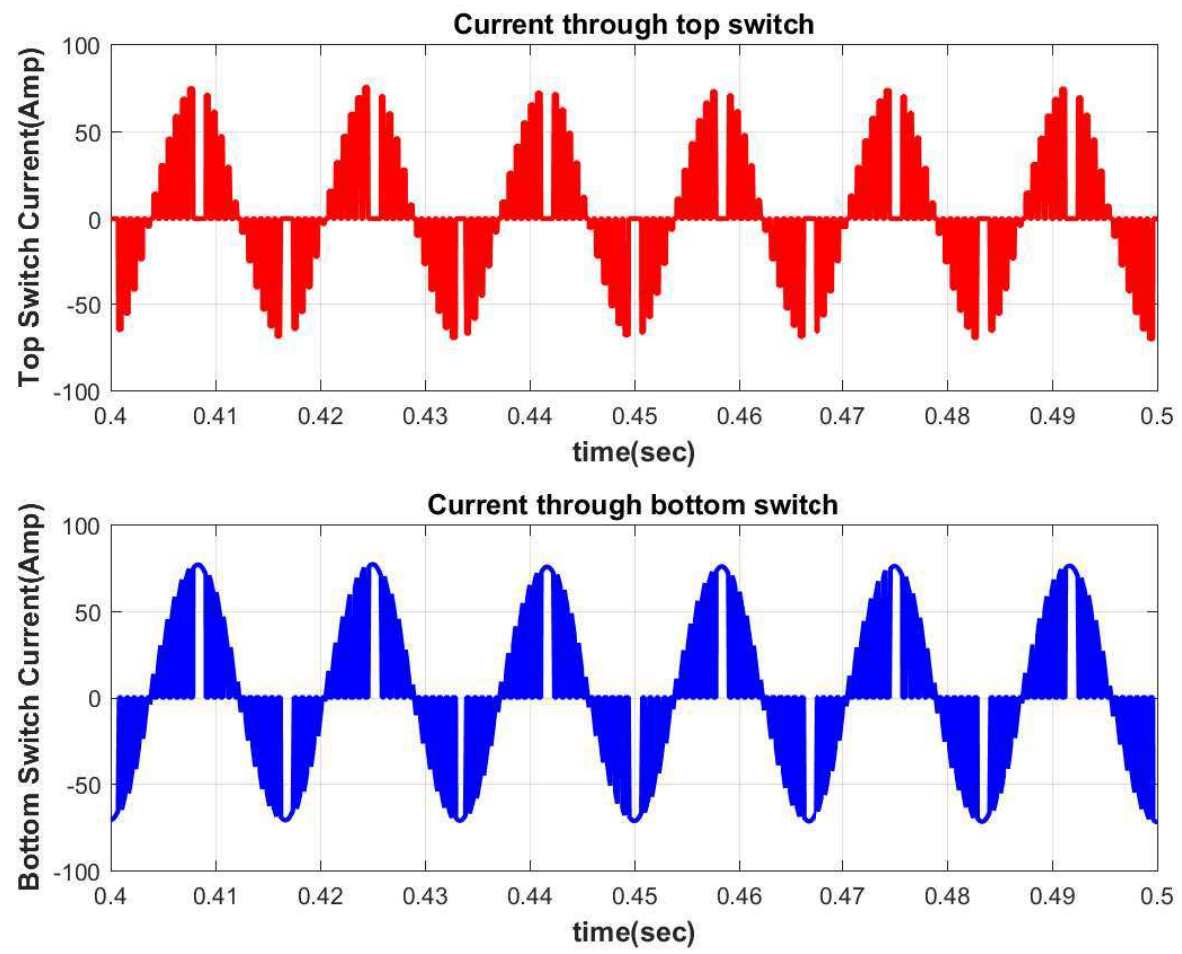

Figure 5.11: Simulation results for the RSVC current through the top and bottom bidirectional switches. 


\subsection{RSVC Output Voltage for Different Duty Cycles}

The RSVC inductance varies inversely with the square of the duty cycle. This means that the reactive power absorbed by the inductor can be adjusted by controlling the duty cycle of the top switch. The RSVC uses this dynamic reactive power approach to regulate the residential voltages. In Figure 5.12, the duty cycle of the top switch is varied from 0.2 to 0.8 . It can be seen that the RSVC output voltage reduces as the duty cycle increases. Therefore, by controlling the duty cycle, it is possible to generate a variable reactive power to regulate residential voltages. 

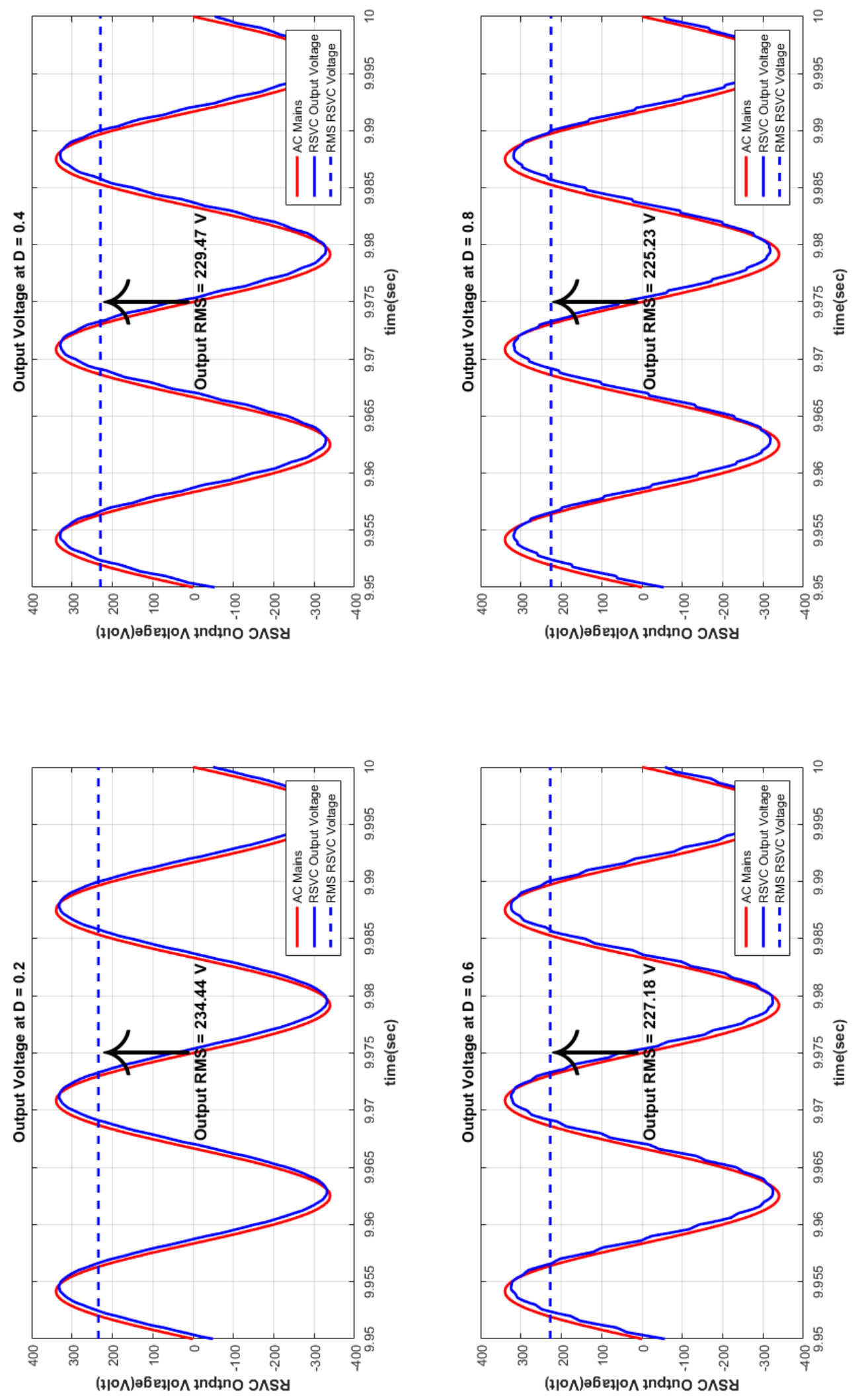

0
0
0
0
0
0
0
0
0
0
0
0
0
0
0
0
0
0
0
0
0
0
0
0
0
0
0
0
0
0

مُ

$\int_{0}^{0}$

I

$\frac{9}{12}$

อِ

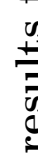

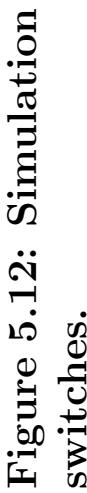




\section{CHAPTER 6}

\section{RSVC EXPERIMENTAL RESULTS AND PERFORMANCE ANALYSIS}

\subsection{Experimental Setup}

The laboratory prototype for the RSVC consists of a 190- $\mu \mathrm{F}$ capacitor and a 30-mH inductor choke. The leakage inductance of the distribution transformer is modeled as the series inductor. The switching frequency for the two bidirectional switches is set at $10 \mathrm{kHz}$, with a variable duty cycle. The laboratory testing for the RSVC was initially performed without any load. The circuit diagram for the RSVC laboratory prototype is shown in Figure 6.1. In order to limit the current within the range of the laboratory equipment, the testing of the RSVC was performed at a voltage level of $60 \mathrm{VAC}$.

The laboratory setup for the RSVC testing is shown in Figure 6.2. A single phase-to-neutral voltage was used from an HP6834B three-phase AC power source for testing the RSVC. Appendix A shows the Bill of Materials (BOM) for this laboratory prototype. 


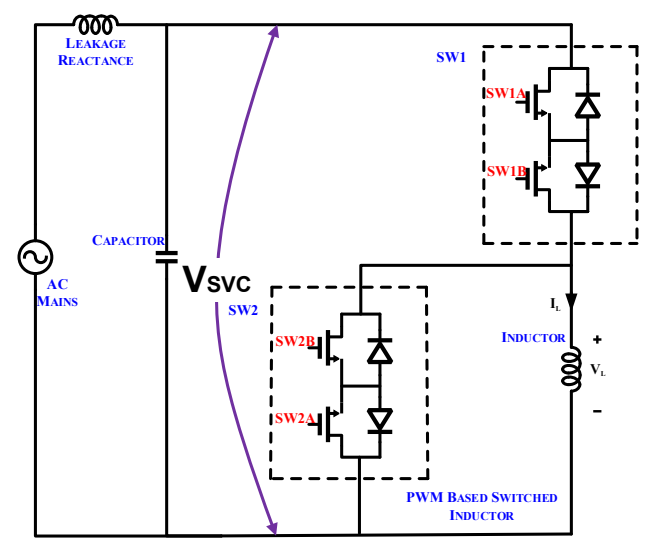

Figure 6.1: Circuit Diagram for the laboratory setup for the RSVC testing.

\subsection{IGBT Gate Driving Signals}

The gate driving signals are generated using a Field Programmable Gate Array (FPGA). In order to drive the high-power IGBTs, opto-isolators are required to provide an adequate current to drive the low-power FPGA signals.

Opto-isolators provide an electrical isolation between the high and low terminals by allowing relatively small FPGA digital signals to control much larger AC voltages, currents and power. Figure 6.3(a) and Figure 6.3(b) show the gate driving signals for the bidirectional switches at duty cycles $\mathrm{D}=0.25$ and $\mathrm{D}=0.75$ respectively.

A short time delay is inserted between each transitional state to account for turnon and turn-off time for the specific IGBT devices. For safe commutation, the time delay between each transitional state is chosen to be 1 us. Figure 6.4(a) shows the IGBT device transition from the steady state, when the top switch is ON and the bottom switch is OFF, to the next steady state, when the top switch is OFF and the bottom state is ON during positive input voltage. Similarly, Figure 6.4(b) shows the transition from the top switch to the bottom switch when the input voltage is less than 0 . 


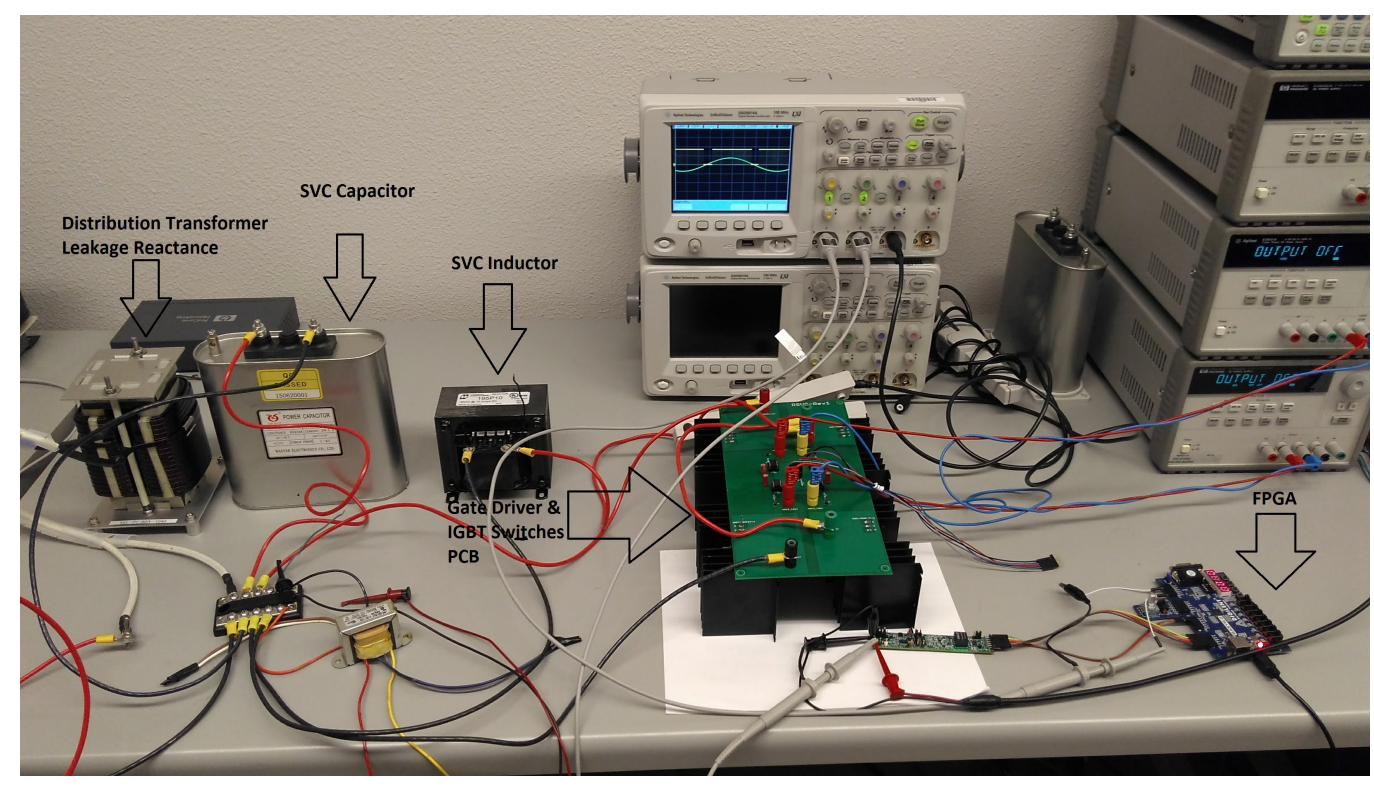

Figure 6.2: Laboratory setup for the RSVC testing.

\subsection{RSVC Experimental Results}

\subsubsection{Input and Output Voltage Waveforms}

An important criterion for the successful operation of the RSVC device is to prevent the short circuiting of the RSVC voltage due to switching of the bidirectional switches. Figure 6.5(a) shows the input voltage from the AC power supply and Figure 6.5(b) shows the regulated RSVC voltage respectively. The RSVC output voltage depends on the amount of reactive power generated by the RSVC device at a particular duty cycle.

\subsubsection{Reactor Voltage and Current Waveforms}

Figure 6.6 shows the continuous reactor current. This current is scaled as 100 $\mathrm{mV} / \mathrm{A}$. The inductor current is continuous and fairly sinusoidal with negligible loworder harmonics. 


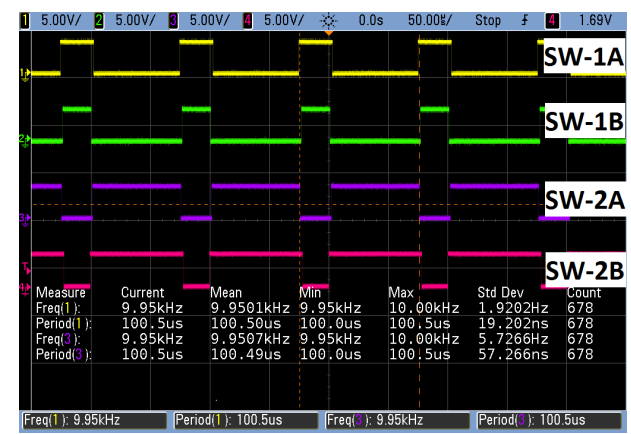

(a)

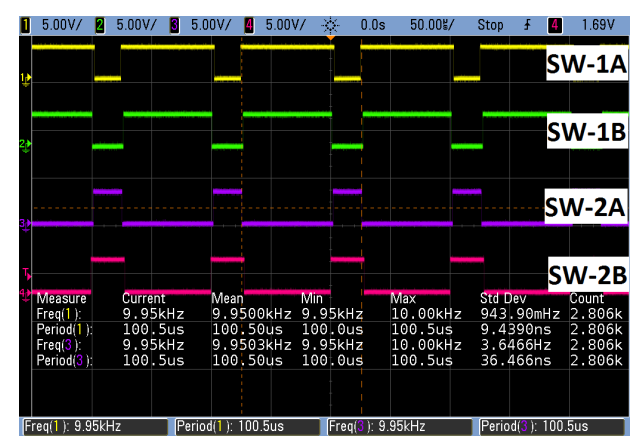

(b)

Figure 6.3: (a) IGBT gate driving signals at $D=0.25$ (b) IGBT gate driving signals at $\mathrm{D}=0.75$.

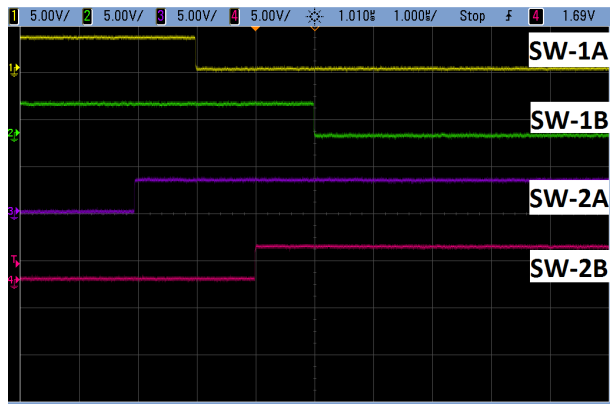

(a)

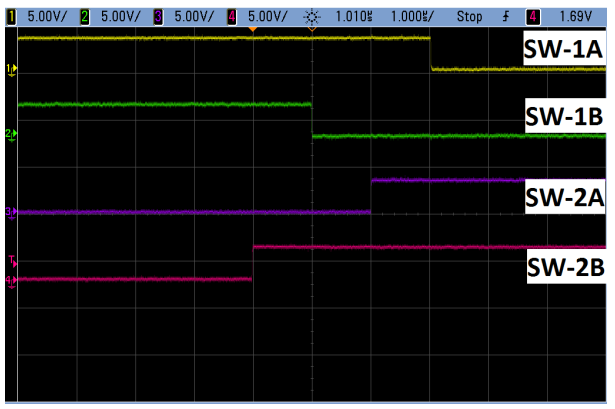

(b)

Figure 6.4: (a) IGBT gate driving signals transition from top switch to bottom switch when input voltage is greater than $0\left(V_{\mathrm{SVC}}>0\right)$ (b) IGBT gate driving signals transition from top switch to bottom switch when input voltage is less than $0\left(\mathrm{~V}_{\mathrm{SVC}}<0\right)$.

It is important to keep the commutation prohibition period small. This interval of time is required for detecting the correct sign of the input voltage but a large prohibition period will cause the inductor to become non-sinusoidal.

The output voltage across the reactor should be a chopped replica of the output RSVC voltage. This means that when the top switch is conducting, the input voltage appears across the reactor. Conversely, when the top switch is OFF, the voltage across the inductor drops to zero. In practice, the voltage across the reactor is not exactly zero due to the forward voltage drops of the conducting devices in the bidirectional 


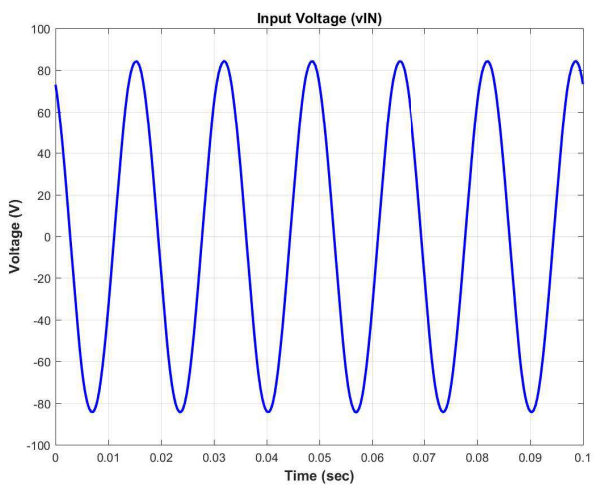

(a)

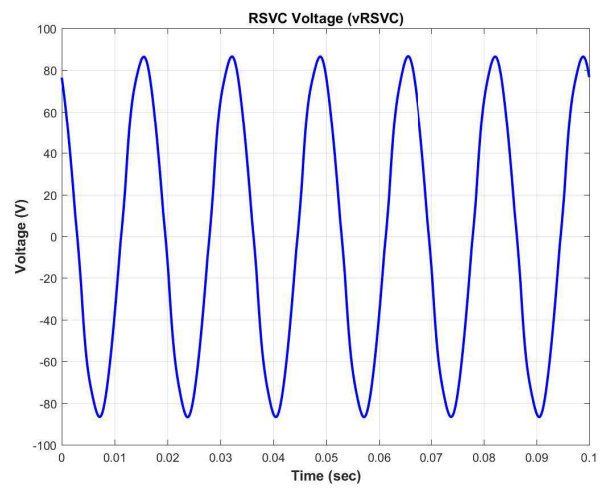

(b)

Figure 6.5: (a) AC Mains Voltage (b) RSVC Output Voltage.

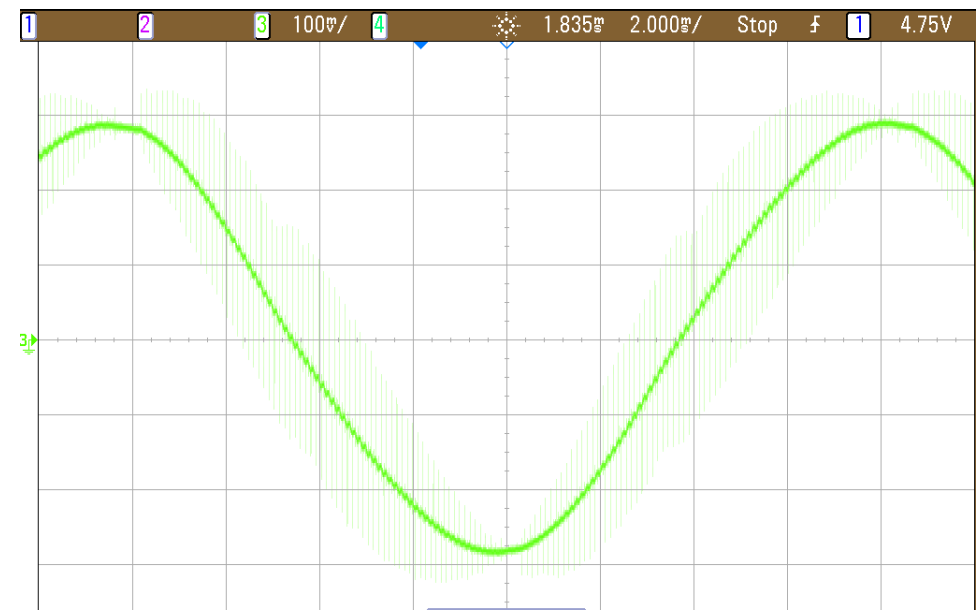

Figure 6.6: Sinusoidal Reactor Current.

switches.

Figure 6.7 shows the $\mathrm{AC}$ mains voltage and chopped inductor voltage. For the sake of clarity, the switching frequency is lowered to $2.4 \mathrm{kHz}$.

\subsubsection{Current through Bidirectional Switches}

Figure 6.8 shows the current through the top bidirectional switches. This current is a chopped envelope of the reactor current. The waveform through the top bidirec- 


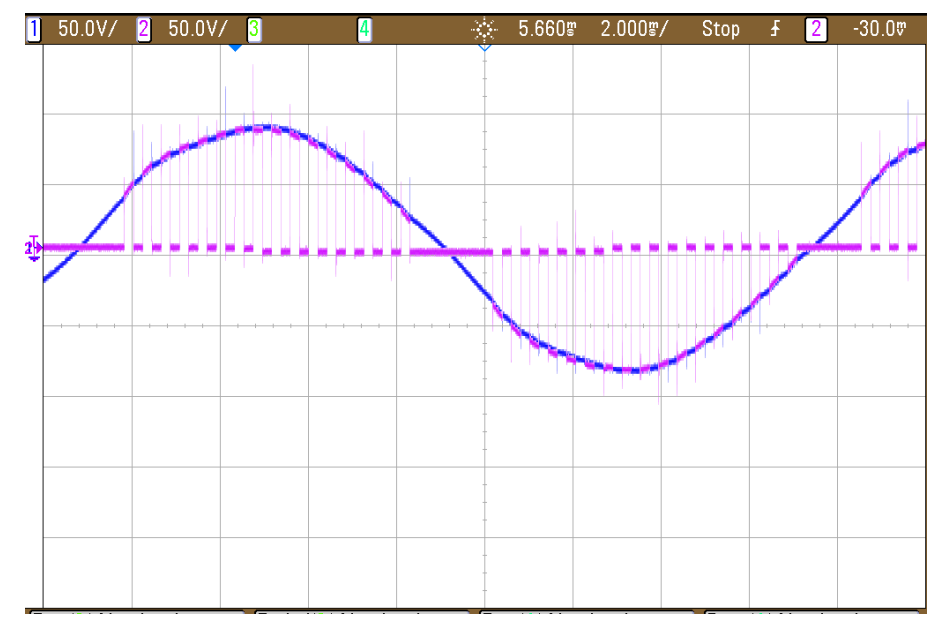

Figure 6.7: Chopped Inductor Voltage when duty cycle D $=0.5$.

tional switch is obtained at a switching frequency of $2.4 \mathrm{kHz}$. This current is scaled as $100 \mathrm{mV} / \mathrm{A}$.

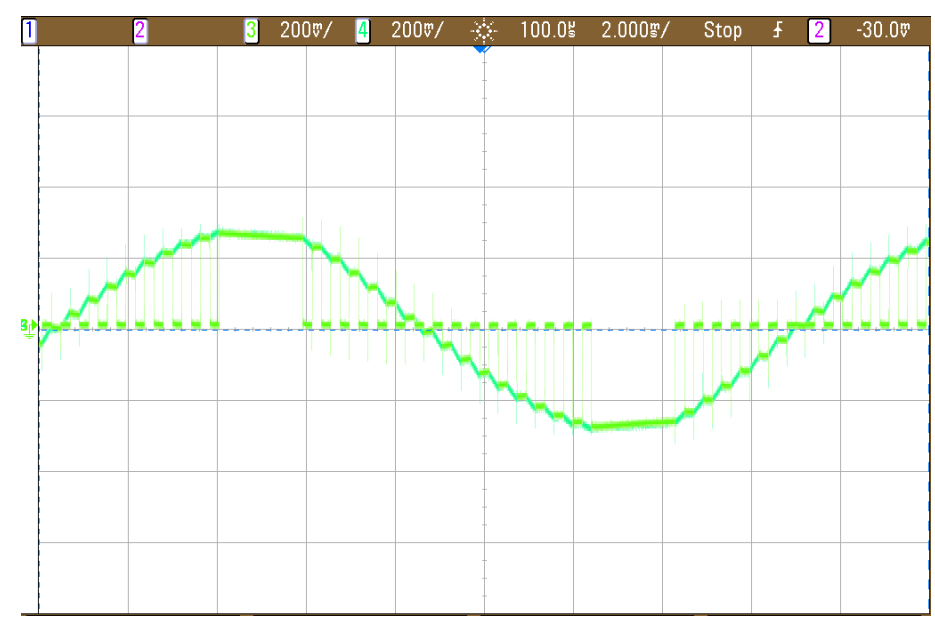

Figure 6.8: Current through the top switch when duty cycle $\mathrm{D}=0.5$.

\subsubsection{Input Current Waveform}

Figure 6.9 shows the sinusoidal input current waveform from the HP6834B threephase AC power source to the RSVC device. 


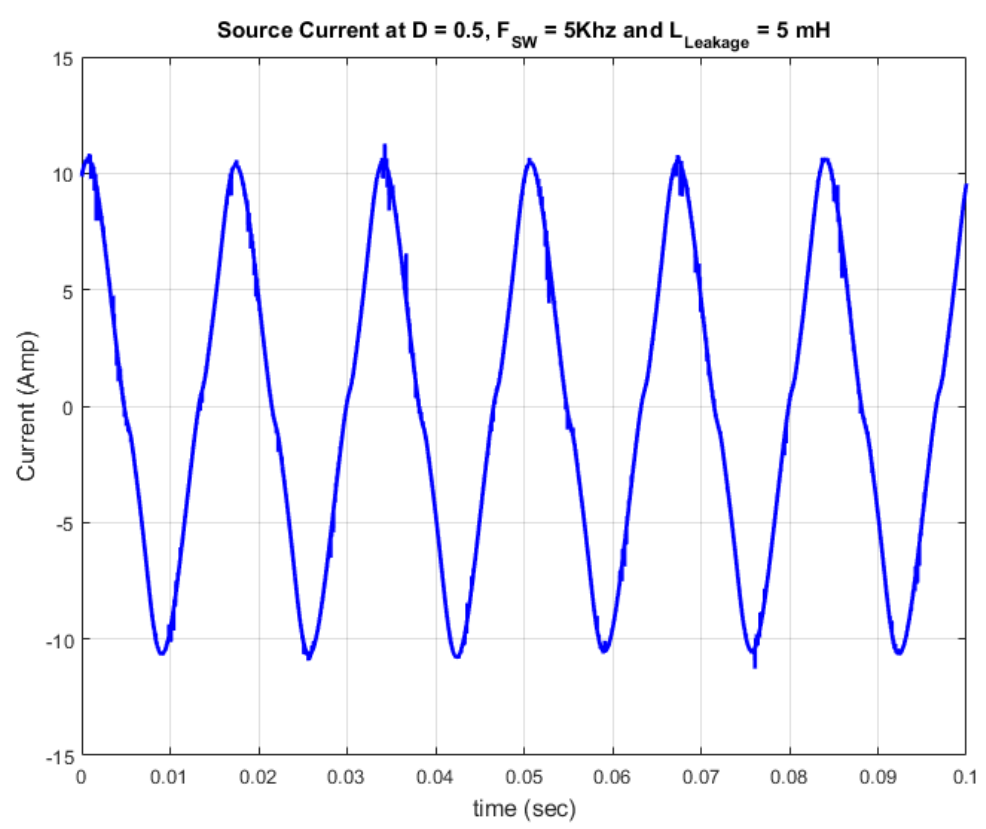

Figure 6.9: Input Current Waveform from the distribution feeder to the RSVC device.

\subsection{Performance of the Laboratory RSVC with a Resistive Load}

The laboratory prototype of the RSVC was tested at $60 \mathrm{VAC}$ with a resistive load of $20 \Omega$. The performance parameters obtained from the laboratory prototype of RSVC can be scaled, depending on the reactive power requirements.

\subsubsection{Reactive Power Generated by the RSVC}

Figure 6.10 shows the amount of reactive power generated by the RSVC device at different duty cycles. When the duty cycle (D) is equal to zero, the reactive power generated by the RSVC is due to the capacitor only. As the duty cycle increases, the reactive power generated by the reactor compensates the reactive power of the fixed 
capacitor. The output reactive power from the RSVC is the net result of the reactive powers from the capacitor and the PWM-based switched reactor.

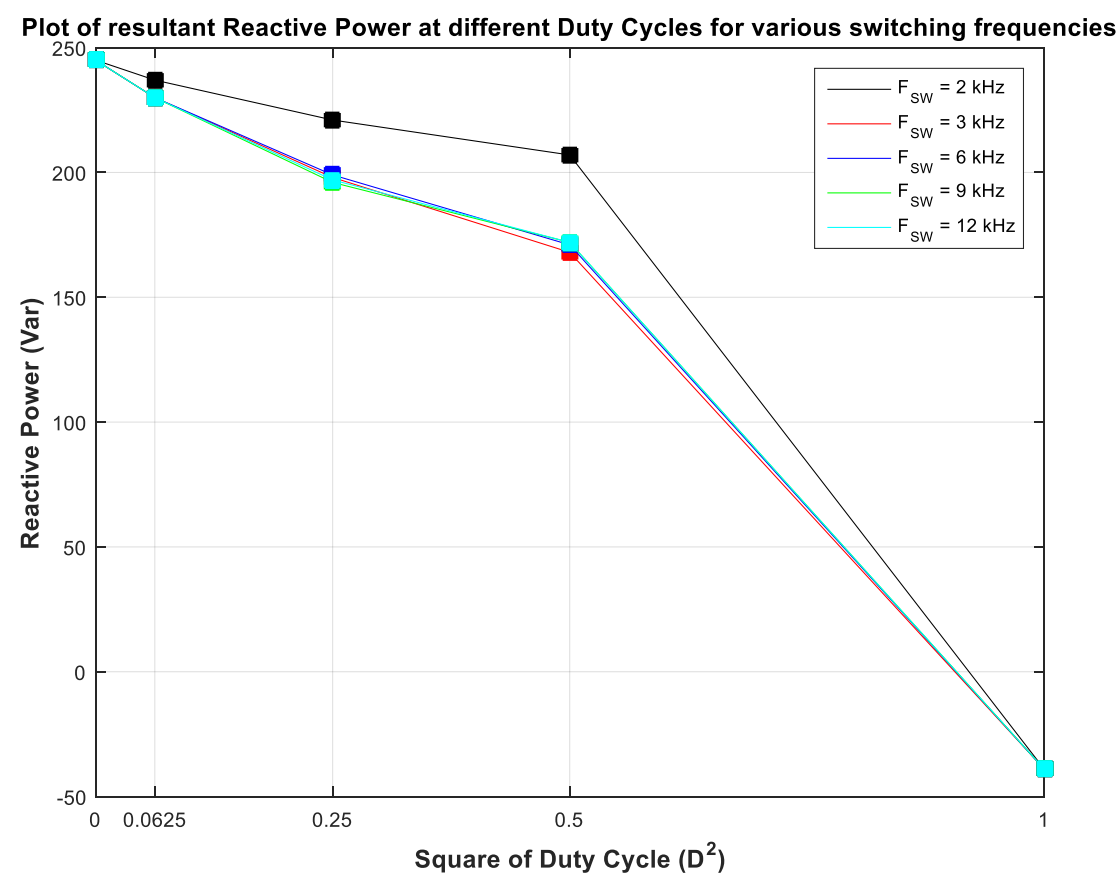

Figure 6.10: Variation of the reactive power generated by the RSVC with variation of the duty cycle.

For the RSVC prototype, the reactive power generated by the fixed capacitor is approximately equal to 250 var. The resultant reactive power that is produced by the RSVC device is representative of the mode in which the RSVC is operating. If the resultant reactive power generated by the RSVC is positive, then it is said to be operating in the "Capacitive Mode." If the resultant reactive power by the RSVC is negative, then it is said to be operating in the "Inductive Mode."

\subsubsection{RSVC Output Voltage and Voltage Regulation}

Figure 6.11 shows the RSVC output voltage as a result of varying the duty cycle at different switching frequencies. It can be seen that the RSVC voltage is maximum 
when the duty cycle is zero. The RSVC voltage starts decreasing as the duty cycle increases and it becomes minimum when the duty cycle is one.

The RSVC voltage regulation is independent of the switching frequency. Identical output voltage curves were obtained from the experimental data when bidirectional switches were switched at different frequencies.

The amount of the voltage regulation is dependent on the size of the reactive components used. For CVR application, the RSVC should be able to operate in the inductive region (negative vars region) as well as in the capacitive region (positive vars region) depending on the residential reactive power requirements.

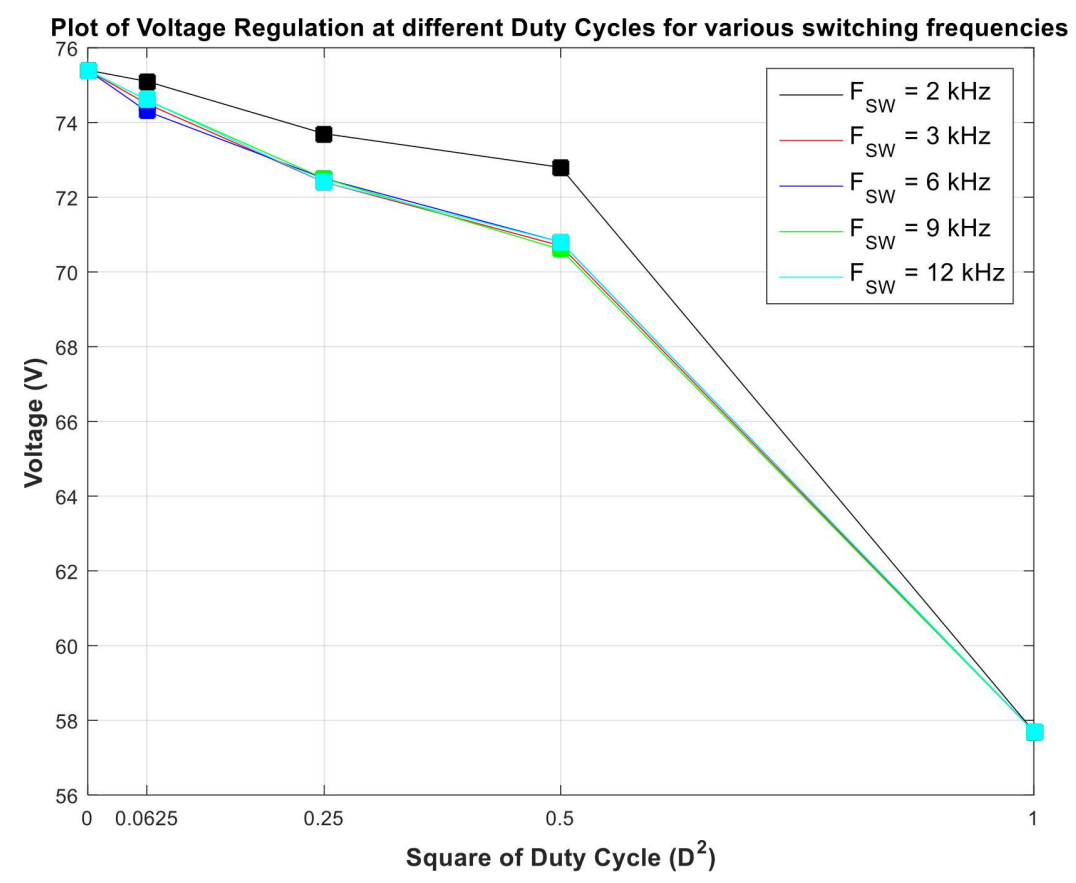

Figure 6.11: Plot of the RSVC voltage at various duty cycles for different switching frequencies. 


\subsubsection{RSVC Power Loss at Different Switching Frequencies}

An important specification of the RSVC device is to estimate its power losses. The power losses are contributed by the switching devices when they are switched at high frequencies. By increasing the switching frequency, the reactor current becomes more sinusoidal but the switching losses for the devices increase. Figure 6.12 shows the impact of the switching losses of the RSVC device at different switching frequencies. The power loss in the RSVC is lowest at the lower duty cycle. At a low duty cycle, the contribution of the reactor current is small and the conduction losses of the switching devices are small.

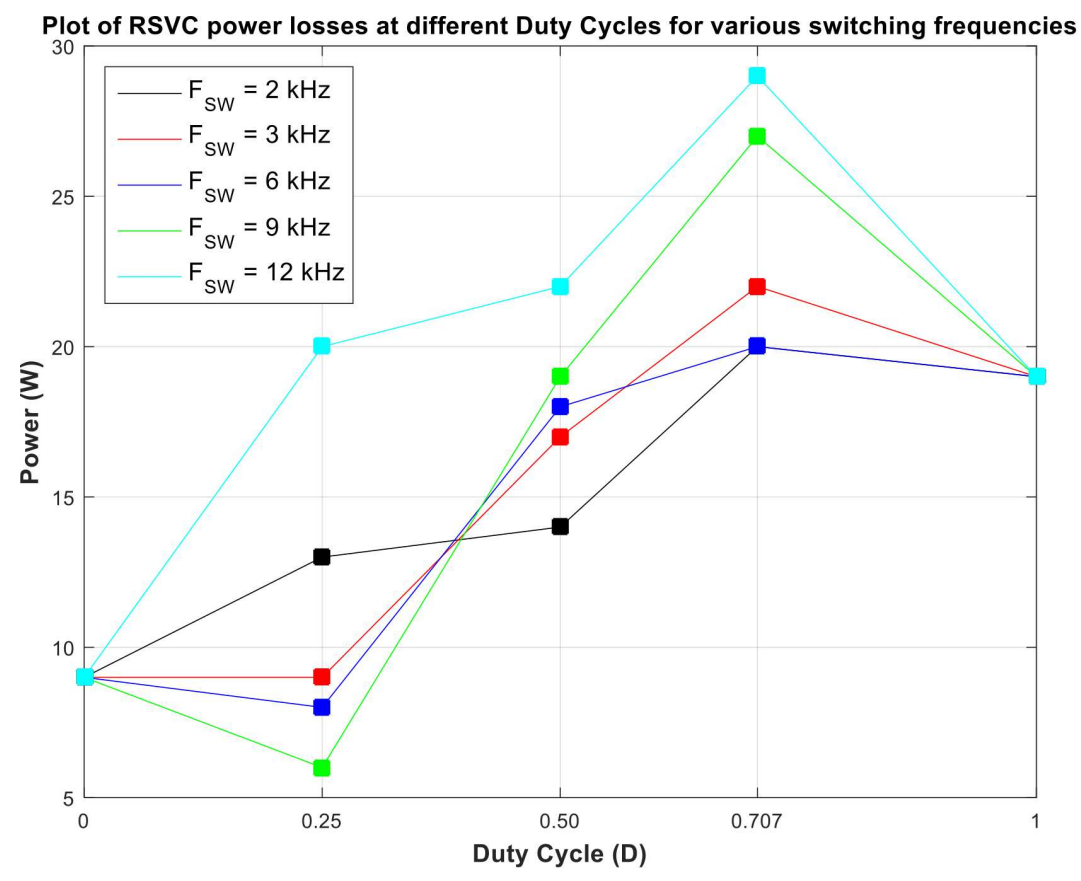

Figure 6.12: Plot of the RSVC power losses at different switching frequencies. 


\subsubsection{Input and Output Power Regulation}

The RSVC device is able to regulate voltage across the distribution feeder. This will benefit loads with a positive CVR coefficient because they will consume less power when the voltage is reduced.

This fact was verified when the RSVC was tested with a resistive load of 20 $\Omega$. Figure 6.13(a) and Figure 6.13(b) shows the input and output power regulations respectively. It can be seen that as the duty dycle is increased, the voltage is reduced, resulting in a lower power consumption.

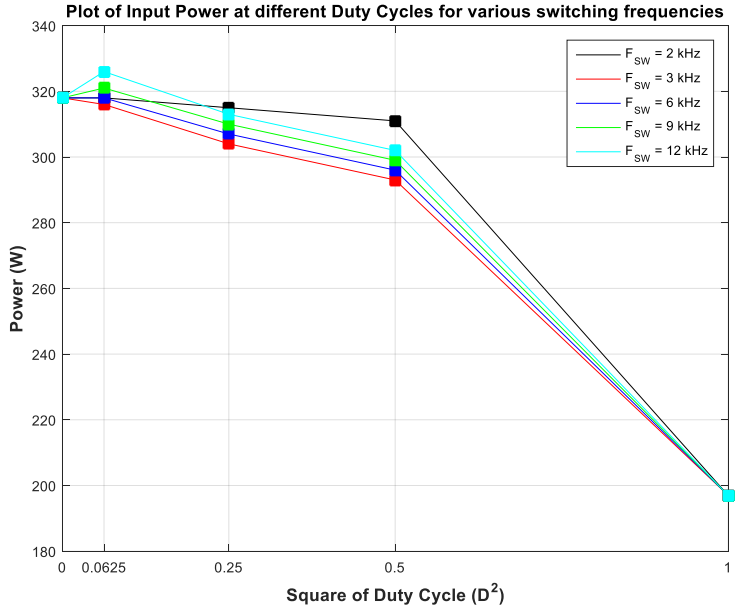

(a)

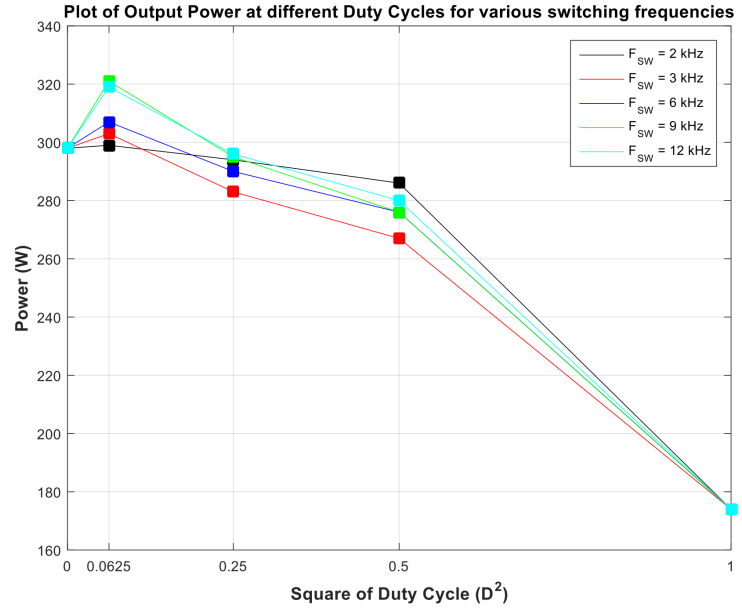

(b)

Figure 6.13: Plot of the RSVC input and output power regulation at different switching frequencies.

\subsection{Hamonic Analysis}

\subsubsection{Harmonic Analysis of the RSVC Output Voltage}

Figure 6.14 shows the harmonic contents for the RSVC output voltage at a switching frequency of $6 \mathrm{kHz}$. In Figure 6.14, the output voltage is obtained at 
three different duty cycles, specifically at $\mathrm{D}=0.25, \mathrm{D}=0.50$ and $\mathrm{D}=0.75$. At each duty cycle, the RSVC output voltage remains sinusoidal. The fundamental frequency component of the RSVC output voltage is present at $60 \mathrm{~Hz}$. The contribution from higher order harmonics is negligible.
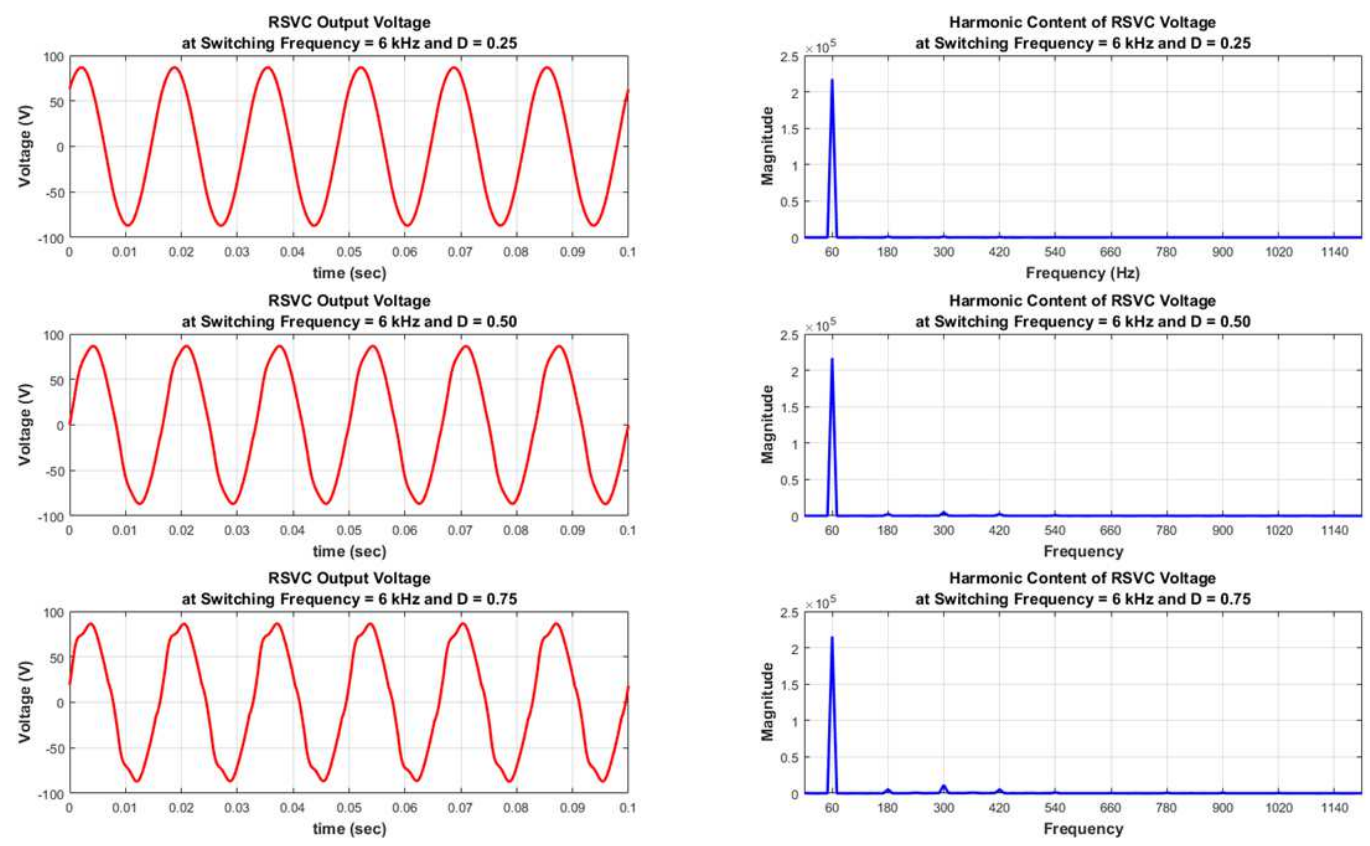

Figure 6.14: Plot of the RSVC output voltage at different duty cycles with their corresponding harmonic analysis.

\subsubsection{Harmonic Analysis of the Reactor Current}

Figure 6.15 and Figure 6.16 show the harmonic content of the reactor current at switching frequencies of $2.4 \mathrm{kHz}$ and $6 \mathrm{kHz}$, respectively. For both frequencies, the reactor current and its harmonics content are plotted at duty cycles of $\mathrm{D}=0.25, \mathrm{D}$ $=0.50$, and $\mathrm{D}=0.75$. The reactor current is a quasi-sine waveform at a lower duty cycle. The reactor current becomes sinusoidal as the duty cycle is increased. It can be seen that the harmonic contribution of the inductor current at the fundamental 
frequency of $60 \mathrm{~Hz}$ is notable for all duty cycles. The harmonic contributions from odd multiples of the fundamental frequency are negligible.
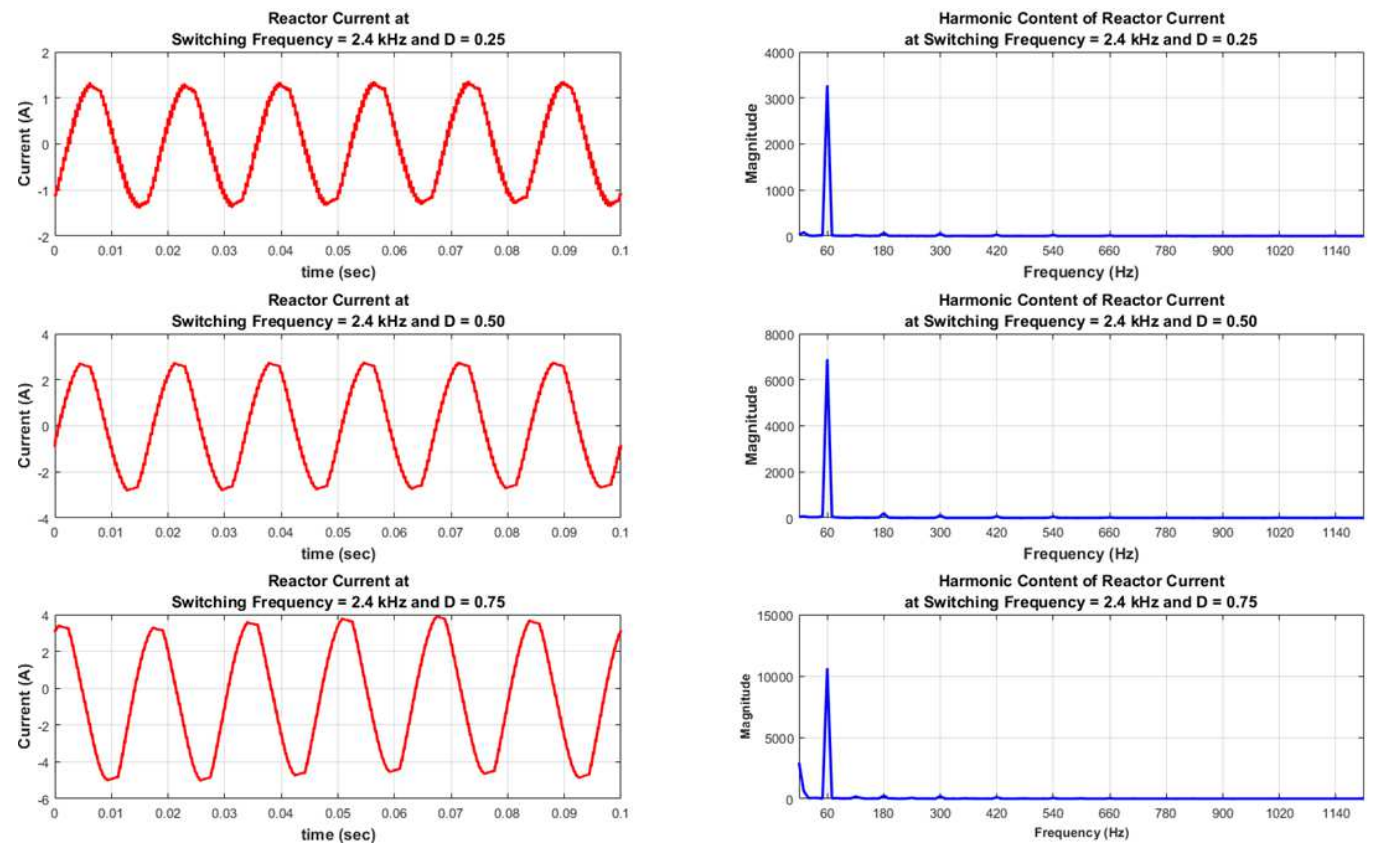

Figure 6.15: Plot of the RSVC reactor current at switching frequency of $2.4 \mathrm{kHz}$ and at different duty cycles with their corresponding harmonic analysis. 

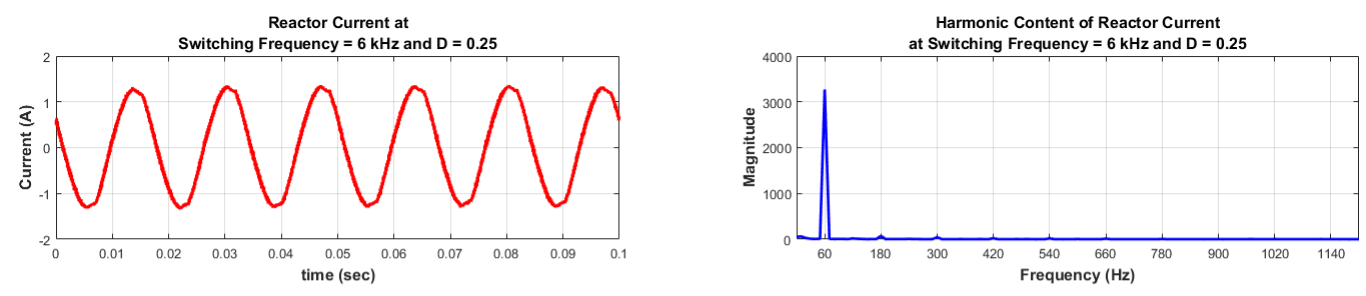

Reactor Current a

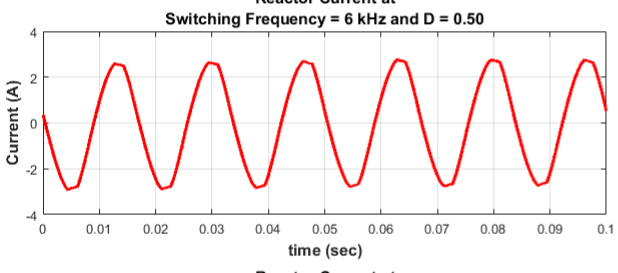

Harmonic Content of Reactor Current
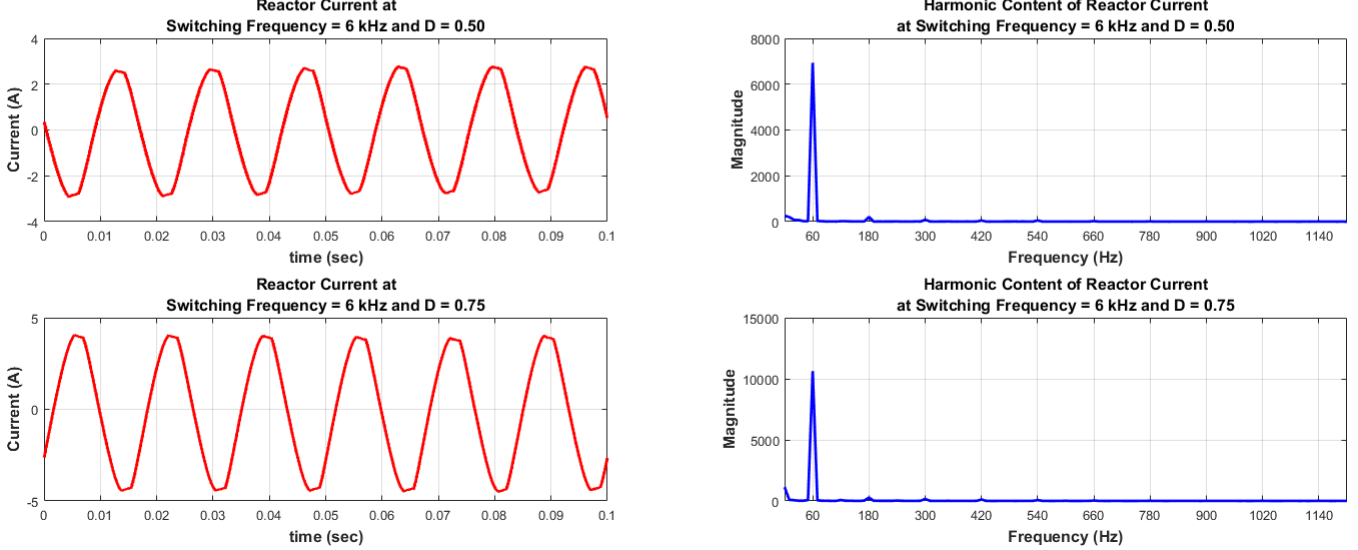

Figure 6.16: Plot of the RSVC reactor current at switching frequency of $6 \mathrm{kHz}$ and at different duty cycles with their corresponding harmonic analysis.

\subsection{RSVC Performance Summary}

The conventional thyristor-controlled reactor requires a harmonic filter that is tuned to block specific harmonic frequencies which are generated due to a nonsinusoidal reactor current. Although it is possible to trap the multiples of third-order harmonics in a three-phase delta network, yet a non-sinusoidal reactor current puts a limitation on building a single-phase SVC device at the residential level. By using the PWM-based switching of the reactor, it is feasible to build a single phase RSVC device.

The laboratory prototype of the RSVC shows that the output voltage can be regulated based on the reactive capability of the reactive components. The laboratory prototype of the RSVC is able to achieve a voltage regulation of approximately 20 
V. The RSVC power losses are moderate between $3 \mathrm{kHz}$ to $10 \mathrm{kHz}$. The switching frequency is dependent on the particular application of the RSVC device. Due to the sinusoidal reactor current, the RSVC does not require an output harmonic filter.

\subsection{RSVC Novel Features}

The novel and unique aspects of the RSVC are summarized as follows:

1. This device can be constructed as a single-phase unit instead of a three-phase unit.

2. The device produces minimal harmonics compared to a device built based on conventional angle firing.

3. No added filtering is needed with the PWM-based switching technique.

4. There is no synchronization module required (for example, a phase-locked loop or PLL) with the AC voltage mains.

5. The reactive power can be continuously adjusted by varying the PWM duty cycle of the switching signals.

6. This device is relatively efficient with low power loss.

7. The device can be built with few components, that is, it will have a low cost and, if properly designed, a high reliability.

8. The device is scalable in terms of reactive power capability at higher voltage levels. 


\section{CHAPTER 7}

\section{APPLICATIONS, CONCLUSIONS AND FUTURE WORK}

\subsection{RSVC Applications}

The RSVC provides reactive power support to the distribution power system. The RSVC can operate in both capacitive and inductive modes, depending on the amount of the reactive power requirement of the power system. In this chapter, some RSVC applications in the distribution power systems are presented. Recommendations for future work are provided at the end of this chapter.

\subsubsection{Conservation by Voltage Reduction using the RSVC}

The RSVC can regulate residential voltages such that they can be decreased to the lowest permissible values according to ANSI Standard C84.1 during peak demand hours. This voltage reduction allows electric utilities to conserve electrical power during peak demand hours. This strategy of conservation by voltage reduction is known by its acronyms as CVR.

Figure 7.1 shows the proposed location for an RSVC installation for CVR. An ongoing study at Boise State University is investigating the feasibility of using RSVC devices on a distribution feeder network in Spokane, Washington. In this study, multiple RSVCs are deployed at various pole-mounted transformers of the distribution network to evaluate their performance for a CVR application. 


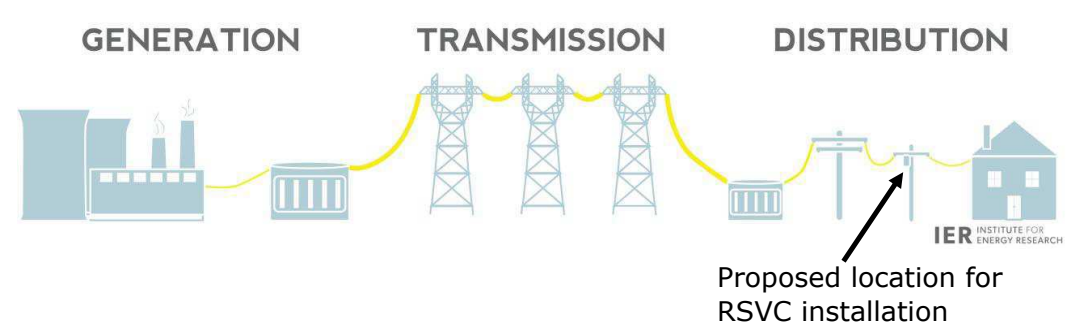

Figure 7.1: Proposed location for the RSVC installation for CVR.

\subsubsection{Power Factor Correction}

Power factor correction can also be achieved using an RSVC. Electric utilities generally require industrial loads with a poor power factor to install power factor correction devices. Common power factor correction units include capacitor banks and unloaded synchronous motors or condensors. However, both of these methods have certain disadvantages. Capacitors in capacitor banks can only be switched in discrete steps whereas synchronous condensers require mechanical maintenance.

The RSVC provides a power electronics solution to compensate the power factor of industrial loads. The amount of reactive power generated can be continuously adjusted and, being a solid-state electronics device, the RSVC requires little maintenance. This concept is referred to as Volt-Var Optimization (VVO) in the literature.

\subsection{Conclusions}

The potential market path of the RSVC simulated and proposed in this thesis is similar to that of other shunt-connected, reactive-injection-based devices currently being deployed by some utilities. The RSVC laboratory prototype was tested for a voltage control application (Conservation by Voltage Reduction) on the consumer side of the distribution feeder. 
The single-phase RSVC device has the advantage over conventional shunt capacitors of being able to operate in either a capacitive or inductive mode without generating large undesirable harmonics. The RSVC harmonics are significantly less than those of most thyristor-based SVCs currently deployed. The RSVC uses a novel pulse-width modulation (PWM) scheme to create the variable var compensation with an almost sinusoidal reactor current. This smart device can be used in multiple applications such as continuous voltage control at a load point, power factor control, and mitigation of power quality issues. The RSVC device has the potential to be a cost effective solution for improving power quality on the distribution side of a power system.

\subsection{Recommendation for Future Work}

\subsubsection{Voltage Reference Tracking}

The present laboratory prototype for an RSVC device is an open-loop device with the ability to manually adjust its duty cycle to vary the reactive power. It is possible to build a control loop that sets a voltage reference point and automatically adjusts the duty cycle to regulate the RSVC output voltage.

\subsubsection{Optimal Power Flow Algorithm for RSVC}

An automatic algorithm is required to calculate the proper size and installation location for the RSVC. The use of an Optimal Power Flow (OPF) algorithm might be helpful in studying the flow of electrical power in an interconnected power distribution system. 


\subsubsection{Interaction of RSVC with Distribution Network}

The dynamic interaction between multiple RSVCs and other voltage control devices which are already deployed in the distribution network is an important consideration before installing several RSVC devices in the distribution power system. 


\section{REFERENCES}

[1] B. W. Kennedy and R. H. Fletcher, "Conservation voltage reduction (CVR) at Snohomish County PUD," IEEE Transactions on Power Systems, vol. 6, no. 3, pp. 986-998, Aug. 1991.

[2] J. C. Erickson and S. R. Gilligan, "The Effects of Voltage Reduction on Distribution Circuit Loads," IEEE Power Engineering Review, vol. PER-2, no. 7, pp. 39-40, July 1982.

[3] V. J. Warnock and T. L. Kirkpatrick, "Impact of Voltage Reduction on Energy and Demand: Phase II," IEEE Power Engineering Review, vol. PER-6, no. 5, pp. 37-38, May 1986.

[4] R. H. Fletcher and A. Saeed, "Integrating engineering and economic analysis for conservation voltage reduction," in Power Engineering Society Summer Meeting, 2002 IEEE, vol. 2, July 2002.

[5] S. Lefebvre, G. Gaba, A. O. Ba, D. Asber, A. Ricard, C. Perreault, and D. Chartrand, "Measuring the efficiency of voltage reduction at Hydro-Qubec distribution," in Power and Energy Society General Meeting - Conversion and Delivery of Electrical Energy in the 21st Century, 2008 IEEE, July 2008.

[6] R. F. Preiss and V. J. Warnock, "Impact of Voltage Reduction on Energy and Demand," IEEE Transactions on Power Apparatus and Systems, vol. PAS-97, no. 5, pp. 1665-1671, Sept. 1978.

[7] D. Steese, Merrick, Tepel, and Callaway, "Assessment of Conservation Voltage Reduction Applicable in the BPA Service Region," PA, PNL 6380, Pacific Northwest Laboratories, Richland, WA, Tech. Rep., 1987.

[8] A. Dwyer, R. E. Nielsen, J. Stangl, and N. S. Markushevich, "Load to voltage dependency tests at B.C. Hydro," IEEE Transactions on Power Systems, vol. 10, no. 2, pp. 709-715, May 1995.

[9] R. Beck, "Distribution Efficiency Initiative Final Report," Northwest Energy Efficiency Alliance, Tech. Rep., December 2007. 
[10] K. Schneider, F. Tuffner, J. Fuller, and R. Singh, "Evaluation of Conservation Voltage Reduction (CVR) on a National Level," in Pacific Northwest National Laboratory, July 2010.

[11] B. Green, "Grid Strategy 2011: Conservation Voltage Reduction and Volt VAR Optimization in the Smart Grid," Electric Power Research Institude, Tech. Rep., 2011.

[12] J. Dixon, L. Moran, J. Rodriguez, and R. Domke, "Reactive Power Compensation Technologies: State-of-the-Art Review," Proceedings of the IEEE, vol. 93, no. 12, pp. 2144-2164, Dec. 2005.

[13] A. Prasai, J. Sastry, and D. M. Divan, "Dynamic Capacitor (D-CAP): An Integrated Approach to Reactive and Harmonic Compensation," IEEE Transactions on Industry Applications, vol. 46, no. 6, pp. 2518-2525, Nov. 2010.

[14] A. Prasai and D. M. Divan, "Control of Dynamic Capacitor," IEEE Transactions on Industry Applications, vol. 47, no. 1, pp. 161-168, Jan. 2011.

[15] N. G. Hingorani and L. Gyugyi, FACTS Concept and General System Considerations. Wiley-IEEE Press, 2000, pp. 1-35. [Online]. Available: http://ieeexplore.ieee.org/xpl/articleDetails.jsp?arnumber $=5264427$

[16] R. M. Mathur and R. K. Varma, Thyristor-Based FACTS Controllers for Electrical Transmission Systems. Wiley-IEEE Press, 2002. [Online]. Available: http://ieeexplore.ieee.org/xpl/articleDetails.jsp?arnumber $=5472092$

[17] D. Coates, "FACTS: A Transmission Utility Perspective," in Flexible AC Transmission Systems - The FACTS (Ref. No. 1998/500), IEE Colloquium, Nov. 1998.

[18] H. Jin, G. Goos, and L. Lopes, "An efficient switched-reactor-based static VAr compensator," IEEE Transactions on Industry Applications, vol. 30, no. 4, pp. 998-1005, July 1994.

[19] S. Kim, H. G. Kim, and H. Cha, "Reactive power compensation using switching cell structured direct PWM AC-AC converter," in 2016 IEEE 8th International Power Electronics and Motion Control Conference (IPEMC-ECCE Asia), May 2016.

[20] S. Xu, R. Plikat, R. Constapel, J. Korec, and D. Silber, "Bidirectional LIGBT on SOI substrate with high frequency and high temperature capability," in Power Semiconductor Devices and IC's, 1997. ISPSD '97., 1997 IEEE International Symposium on, May 1997. 
[21] Y.-K. Leung, A. K. Paul, J. D. Plummer, and S. S. Wong, "Lateral IGBT in thin SOI for high voltage, high speed power IC," IEEE Transactions on Electron Devices, vol. 45, no. 10, pp. 2251-2254, Oct. 1998.

[22] "IXYS(2003) Bidirectional Switch with NPT3 IGBT and fast Diode Bridge," http://www1.futureelectronics.com/doc/ixys/fio50-12bd.pdf, accessed: 2016-0910.

[23] S. Bernet, T. Matsuo, and T. A. Lipo, "A matrix converter using reverse blocking NPT-IGBTs and optimized pulse patterns," in Power Electronics Specialists Conference, 1996. PESC '96 Record., 27th Annual IEEE, vol. 1, June 1996.

[24] P. D. Ziogas, S. I. Khan, and M. H. Rashid, "Analysis and design of Forced Commutated Cycloconverter structures with improved transfer characteristics," in Power Electronics Specialists Conference, 1985 IEEE, June 1985.

[25] C. L. Neft and C. D. Schauder, "Theory and design of a 30-hp matrix converter," in Industry Applications Society Annual Meeting, 1988., Conference Record of the 1988 IEEE, Oct. 1988.

[26] A. Alesina and M. G. B. Venturini, "Analysis and design of optimum-amplitude nine-switch direct AC-AC converters," IEEE Transactions on Power Electronics, vol. 4, no. 1, pp. 101-112, Jan. 1989.

[27] C. Klumpner, P. Nielsen, I. Boldea, and F. Blaabjerg, "New steps towards a low-cost power electronic building block for matrix converters," in Industry Applications Conference, 2000. Conference Record of the 2000 IEEE, vol. 3, 2000.

[28] M. Ziegler and W. Hofmann, "Semi natural two steps commutation strategy for matrix converters," in Power Electronics Specialists Conference, 1998. PESC 98 Record. 29th Annual IEEE, vol. 1, May 1998.

[29] L. Empringham, P. W. Wheeler, and J. C. Clare, "Intelligent commutation of matrix converter bi-directional switch cells using novel gate drive techniques," in Power Electronics Specialists Conference, 1998. PESC 98 Record. 29th Annual IEEE, vol. 1, 1998.

[30] B. H. Kwon, B. D. Min, and J. H. Kim, "Novel commutation technique of AC-AC converters," IEE Proceedings - Electric Power Applications, vol. 145, no. 4, pp. 295-300, July 1998.

[31] C. Klumpner, P. Nielsen, I. Boldea, and F. Blaabjerg, "A new matrix converter motor (MCM) for industry applications," IEEE Transactions on Industrial Electronics, vol. 49, no. 2, pp. 325-335, Apr. 2002. 
[32] J. L. Galvez, X. Jorda, M. Vellvehi, J. Millan, M. A. Jose-Prieto, and J. Martin, "Intelligent bidirectional power switch module for matrix converter applications," in Power Electronics and Applications, 2007 European Conference on, Sept. 2007.

[33] P. W. Wheeler, J. Rodriguez, J. C. Clare, L. Empringham, and A. Weinstein, "Matrix converters: a technology review," IEEE Transactions on Industrial Electronics, vol. 49, no. 2, pp. 276-288, Apr. 2002.

[34] L. Empringham, P. Wheeler, and J. Clare, "A matrix converter induction motor drive using intelligent gate drive level current commutation techniques," in Industry Applications Conference, 2000. Conference Record of the 2000 IEEE, vol. 3, 2000.

[35] J. Mahlein, J. Igney, J. Weigold, M. Braun, and O. Simon, "Matrix converter commutation strategies with and without explicit input voltage sign measurement," IEEE Transactions on Industrial Electronics, vol. 49, no. 2, pp. 407-414, Apr. 2002.

[36] T. E. Grebe, "Application of distribution system capacitor banks and their impact on power quality," in Rural Electric Power Conference, 1995. Papers Presented at the 39th Annual Conference, Apr. 1995.

[37] R. A. Adams, S. W. Middlekauff, E. H. Camm, and J. A. McGee, "Solving customer power quality problems due to voltage magnification," IEEE Transactions on Power Delivery, vol. 13, no. 4, pp. 1515-1520, Oct. 1998.

[38] G. C. Giaconia, G. Fiscelli, F. L. Bue, A. D. Stefano, D. L. Cascia, and R. Miceli, "Integration of distributed on site control actions via combined photovoltaic and solar panels system," in Clean Electrical Power, 2009 International Conference on, June 2009.

[39] F. Y. Xu, X. Wang, L. L. Lai, and C. S. Lai, "Agent-Based Modeling and Neural Network for Residential Customer Demand Response," in 2013 IEEE International Conference on Systems, Man, and Cybernetics, Oct. 2013.

[40] A. Capasso, W. Grattieri, R. Lamedica, and A. Prudenzi, "A bottom-up approach to residential load modeling," IEEE Transactions on Power Systems, vol. 9, no. 2, pp. 957-964, May 1994. 


\section{APPENDIX A}

\section{BILL OF MATERIALS FOR RSVC PROTOTYPE}

Table A.1 shows the list of components and the bill-of-materials for the RSVC lab-prototype. This table does not include the cost for FPGA and ADC boards which were used for generating the commutation signals for the bidirectional switches.

Table A.1: Bill of Materials for RSVC prototype.

\begin{tabular}{|c|c|c|}
\hline Component Name & Description & Cost per unit \\
\hline \hline HCLP-3140-00E & Opto-coupler gate driver IC $(4)$ & $\$ 2.50$ \\
\hline IRGP4066DPBF & IGBT with soft revocery diode $(4)$ & $\$ 10.20$ \\
\hline $421 \mathrm{~K}$ & Black Anodized Heat Sink $\left(\mathrm{R}_{\lambda}=1.16^{\circ} \mathrm{C} / \mathrm{W}\right)$ & $\$ 14.80$ \\
\hline Power Capacitor & $415 \mathrm{~V} 10$ kVar single phases power capacitor $)$ & $\$ 125.00$ \\
\hline Power Reactor & Fixed Inductor $(30 \mathrm{mH})$ & $\$ 108.98$ \\
\hline Power Reactor & Fixed Inductor $(5 \mathrm{mH})$ & $\$ 100.00$ \\
\hline
\end{tabular}

